\title{
A Method for Including Operation and Maintenance Costs in the Economic Analysis of Active Solar Energy Systems
}

Walter D. Short

August 1986

Prepared under Task No. 3002.10

FTP No. 01-465

Solar Energy Research Institute

A Division of Midwest Research Institute

1617 Cole Boulevard

Golden, Colorado 80401

Prepared for the

U.S. Department of Energy

Contract No. DE-AC02-83CH10093 


\section{NOTICE}

This report was prepared as an account of work sponsored by the United States Governme?11 United States nor the United States Department of Energy, nor any of their employees. m.1 contractors, subcontractors, or their employees, makes any warranty, expressed or implied, (1) legal liability or responsibility for the accuracy, completeness or usefulness of any informat 1,1 product or process disclosed, or represents that its use would not infringe privately owned rulli!

Printed in the United States of America Available from:

National Technical Information Service

U.S. Department of Commerce

5285 Port Royal Road

Springfield, VA 22161

Price: Microfiche $A 01$

Printed Copy A05

Codes are used for pricing all publications. The code is determined by the number of pages in th... Information pertaining to the pricing codes can be found in the current issue of the following: Information pertaining to the pricing codes can libraries: Energy Research Abstracts. (ERA): Govern.. Announcements and Index (GRA and 1); Scientific and Technical Abstract Reports (STAR): an: NTIS-PR-360 available trom NTIS at the above address. 
PREFACE

in keeping with the national energy policy goal of fostering an adequate Mply of energy at a reasonable cost, the United States Department of Energy (I)E) supports a variety of programs to promote a balanced and mixed energy anource system. The mission of the DOE Solar Buildings Research and : welopment Program is to support this goal by providing for the development "1 solar technology alternatives for the buildings sector. It is the goal of the program to establish a proven technology base to allow industry to develop wolar products and designs for buildings that are economically competitive and in contribute significantly to the nation's building energy supplies. Toward this end, the program sponsors research activities related to increasing the afficiency, reducing the cost, and improving the long-term durability of passive and active solar systems for building water and space heating, cooling, and daylighting applications. These activities are conducted in four major areas: Advanced Passive Solar Materials Research, Collector Technology Research, Cooling Systems Research, and Systems Analysis and Applications Research.

Advanced Passive Solar Materials Research - This activity area includes work on new aperture materials for controlling solar heat gains, and for enhancing the use of daylight for building interior lighting purposes. It also encompasses work on low-cost thermal storage materials that have high thermal storage capacity and can be integrated with conventional building elements, and work on materials and methods to transport thermal energy efficiently between any building exterior surface and the building interior by nonmechanical means.

Collector Technology Research - This activity area encompasses work on advanced low- to medium-temperature (up to $180^{\circ} \mathrm{F}$ useful operating temperature) flat-plate collectors for water and space heating applications, and medium- to high-temperature (up to $400^{\circ} \mathrm{F}$ useful operating temperature) evacuated tube/concentrating collectors for space heating and cooling applications. The focus is on design innovations using new materials and fabrication techniques.

Cooling Systems Research - This activity area involves research on highperformance dehumidifiers and chillers that can operate efficiently with the variable thermal outputs and delivery temperatures associated with solar collectors. It also includes work on advanced passive cooling techniques.

Systems Analysis and Applications Research - This activity area encompasses experimental testing, analysis, and evaluation of solar heating, cooling, and daylighting systems for residential and nonresidential buildings. This involves system integration studies, the development of design and analysis tools, and the establishment of overall cost, performance, and durability targets for various technology or system options.

This report is an account of research conducted in the area of systems Analysis and Applications Research. It describes a methodology for determining the total 1 ife-cycle operation and maintenance costs for an active solar energy system. This provides a means for determining the total cost of a system and allows for a more realistic comparison between proposed new systems by quantitatively accounting for reliability issues. 
This work was supported by the Office of Solar Heat Technologies of the U.S. Department of Energy as a part of the Active Heating and Cooling Program. The author is grateful for the assistance of Charles Kutscher of SERI in the development of the method and for the comments provided by a number of reviewers of the draft report, especially those of Ed Gray of Science Applications International Corporation, Paul Pekrul of Rockwell International Corporation, and Harry Martz of Los Alamos National Laboratory.

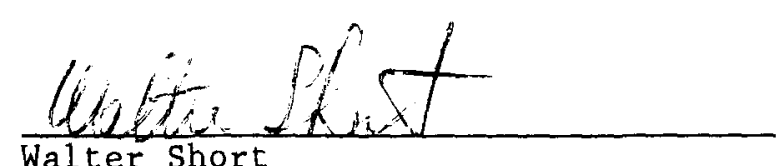

Approved for

SOLAR ENERGY RESEARCH INSTITUTE

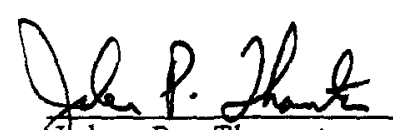

John P. Thornton, Manager

Thermal Systems and Engineering Branch

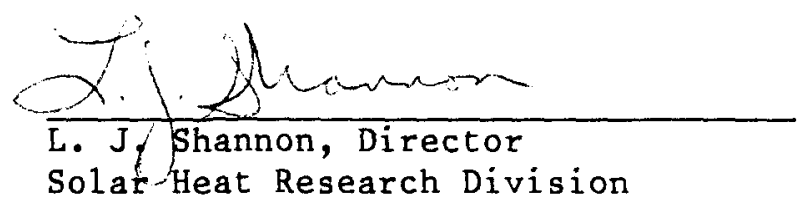




\section{SUMMARY}

\section{Objective}

The objective of the work reported here is to present a method of representing operation and maintenance (O\&M) costs that explicitly accounts for the uncertainties and risks inherent in the operation of any equipment.

\section{Discussion}

For a developing technology such as solar energy, O\&M costs can be substantial. In the past, most economic analyses included these costs by simply assuming that an annual cost will be incurred that is proportional to the initial cost of the system. However, in assessing the economics of new systems proposed for further research and development, a more detailed representation is required. For example, when the typical method for including O\&M costs in an economic analysis is used, the O\&M costs associated with a newly developed, more reliable, and slightly more expensive controller will be assumed to increase-an obvious inconsistency. This report documents a method designed to eliminate such inconsistencies through a more detailed representation of O\&M costs. In this summary we present not only an overview of the method, but also a step-by-step procedure that should allow the reader to implement the method without referring to the detailed explanations found in the text.

Basically, the method

- Computes an expected value for the life-cycle costs of component repairs and replacements

- Accounts for system downtime as well as parts and labor costs

- Does not account explicitly for the cost of energy losses caused by system degradation before repairs are made

- Has a limited ability to account for the interdependencies of component failures (e.g., a sensor failure may cause a pipe to freeze and fail)

- Does not distinguish between repair and replacement costs paid by the consumer and those paid by the manufacturer or distributor under a warranty program.

O\&M costs can be divided into operating and preventive maintenance (OPM) costs that occur on a scheduled basis and repair and replacement costs that occur randomly when equipment fails. Once the annual operating and preventive maintenance costs OPM $_{t}$ are estimated, their present value over the system 1 ifetime $O P M$ can be easily included in an economic analysis by the typical discouhting equation

$$
O P M_{p v}=\sum_{t=1}^{N} \frac{O P M_{t}}{(1+d)^{t}},
$$


where $\mathbf{N}$ is the system lifetime, and $\mathrm{d}$ is the discount rate. However, to accurately include repair and replacement costs, we must consider their random or probabilistic structure in the economic analysis by including the expected present-value cost of all failures. Our method calculates this expected cost through a five-step process, which is to

1. Identify the more important failures and the ramifications of each; i.e., what will need to be repaired or replaced.

2. Divide the system into components and subcomponents at the lowest possible level with respect to repair or replacement. For example, if it is possible to replace the glazing on a collector without replacing the collector as a whole, then the glazing should be considered a separate component from the rest of the collector.

3. Estimate the cost of a single failure of each component and subcomponent identified in step 2.

4. Estimate the failure probability distribution of each component and subcomponent and calculate the life-cycle cost multiplier (LCCM) that should be applied to the cost of a single failure (as calculated in step 3) of that component to represent the expected present-value cost $\mathrm{EC}_{c}$ of all failures of that component over the analysis period.

$$
\mathrm{EC}_{\mathrm{C}}=\text { (cost of a single failure) } \times \text { LCCM. }
$$

5. Sum over all components and subcomponents to determine the expected present value cost of all failures for the system ( $E C_{s}$ ) during the analysis period:

$$
\mathrm{EC}_{\mathrm{s}}=\sum_{\mathrm{c}=1}^{\text {components }} \mathrm{EC}_{\mathrm{c}}
$$

This method is straightforward, with the possible exception of the calculation of LCCM for each component in step 4. To calculate LCCM for an individual component, we need to know the distribution that best represents the probability of failure over time of that component. Unfortunately, very few data are available on the pattern of active solar energy system component failures over a period of time. Therefore, Table s-1 presents some rough guidelines for selecting appropriate failure distributions and approximate formulas for LCCM based on these distributions.

As an example, we used our method to calculate the O\&M costs for a closedloop, glycol domestic hot water (DHW) system. For this system the owner can perform the operating and preventive maintenance tasks for essentially no cost. Thus, our method focuses on repair and replacement costs during the analysis period, as shown in Table S-2. This table shows the breakdown of components and subcomponents determined through steps 1 and 2; the repair, replacement, and downtime cost for each component and subcomponent for a single failure from step 3; the failure probability distributions, mean 1 ifetimes, calculated LCCM values, and the cost of failures over the analysis period from step 4; and, finally, from step 5 the expected present-value cost ( $\$ 1558)$ of all failures over the analysis period. The equivalent levelized annual cost is $\$ 147$ or $3.3 \%$ of the system's initial cost of $\$ 4500$. 
Table S-1. Failure Probability Distributions and LCCM Formulas

\begin{tabular}{|c|c|c|c|c|c|}
\hline & $\begin{array}{l}\text { Cause of } \\
\text { Component } \\
\text { Faflure }\end{array}$ & $\begin{array}{l}\text { Assumptions/ } \\
\text { Constraints }\end{array}$ & $\begin{array}{l}\text { Representative } \\
\text { Probability } \\
\text { Distributions }\end{array}$ & $\begin{array}{l}\text { LCCM } \\
\text { Formula }\end{array}$ & Example \\
\hline 1. & Wearout & $\begin{array}{l}\lambda<<N \\
\sigma<\lambda / 2\end{array}$ & $\begin{array}{l}\text { Normal; } \\
\text { lognorma1; } \\
\text { Welbu11 }(\beta>2)\end{array}$ & $\frac{1-\frac{1}{(1+d)^{\lambda}}\left\lfloor\frac{\mathbb{N}}{\lambda}\right\rfloor}{(1+d)^{\lambda}-1}$ & $\begin{array}{l}\text { Pump bearing fallure; } \\
\text { heat exchanger corrosion }\end{array}$ \\
\hline 2. & Wearout & $\begin{array}{l}\lambda \approx N \\
\lambda \rho^{r} \mathrm{~N} \\
\sigma<\lambda / 2\end{array}$ & $\begin{array}{l}\text { Normal; } \\
\text { lognorma1; } \\
\text { We1bu11 }(\beta>2)\end{array}$ & $\exp \left(\frac{d^{\prime} \sigma^{2}}{2}-\lambda d^{\prime}\right)\left[F\left(\frac{N-\lambda+d^{\prime} 2 \sigma^{2}}{\sigma}\right)-F\left(\frac{d^{\prime} \sigma^{2}-\lambda}{\sigma}\right)\right]$ & $\begin{array}{l}\text { Pump bearing fallure, } \\
\text { heat exchanger corrosion }\end{array}$ \\
\hline 3 . & Wearout & $\begin{array}{l}\lambda<N \\
\sigma>\lambda / 2\end{array}$ & Wefbu11 ( $\beta=2$, Rayleigh $)$ & $\frac{1-e^{-d^{\prime} N}}{\lambda d^{\prime}}-\frac{1-\exp -\left(\frac{3}{\lambda}+d^{\prime}\right)^{N}}{3+\lambda d^{\prime}}$ & $\begin{array}{l}\text { Multiple failure causes } \\
\text { for a simple component } \\
\text { (e.g., absorber plate can } \\
\text { fal1 due to freezing, } \\
\text { corrosion, or degradation } \\
\text { of the selective coating) }\end{array}$ \\
\hline 4. & $\begin{array}{l}\text { Total1y } \\
\text { random }\end{array}$ & $\begin{array}{l}\text { Failure is equally } \\
\text { likely in all } \\
\text { time perlods }\end{array}$ & Exponential & $\frac{1-e^{-d \cdot N}}{\lambda d^{\prime}}$ & Hall damage \\
\hline 5. & $\begin{array}{l}\text { Installation, } \\
\text { random, or } \\
\text { wearout }\end{array}$ & $\begin{array}{l}\text { Different fallure } \\
\text { casuses at different } \\
\text { points in time }\end{array}$ & Bathtub ${ }^{b}$ & $\begin{array}{l}\text { define } \lambda^{\prime}=P+\frac{(1-P) \lambda}{(1+d)^{\lambda P(1-P)}} \\
\text { and use } \lambda^{\prime} \text { in place of } \lambda \text { in the equation } \\
\text { above for wearout with } \lambda \ll N \text {. }\end{array}$ & $\begin{array}{l}\text { Collector may fall due to } \\
\text { Insta1lation problems, random } \\
\text { damage, or wearout. }\end{array}$ \\
\hline
\end{tabular}

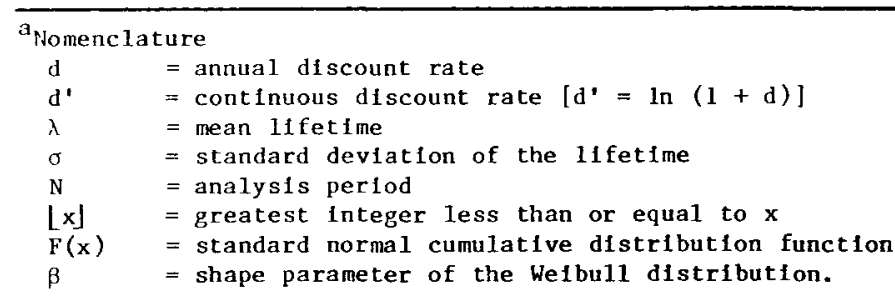

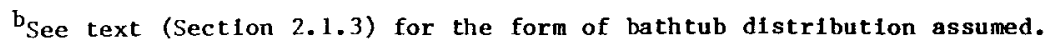


Table S-2. Repair and Replacement LCC for a Closed-Loop Glycol Domestic Hot Water Solar System

\begin{tabular}{|c|c|c|c|c|c|c|c|c|c|}
\hline \multirow[b]{2}{*}{$\begin{array}{l}\text { Component/ } \\
\text { Subcomponent }\end{array}$} & \multicolumn{3}{|c|}{ Repa1r and Replacement Cost ${ }^{a}$} & \multirow{2}{*}{$\begin{array}{c}\text { Mean } \\
\text { Lifetime } \\
\text { (years) }\end{array}$} & \multirow{2}{*}{$\begin{array}{l}\text { Assumed } \\
\text { Faflure } \\
\text { Probability } \\
\text { D1stribution }\end{array}$} & \multirow{2}{*}{$\left(d=0.07^{d}{ }_{N=20}^{L C C M}\right)$} & \multirow{2}{*}{$\begin{array}{c}\text { Repa1r/ } \\
\text { Replacement } \\
\text { LCC }\end{array}$} & \multirow{2}{*}{$\begin{array}{l}\text { Number } \\
\text { Units per } \\
\text { System }\end{array}$} & \multirow{2}{*}{$\begin{array}{c}\text { Total } \\
\text { Repa1r/ } \\
\text { Replacement } \\
\text { LCC }\end{array}$} \\
\hline & Parts ${ }^{b}$ & $\begin{array}{c}\text { Labor } \\
\text { and } \\
\text { other }\end{array}$ & Total & & & & & & \\
\hline Collector $(4 \times 8 \mathrm{ft}$ pane 1$)$ & $500^{\mathrm{f}}$ & & & & & & & & \\
\hline Glass glazing & 25 & 40 & 65 & 50 & Exponentia 1 & 0.22 & 14 & $2^{\mathrm{g}}$ & 28 \\
\hline Absorber & 175 & 75 & 250 & 15 & Rayleigh & 0.47 & 118 & 2 & 236 \\
\hline Insulation & 36 & 60 & 80 & 20 & Ray le Igh & 0.31 & 25 & 2 & 50 \\
\hline Seals & 5 & 40 & 45 & 8 & Normal & 0.92 & 41 & 2 & 82 \\
\hline \multicolumn{10}{|l|}{ Control system } \\
\hline Sensor & 10 & 40 & 50 & 15 & Exponential & 0.72 & 36 & 2 & 72 \\
\hline Mixing valve & 50 & 35 & 85 & 12 & Norma1 & 0.44 & 37 & 1 & 37 \\
\hline Pressure/temperature & 10 & 30 & 40 & 15 & Norma1 & 0.36 & 14 & 2 & 28 \\
\hline Relief valve & & & & & & & & & \\
\hline Check valve & 10 & 35 & 45 & 15 & Normal & 0.36 & 16 & 2 & 32 \\
\hline \multicolumn{10}{|l|}{ Transport system } \\
\hline Piping & 5 & 30 & 35 & 10 & Exponent la1 & 1.08 & 38 & 1 & 38 \\
\hline Expansion tank & 50 & 50 & 100 & 15 & Normal & 0.36 & 36 & 1 & 36 \\
\hline Pump & 130 & 40 & 170 & 12 & Norma1 & 0.44 & 75 & 1 & 75 \\
\hline Heat transfer flufd & 32 & 40 & 72 & 3 & Norma1 & 3.13 & 225 & 1 & 225 \\
\hline Auxiliary tank & 150 & 50 & 200 & 12 & We1bu11 $(\beta=4)$ & 0.44 & 88 & 1 . & 88 \\
\hline TOTAL & & & & & & & & & $\$ 1558$ \\
\hline
\end{tabular}

${ }^{a}$ Cost per failure. Assumed to escalate at the rate of inflation.

${ }^{b}$ Includes $6 \%$ sales tax.

c Includes repalrman travel time and cost as well as customer downtime costs.

dpeal discount rate (excludes inflation).

Excludes Initial costs at the time of original installation.

Shown for comparison with subcomponent costs. Based on Novan $48 \mathrm{sc}$ collector ( $4 \times 8 \mathrm{ft}$ pane1)

Btwo panels are assumed. 
As with all discounted cash-flow economic analyses, these results depend on the assumed discount rate ( $7 \%$ real), analysis period (20 years), etc. However, they are most sensitive to the mean lifetimes determined in step 3 .

\section{Conclusions and Recommendations}

The common practice of assuming annual O\&M costs to be a fixed fraction of the initial investment is inaccurate since it does not capture enough systemspecific detail and favors less reliable, less expensive systems. A better alternative in calculating the system O\&M costs is to explicitly consider the probability distributions of the times to failure of the individual components. The common reliability analysis assumption that the failure distributions are exponential may result in a significant underestimation of O\&M costs. Our example calculation of the levelized O\&M costs for a closed-loop glycol solar DHW system indicates that O\&M costs may be higher than generally expected when considered over a 20-year analysis period.* However, the accuracy of the results of this example and any other analysis undertaken with the method described in the report will depend on the availability of data on the failure of solar energy system components over a period of time. Currently, such data are extremely sparse. Future efforts should be directed to generating additional time-to-failure data.

*The cost to the consumer may not be as high since many of the O\&M costs may be covered by the manufacturer or distributor under a warranty. 
TABLE OF CONTENTS

Page

1.0 Introduction $\ldots \ldots \ldots \ldots \ldots \ldots \ldots \ldots \ldots \ldots \ldots \ldots \ldots \ldots \ldots \ldots \ldots \ldots, 1$

2.0 Method for Determining Life-Cycle Repair and Replacement Costs...... 4

2.1 Life-Cycle Cost Multiplier (LCCM).................... 5

2.1.1 Discrete Probability Distributions.................. 5

2.1.2 Continuous Probability Distributions.................. 7

2.1.3 Bathtub-Shaped Failure Distributions................. 12

2.1 .4 Integral Subcomponent Failure..................... 16

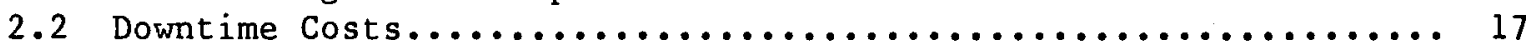

2.3 System Performance Degradation..........................18

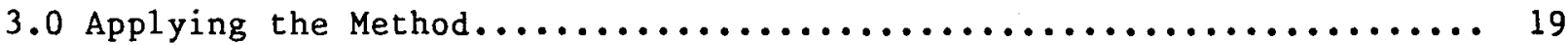

3.1 Variations and Data Uncertainties..................... 19

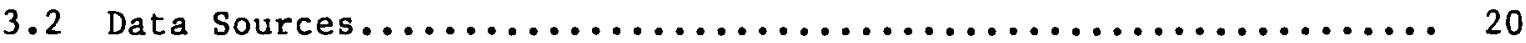

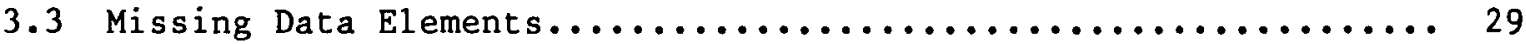

3.4 Life-Cycle O\&M Costs for a Closed-Loop Glycol DHW System....... 31

4.0 Conclusions and Recommendations......................... 42

5.0 References........................................ 43

Appendix A Probability Distributions Commonly Employed in Reliability Analysis........................... 45

Appendix B Derivation of an Approximate Formula for the Life-Cycle Cost Multiplier Associated with a Rayleigh Failure

Distribution..................................

Appendix C Derivation of an Approximate Formula for LCCM for Repair and Replacement Costs when the Component Mean Lifetime Approaches or Exceeds the Analysis Period..................... 52

Appendix D Response Time of Repairman.................... 54

Appendix E Sampling................................ 57

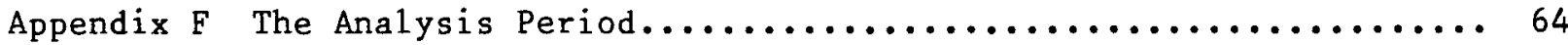




\section{LIST OF FIGURES}

Page

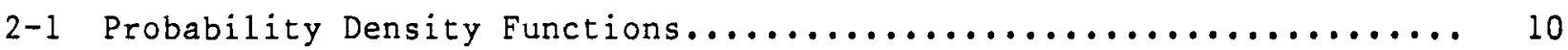

2-2 Bathtub-Shaped Failure Rates........................... 13

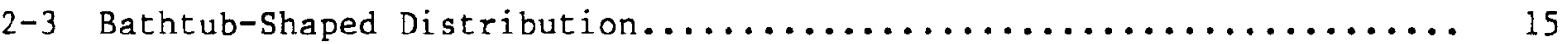

3-1 System Downtime................................ 30

3-2 Closed-Loop System--Two Tanks....................... 32

3-3 Comparison of Energy Savings and Failure Costs as a Function of

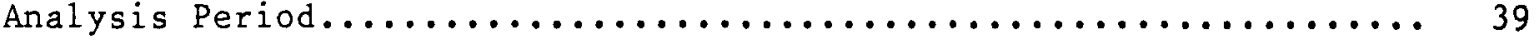

A-1 Probability Distributions.......................... 47

A-2 Bathtub-Shaped Failure Rates....................... 49

B-1 Renewal Rate of Failure for the Rayleigh Distribution.......... 51

D-1 Waiting Times....................................... 55 


\section{LIST OF TABLES}

$\underline{\text { Page }}$

2-1 Example of Discrete Distribution....................... 6

2-2 Sample Life-Cycle Cost Multipliers...................... 8

2-3 LCCM Approximation Results for the Case When the Mean Lifetime Approaches or Exceeds the Analysis Period..................... 11

2-4 Sample Expected Replacement Cost Multipliers for the Sample Bathtub-Shaped Distribution.......................... 14

2-5 Selection of the $\beta$ Parameter for the Weibull Distribution........ 16

3-1 Mean Life of Major Elements in Flat-Plate Collectors........... 22

3-2 Failure Rates for Control System Electrical and Electronic Components..................................... 22

3-3 Failure-Rate Ranges for Solar DHW Components................ 23

3-4 Reliability and Failure Classification by Component............ 24

3-5 Equipment Service Life............................. 25

3-6 Mean Service Life................................ 26

3-7 Status Summary of the Draindown System................... 27

3-8 Summary of Manufacturer's Warranty Labor Schedules............ 28

3-9 Annual Operating and Preventive Maintenance Procedures for a Closed-Loop, Glycol DHW System....................... 33

3-10 Principal Components and Failure Causes for Closed-Loop, Glycol DHW system...................................... 34

3-11 Repair and Replacement LCC for a Closed-Loop, Glycol DHW

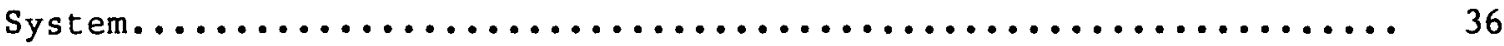

3-12 LCC of Repair and Replacement Costs for a Closed-Loop, Glycol DHW system (Sensitivities)............................ 40

A-1 Probability Distribution Functions..................... 48

D-1 Expected Average Waiting Times for Repairman Response......... 56

E-1 Exponential Distribution Confidence Intervals on Mean Lifetime.... 59

E-2 Time on Test Statistic............................. 61 


\section{NOMENCLATURE}

\begin{tabular}{|c|c|}
\hline $\mathrm{C}_{\mathrm{d}}$ & downtime cost \\
\hline $\mathrm{d}$ & real discount rate \\
\hline$d^{\prime}$ & continuous real discount rate \\
\hline DHW & domestic hot water \\
\hline e & annual escalation rate for O\&M costs \\
\hline $\mathrm{EC}_{\mathrm{c}}$ & $\begin{array}{l}\text { expected present-value cost of all failures of a component over } \\
\text { the analysis period }\end{array}$ \\
\hline $\mathrm{EC}_{\mathbf{s}}$ & $\begin{array}{l}\text { expected present-value cost of all failures for a system over the } \\
\text { analysis period }\end{array}$ \\
\hline$f(t)$ & $\begin{array}{l}\text { density function of the probability distribution of the time to } \\
\text { failure }\end{array}$ \\
\hline $\mathrm{F}_{\mathrm{s}}$ & solar fraction \\
\hline$F(t)$ & $\begin{array}{l}\text { cumulative probability distribution function of the time to } \\
\text { failure }\end{array}$ \\
\hline IC & initial system cost \\
\hline LCC & life-cycle cost \\
\hline $\begin{array}{l}\operatorname{LCCM} \\
\mathrm{n} \\
\mathrm{N}\end{array}$ & $\begin{array}{l}\text { life-cycle cost multiplier for the calculation of } \mathrm{EC}_{c} \\
\text { number of systems in a sample } \\
\text { analysis period }\end{array}$ \\
\hline O\&M & operation and maintenance (including repairs and replacements) \\
\hline$P_{c}$ & conventional fuel price \\
\hline$P_{t}$ & probability of failure in time period $t$ \\
\hline$Q_{L}$ & average load per unit time \\
\hline S & time on test statistic \\
\hline$t$ & time \\
\hline$T_{d}$ & downtime \\
\hline$u$ & number of repairs per repairman per day \\
\hline$y$ & number of years that systems in a sample are monitored \\
\hline & \\
\hline
\end{tabular}

GREER

$\alpha$

$\beta$

size parameter of the Weibull probability distribution

shape parameter of the Weibull probability distribution 


$\begin{array}{ll}\Gamma(x) & \text { gamma function } \\ \eta_{c} & \text { conventional system efficiency } \\ \lambda & \text { mean 1ifetime } \\ \phi & \text { average number of service calls per day } \\ \sigma & \text { standard deviation of the lifetime } \\ x^{2} & \text { chi-square statistic }\end{array}$


SECTION 1.0

\section{INTRODUCTION}

Because most renewable energy systems are highly capital intensive, evaluations of their economic viability frequently consider only those costs associated with their initial installation. Such evaluations ignore additional costs that can occur throughout the useful life of the system--operation, maintenance, and repair and replacement (O\&M) costs. For a developing technology, these ongoing costs can be substantial. They should be examined and, if warranted, included in any economic analysis of the technology.

The accurate representation of $0 \& M$ costs in an economic analysis is especially important when the analysis is to be used in determining research directions. Without accurate representation of such costs, the economic analysis will favor research and development of inexpensive materials, processes, and systems without regard for their durability. For example, the energy saved by a system developed to attain high performance through complex controls might be far outweighed by the O\&M costs associated with the controls. This report presents a method for including O\&M costs in the economic analysis of proposed active solar energy systems under consideration for further research.

Obviously, estimates of O\&M costs for proposed systems will contain a large number of risks and uncertainties. Although no method can remove the uncertainties, we will identify the risks and provide a simple means for including them in the analysis. In this introduction we review how O\&M costs and their associated risks are typically treated in the economic analysis of a solar system. Sections 2.0 and 3.0 distinguish between two types of uncertainties. In Section 2.0 we address methods for incorporating in an economic analysis the probability structure associated with the uncertainty as to when repair and replacement costs will occur; i.e., the probability distribution of the time to failure. In section 3.0 we address the uncertainties inherent in estimating $O \& M$ costs and the parameters of the failure rate distributions. In Section 3.0 we also construct approximate numerical values for the life-cycle O\&M costs of a representative solar energy system.

Operation and maintenance costs typically are included in an economic analysis of a solar energy system by assuming some fixed annual value proportional to the initial cost of the system. For example, the equation for the life-cycle cost (LCC) of a solar system might appear as

$$
L C C=I C+\sum_{t=1}^{N} O M\left(\frac{1+e}{1+d}\right)^{t}
$$

where

$$
\begin{aligned}
& \mathrm{IC}=\text { initial system cost } \\
& \mathrm{N}=\text { analysis period } \\
& \mathrm{d}=\text { discount rate }
\end{aligned}
$$




$$
\begin{aligned}
e= & \text { annual escalation rate for } O \& M \text { costs } \\
O M= & \text { annual operation and maintenance costs, frequently determined as } \\
& O M=E \times I C \text {, where } f \text { is } 0.01 \text { or } 0.02 \text {. }
\end{aligned}
$$

This representation of $0 \& M$ costs is attractive primarily because it requires that the analyst estimate only a single value (OM) from which the life-cycle cost for operation and maintenance can be derived. The drawback is that this single value comprises a large number of costs occurring over the life of the system. As such, it cannot simply be assumed to be independent of the system, or as is frequently assumed, proportional to the initial system cost. The difficulty with such a proportionality assumption is best illustrated through an example. Suppose we compare the economics of two systems identical in all ways except that one has a more reliable, yet slightly more expensive, controller. By the proportionality assumption, the increase in initial costs caused by the improved controller will result in an increase in o\&M costs, an obvious contradiction.

In general, O\&M costs for an active solar energy system can be classified as either operating and preventive maintenance costs or repair and replacement costs. The former includes such costs as annual cleaning, lubricating, startup, and parasitic energy costs while the latter includes such costs as component repair or replacement. Since operating and preventive maintenance costs frequently occur on an annual basis, Eq.1-1 is an adequate representation, provided the annual cost is accurately estimated. However, this approach is not appropriate for repair and replacement costs since these costs normally cover repairs and replacements at the time of equipment failure, which is highly irregular and cannot be explicitly included in an annual O\&M value.

One deterministic method sometimes employed to explicitly account for the infrequent nature of the failure of individual components assumes that each component will fail at its mean lifetime $\lambda$. For this method LCC is calculated as

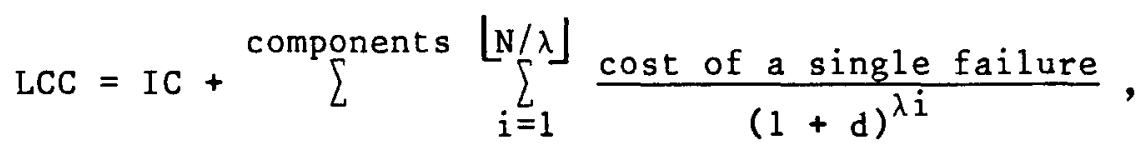

where $N / \lambda$ represents the greatest integer less than $N / \lambda$.

The methodology section that follows shows that this deterministic representation is a valid approximation for some failures. However, in other cases this approximation is strongly biased because the cost of random failures of a component that occur before the mean lifetime of the component are discounted significantly less than those that occur after the mean lifetime. To accurately assess this discounting effect, it is necessary to address these costs through reliability theory.

The concept of reliability, defined as the probability that an item will successfully perform its function during a stated time interval (Green and Bourne 1972), has developed in a quantitative sense with the introduction of modern technology and its complexities. Some of the earliest quantitative reliability estimates were made after World War I for aircraft failure. In 
World War II the Germans refined their reliability calculations when deve1oping the V1 and V2 missiles. In more recent times, reliability calculations have played an important role in spacecraft and nuclear power plant designs (Green and Bourne 1972). In these applications the desired result is a reliability estimate that essentially reflects the probability that the mission will succeed. This probability is usually developed from the reliabilities or probability distributions of the times to failure of the individual components that make up the system. (See Appendix A for a review of the probability distributions commonly employed in reliability analyses.)

With respect to the value of a system reliability estimate, a significant distinction can be made between military and aerospace systems and solar energy systems. For the former, failure of a single component can result in the catastrophic failure of the total system and mission. For solar energy applications, however, the failure of a component or components carries only the penalties of repair and replacement costs and the cost of conventional energy used by the backup system during the downtime. Therefore, for a solar energy system the measure of interest is not the system reliability but rather the expected value of the costs incurred because of failed components. Since the repair and replacement cost is normally different for each component, the expected value of all failure costs for the system must be constructed from the individual component costs and their associated failure rate probability distributions, not from the system reliability. Thus, the system reliability is of limited value when assessing the economics of a solar energy system. 
SECTION 2.0

\section{METHOD FOR DETERMINING LIFE-CYCLE REPAIR AND REPLACEMENT COSTS}

In a solar energy system, a failure can take on many forms. It may be the catastrophic result of a freeze-protection sensor failure or the slow degradation of a collector glazing caused by ultraviolet radiation. It may affect only the individual component or it may result in damage to several components. Similarly, a failure can result in several different additional costs, including downtime cost and repair and replacement costs. We make no attempt to delineate all the possible types of failures or costs in active solar energy systems.* Rather, we provide in this section a method by which an analyst who has identified the failures and costs of his particular system can combine the costs and failure distributions in a single value--the expected 1 ife-cycle cost of repairs and replacements.

In essence, the approach consists of five steps as follows:

1. Identify the more important failures and the ramifications of each; i.e., what will need to be repaired or replaced. Failures that are easily corrected by the owner with little or no equipment costs can usually be ignored.

2. Divide the system into components and subcomponents at the lowest possible level with respect to repair and replacement. For example, if it is possible to replace the glazing on a collector without replacing the collector as a whole, then the glazing should be considered a separate component from the rest of the collector.

3. Estimate the cost of a single failure of each component and subcomponent identified in step 2.

4. Estimate the failure probability distribution of each component and subcomponent and calculate the life-cycle cost multiplier (LCCM) that should be applied to the cost of a single failure of that component (as calculated in step 3) to represent the expected present value cost $\mathrm{EC}_{\mathrm{c}}$ of all failures of that component over the analysis period.

$$
\mathrm{EC}_{\mathrm{C}}=\text { (cost of a single failure) } \times \text { LCCM } .
$$

5. Sum over all components and subcomponents to determine the expected present value cost of all failures for the system $\left(\mathrm{EC}_{\mathrm{s}}\right)$ during the analysis period.

$$
\mathrm{EC}_{\mathrm{s}}=\sum_{\mathrm{c}=1}^{\text {components }} \mathrm{EC}_{\mathrm{c}}
$$

*Section 3.0 provides some guidelines for estimating the types of failures and their distributions over time for components commonly found in active solar energy systems. 
The first three steps will be explained and illustrated by the example presented in section 3.0. In this section we concentrate on the calculations required in the last two steps.

\subsection{LIFE-CYCLE COST MULTIPLIER (LCCM)}

The method presented in this report for a cost analysis of repairs and replacements revolves around the calculation of LCCM in step 4. This value assimilates the probability distribution of the time to failure of a component or subcomponent with the analysis period and the owner's discount rate. By multiplying LCCM by the cost of a single failure, we can determine the present value cost of all failures of the component or subcomponent during the analysis period.

The procedure for calculating LCCM depends heavily on the type of failure probability distribution used. For example, the time to a failure caused by a totally random event such as an electrical surge in a controller is best represented by an exponential failure distribution that is characterized by a constant rate of failure. However, the time to a failure caused by a component wearing out is best represented by probability distributions such as a normal, lognormal, or Weibull distribution that can be characterized by failure rates that increase with time. Explicit formulas and approximations for LCCM for probability distributions commonly used in reliability analysis are derived in Sections 2.1.1-2.1.3.

\subsubsection{Discrete Probability Distributions}

Although our method will focus on using continuous probability distributions to represent failures over time, it is more easily illustrated and understood with discrete probability distributions. For a component or subcomponent with a discrete failure probability distribution, we have

$$
\mathrm{EC}_{c}=\sum_{t=1}^{N} P_{t} \times \frac{\text { cost of a single failure* }}{(1+d)^{t}}
$$

where

$$
P_{t}=\text { probability of a failure in time period } t
$$

*Since repair and replacement costs for a single failure can be expected to increase over time, an escalation factor should be included in the analysis. The easiest way to do this is to modify the discount rate to account for the replacement cost annual escalation e according to the formula

$$
\mathrm{d}^{\prime \prime}=\left(\frac{1+\mathrm{d}}{1+\mathrm{e}}\right)-1 \text {. }
$$

The effective discount rate $d^{\prime \prime}$ can be used in place of $d$ in the equations presented throughout this report. 


$$
\begin{aligned}
& \mathrm{d}=\text { discount rate } \\
& \mathrm{N}=\text { analysis period } .
\end{aligned}
$$

$P_{t}$ is calculated recursively (i.e., after calculating $P_{1}, P_{2}, . . . P_{t-1}$ ) as follows:

$$
P_{t}=\sum_{s=0}^{t-1} P_{s} f(t-s),
$$

where $P_{0}=1$, and $f(x)$ is the discrete density function for the failure rate probability distribution; i.e., $f(x)$ is the probability that a failure occurs $x$ years after the last repair and replacement or original installation.

Equation 2-3 might also be written

$$
\mathrm{EC}_{\mathrm{c}}=\text { cost of a single failure } \times \text { LCCM },
$$

where

$$
\operatorname{LCCM}=\sum_{t=1}^{N} \frac{P_{t}}{(1+d)^{t}} .
$$

Table 2-1 presents a simple example calculation of $E C_{c}$ for which failure occurs in either the second or third year since the last repair and replacement; the analysis period is six years, the cost of a single failure is $\$ 5$, and the discount rate is $10 \%$.

Table 2-1. Example of Discrete Distribution

\begin{tabular}{lllll}
\hline$t$ & $f(t)$ & $P_{t}$ & $\begin{array}{c}\text { Discount } \\
\text { Factor } \\
(1+d)^{t}\end{array}$ & $\frac{P_{t}}{(1+d)^{t}}$ \\
\hline 1 & 0.0 & 0.0 & 1.1 & 0.0 \\
2 & 0.3 & 0.3 & 1.21 & 0.248 \\
3 & 0.7 & 0.7 & 1.331 & 0.526 \\
4 & 0.0 & 0.09 & 1.46 & 0.062 \\
5 & 0.0 & 0.42 & 1.61 & 0.261 \\
6 & 0.0 & 0.517 & 1.77 & $\underline{0.292}$ \\
& & & LCCM $=1.388$
\end{tabular}

${ }^{a}$ Cost for a single failure $=\$ 5$. 


\subsubsection{Continuous Probability Distributions}

For continuous distributions, the formulation and solution for LCCM are analytically intractable except for the exponential distribution. The exponential distribution is unique in that the probability of a failure is independent of time. Thus, LCCM can be determined by integrating the constant failure rate over the analysis period and discounting continuously:

$$
\operatorname{LCCM}=\int_{0}^{N} \frac{1}{\lambda} e^{-d^{\prime} x} \partial x=\frac{1-e^{-d^{\prime} N}}{\lambda d^{\prime}} \text {, }
$$

where

$$
\begin{aligned}
\lambda & =\text { mean } 1 \text { ifetime }\left(\frac{1}{\lambda} \text { is the failure rate }\right) \\
d^{\prime} & =\text { continuous discount rate.* }
\end{aligned}
$$

For example, the expected present value cost of replacing a $\$ 5$ item with a mean life of 4 years and an exponential failure distribution over a 20-year period when costs are discounted $10 \%$ is

$$
\mathrm{EC}_{\mathrm{C}}=\$ 5 \times \operatorname{LCCM}=\$ 5 \times\left[\frac{1-\mathrm{e}^{-(0.1 \times 20)}}{4 \times 0.1}\right]=\$ 10.81 \text {. }
$$

Table 2-2 presents examples of replacement cost multipliers for the normal, lognormal, and Weibull distributions--three principal continuous distributions of interest in failure analysis. We determined these factors by numerically integrating the respective distributions.** Note that the LCCM factors for these three distributions are similar in most cases.

Table 2-2 also presents the expected replacement cost multiplier when the probabilistic nature of the failures is ignored in favor of a deterministic approximation approach in which the failure is assumed to occur with certainty at every multiple of the mean component lifetime. For example, if the mean lifetime is 4 years, the deterministic approach assumes that a failure occurs at the end of the $4 \mathrm{th}, 8 \mathrm{th}, 12 \mathrm{th}$, etc., years. In this modified deterministic approach, LCCM is easily calculated as

$$
\operatorname{LCCM}=\sum_{i=1}^{\lfloor N / \lambda\rfloor}\left[\frac{1}{(1+d)^{\lambda}}\right]^{i}=\frac{1-\left[\frac{1}{(1+d)^{\lambda}}\right]^{\lfloor N / \lambda\rfloor}}{(1+d)^{\lambda}-1},
$$

\footnotetext{
*The continuous discount rate assumes continuous compounding. It can be found from the annual discount rate $d$ by the formula $d^{\prime}=1 n(1+d)$.

*:Each distribution was integrated over small time increments ( $1 / 10$ of a year) and treated as a discrete distribution using Eqs. 2-3 and 2-4.
} 
Table 2-2. Sample Life-Cycle Cost Multipliers

\begin{tabular}{|c|c|c|c|c|c|c|c|c|c|c|c|c|c|c|c|}
\hline \multirow{3}{*}{ Case } & \multirow{3}{*}{$\begin{array}{c}\text { Analysis } \\
\text { Period } \\
\text { (years) }\end{array}$} & \multirow{3}{*}{$\begin{array}{c}\text { Mean } \\
\text { L1fet1me } \\
\text { (years) }\end{array}$} & \multirow{3}{*}{$\begin{array}{c}\text { Discount } \\
\text { Rate } \\
(\%)\end{array}$} & \multicolumn{12}{|c|}{ LCCM } \\
\hline & & & & \multicolumn{4}{|c|}{ Normal } & \multicolumn{2}{|c|}{ Lognormal } & \multicolumn{4}{|c|}{ WeIbull } & \multirow[t]{2}{*}{$\begin{array}{l}\text { Modified } \\
\text { Determin- } \\
\text { istic }\end{array}$} & \multirow[t]{2}{*}{$\begin{array}{c}\text { Rayleigh }^{\mathrm{a}} \\
\text { Approximation }\end{array}$} \\
\hline & & & & $\sigma=1$ & $\sigma=2$ & $\sigma=4$ & $\sigma=8$ & $\sigma=1^{b}$ & $\sigma=2$ & $\beta^{c}=1$ & $\beta^{a}=2$ & $\beta=4$ & $\beta=8$ & & \\
\hline 1 & 20 & 4 & 0 & 4.48 & 4.14 & $-{ }^{d}$ & -- & 4.48 & 4.57 & 4.88 & 4.58 & 4.49 & 4.43 & 5.0 & 4.67 \\
\hline 2 & 20 & 4 & 10 & 1.77 & 1.70 & -- & - & 1.77 & 1.85 & 2.16 & 1.87 & 1.78 & 1.75 & 1.834 & 1.87 \\
\hline 3 & 20 & 8 & 10 & 0.685 & 0.707 & 0.725 & - & 0.684 & 0.703 & 1.08 & 0.805 & 0.714 & 0.690 & 0.684 & 0.817 \\
\hline 4 & 20 & 16 & 10 & 0.217 & 0.217 & 0.216 & 0.256 & 0.218 & 0.216 & 0.540 & 0.298 & 0.220 & 0.219 & 0.217 & 0.323 \\
\hline 5 & 20 & 4 & 25 & 0.697 & 0.715 & - & -- & 0.696 & 0.771 & 0.993 & 0.796 & 0.706 & 0.678 & 0.686 & 0.743 \\
\hline 6 & 20 & 8 & 25 & 0.199 & 0.218 & 0.266 & -- & 0.199 & 0.215 & 0.497 & 0.305 & 0.226 & 0.202 & 0.196 & 0.296 \\
\hline 7 & 20 & 8 & 50 & 0.043 & 0.056 & 0.102 & -- & 0.043 & 0.052 & 0.250 & 0.119 & 0.061 & 0.045 & 0.041 & 0.107 \\
\hline 8 & 30 & 4 & 10 & 2.01 & 1.90 & - & - & 1.976 & 2.06 & 2.38 & 2.11 & 2.01 & 1.99 & 2.01 & 2.08 \\
\hline 9 & 20 & 11 & 10 & 0.362 & 0.396 & 0.453 & -- & 0.361 & 0.396 & 0.786 & 0.523 & 0.429 & 0.385 & 0.351 & 0.542 \\
\hline 10 & 20 & 7 & 10 & 0.819 & 0.862 & -- & -- & 0.820 & 0.861 & 1.235 & 0.956 & 0.862 & 0.820 & 0.776 & 0.965 \\
\hline 11 & 20 & 7 & 5 & 1.32 & 1.38 & -- & -- & 1.32 & 1.38 & 1.806 & 1.48 & 1.38 & 1.32 & 1.22 & 1.51 \\
\hline 12 & 10 & 4 & 10 & 1.17 & 1.15 & -- & -- & 1.16 & 1.24 & 1.58 & 1.26 & 1.17 & 1.15 & 1.15 & 1.29 \\
\hline 13 & 10 & 4 & 25 & 0.595 & 0.621 & - & -- & 0.591 & 0.666 & 0.918 & 0.691 & 0.602 & 0.579 & 0.577 & 0.668 \\
\hline 14 & 10 & 6 & 10 & 0.594 & 0.671 & -- & - & 0.589 & 0.664 & 1.05 & 0.749 & 0.655 & 0.589 & 0.564 & 0.776 \\
\hline 15 & 10 & 10 & 10 & 0.207 & 0.225 & 0.174 & -- & 0.215 & 0.239 & 0.632 & 0.347 & 0.240 & 0.201 & 0.385 & 0.387 \\
\hline
\end{tabular}

$a_{\text {Weibu11 with } \beta=2}$ is the Rayleigh distribution. The Rayleigh analytical approximation should be compared with the numerical results given for the Weibull with $\beta=2$.

bstandard deviations are for the component lifetime, not for the logarithm of the component lifetime.

$c_{\text {Weibull with } \beta=1}$ is the exponential distribution.

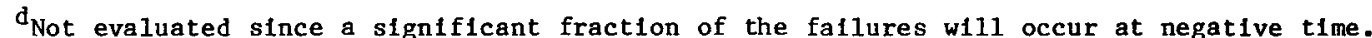


where $\lfloor N / \lambda\rfloor$ is the largest integer less than or equal to $\mathrm{N} / \lambda^{*}$ (i.e., the number of full mean lifetimes in the analysis period).

The principal pattern shown in Table $2-2$ is that with only a few exceptions the expected present value of the cost of repair and replacement for failures with a normal, lognormal, or Weibull distribution is very closely approximated by the present value cost of failures from the modified deterministic approach. Thus, with the few exceptions noted here we will ignore the failure probability distribution in calculating LCCM in favor of the modified deterministic approximation.

The largest divergence from the modified deterministic approximation occurs for the Weibull distribution with $\beta=1$; but this is none other than the exponential distribution for which we have already derived an explicit formula (Eq. 2-7). The reason for the divergence of the LCCM in the exponential distribution from that of the other distributions and the modified deterministic approximation is shown in Figure 2-1. The exponential distribution is highly nonsymmetrical; $63 \%$ of the failures occur before the mean lifetime $\lambda$ and only $37 \%$ after the mean 1 ifetime. Since the $63 \%$ is discounted less than the $37 \%$, the expected value of all replacement costs is larger than that of the normal distribution, which is perfectly symmetrical.

Significant divergence from the modified deterministic approximation also occurs for the Weibull distribution with $\beta=2$. This is the Rayleigh distribution that is less skewed than the exponential but still is not well represented by the deterministic approximation. Although an analytical formula for the LCCM of a Rayleigh distribution cannot be derived, the following formula provides a better approximation (see Appendix B for a derivation of this formula):

$$
\operatorname{LCCM}=\frac{1-e^{-d N}}{\lambda d}-\frac{1-\exp [-(3 / \lambda+d) N]}{(3 / \lambda+d) \lambda} .
$$

Table 2-2 also shows the LCCM multipliers calculated through this approximation compared with the numerical integration results for the Rayleigh distribution (Weibull with $\beta=2$ ).

A third significant discrepancy from the modified deterministic approximation occurs when the mean lifetime approaches or exceeds the analysis period (see case 15, Table 2-2). When the mean lifetime is slightly less than or equal to the analysis period, there is a high probability that no failure will occur during the analysis period. However, since the modified deterministic approximation to the LCCM assumes that a failure will occur with probability one, the LCCM from the modified deterministic approximation is significantly larger than the values determined by numerical integration. On the other hand, when

*When $\lfloor N / \lambda\rfloor$ is equal to $N / \lambda$, Eq. 2-9 implicitly assumes that the component is replaced at the end of the last year of the analysis period. In most cases this modification of the deterministic approach yields a better approximation than the alternative, wherein $N / \lambda$ is defined as the largest integer strictly less than $\mathrm{N} / \lambda$. 


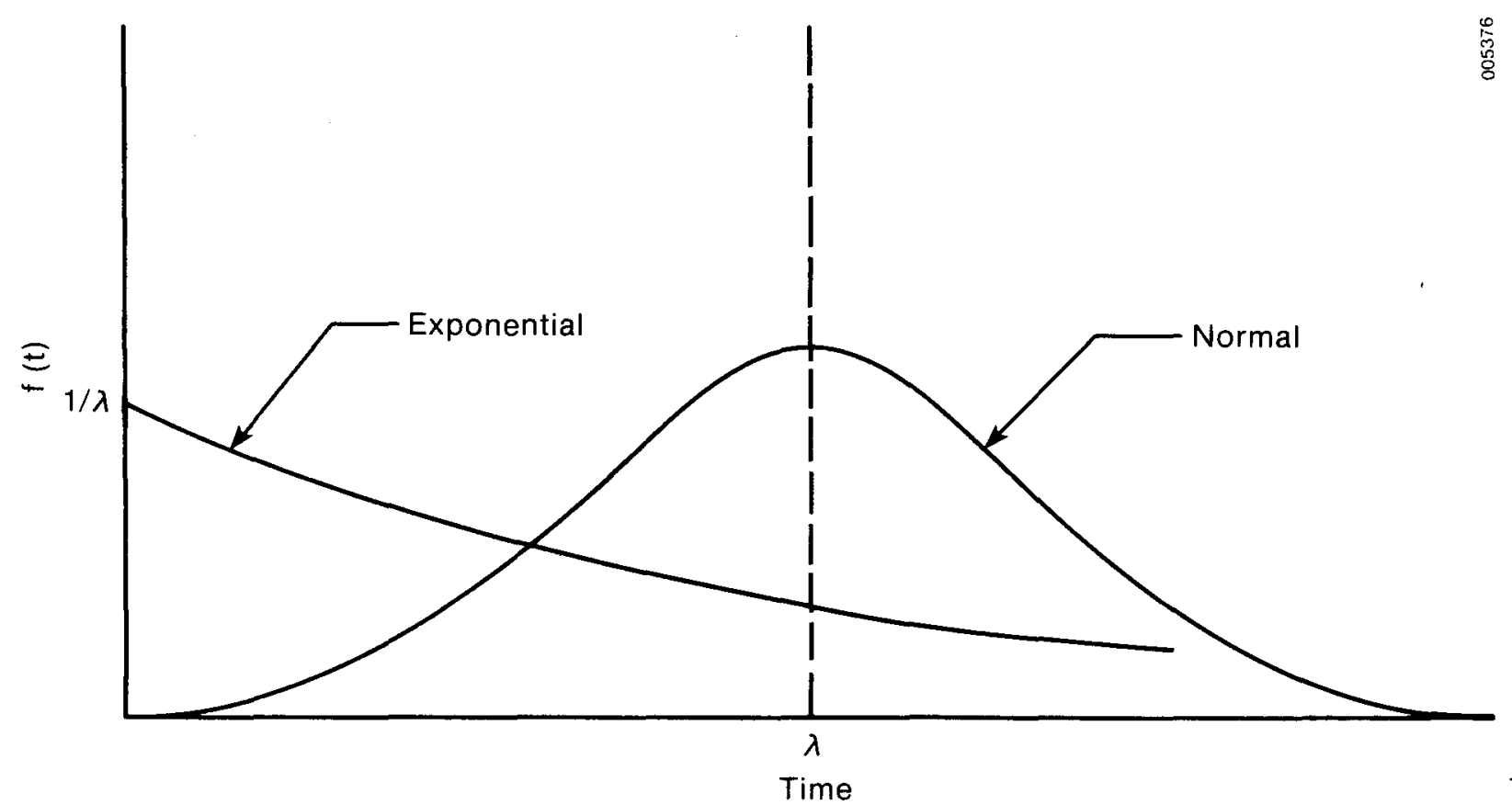

Figure 2-1. Probability Density Functions

the mean 1 ifetime exceeds the analysis period, the deterministic approximation will yield a value of zero for the LCCM when in fact there is a significant probability that a failure will occur during the analysis period. For the exponential and Rayleigh distributions, Eqs. 2-7 and 2-10, respectively, will properly handle these situations. However, the normal, lognormal, and Weibull $(\beta>2)$ distributions require another approximation. The following formula is recommended if $\sigma^{2}<2 \lambda / \mathrm{d}$ :

$$
L C C M=e^{\left(\frac{d^{\prime} 2 \sigma^{2}}{2}-\lambda d^{\prime}\right)}\left[F\left(\frac{N-\lambda+d^{\prime} \sigma^{2}}{\sigma}\right)-F\left(\frac{d^{\prime} \sigma^{2}-\lambda}{\sigma}\right)\right],
$$

where

$$
\begin{aligned}
& d^{\prime}=\ln (1+d) \text {, } \\
& \lambda, \sigma=\text { mean and standard deviation of the component lifetime, respec- } \\
& \text { tively } \\
& F(x)=\text { standardized normal cumulative distribution function evaluated } \\
& \text { at } x \text {. }
\end{aligned}
$$

(See Appendix $\mathrm{C}$ for a derivation of this approximation.) Table 2-3 compares the numerical integration results for case 15 of Table 2-2 with the values yielded by this approximation. 
Table 2-3. LCCM Approximation Results for the Case When the Mean Lifetime Approaches or Exceeds the Analysis Period ${ }^{a}$

\begin{tabular}{|c|c|c|c|c|c|c|c|c|c|c|c|c|c|c|}
\hline \multirow[b]{2}{*}{ Case } & \multirow{2}{*}{$\begin{array}{c}\text { Analysis } \\
\text { Period } \\
\text { (years) }\end{array}$} & \multirow{2}{*}{$\begin{array}{c}\text { Mean } \\
\text { Lifetime } \\
\text { (years) }\end{array}$} & \multirow{2}{*}{$\begin{array}{c}\text { Discount } \\
\text { Rate } \\
(\%)\end{array}$} & \multirow{2}{*}{ Method } & \multicolumn{10}{|c|}{ LCCM } \\
\hline & & & & & \multicolumn{4}{|c|}{ Normal } & \multicolumn{4}{|c|}{ Lognormal } & \multicolumn{2}{|c|}{ Weibull } \\
\hline 1 & 20 & 25 & 10 & $\begin{array}{c}\text { Numerical } \\
\text { eq. } 2-1\end{array}$ & $\begin{array}{l}0 \\
0\end{array}$ & $\begin{array}{l}0 \\
0\end{array}$ & $\begin{array}{l}0.019 \\
0.019\end{array}$ & $\begin{array}{l}0.068 \\
0.067\end{array}$ & $0^{--}$ & $0^{--}$ & $\begin{array}{l}0.016 \\
0.019\end{array}$ & $\begin{array}{l}0.060 \\
0.067\end{array}$ & $\begin{array}{l}0.057 \\
0.055\end{array}$ & $\begin{array}{l}0.018 \\
0.014\end{array}$ \\
\hline
\end{tabular}

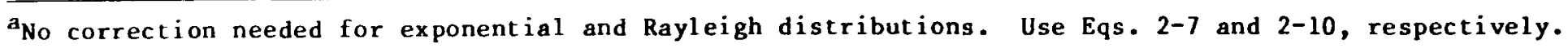

bstandard deviations are for the lifetime, not for the logarithm of the lifetime.

${ }^{c}$ Case 15 from Table 2-2. 
Other discrepancies occur between the modified deterministic approximation and the normal, lognormal, and Weibull $(\beta>2)$ distributions as the discount rate increases or as the standard deviation of the lifetimes increases. These errors are the result of greater emphasis on failures before the mean lifetime than on those after it. These errors as well as all others introduced by the approximation should be examined in light of the total life-cycle cost of each component. In this discussion the total 1 ife-cycle cost of a component is the sum of the repair and replacement costs during the analysis period plus the initial component cost.* Since the cost multipliers in Table 2-2 include only the cost of repairs and replacements, a cost multiplier that represents the total life-cycle cost would be equal to those in Table 2-2 plus one (assuming that the cost of a repair or replacement is equivalent to the initial cost). For example, in case 7 of Table 2-2 the deterministic approach yields an error in the LCCM of $60 \%\left[1-\left(\frac{0.041}{0.102}\right)\right]$ of the numerical integration result for the normal distribution with $0=4$. However, the total LCCM is in error by only $6 \%\left(1-\frac{1.041}{1.102}\right)$. Using the relative error in the total LCCM as the criterion, the largest error in Table 2-2 occurs in case 1 for the normal distribution with $\sigma=2$. Even for this unusual case, the error is only $14 \%$. This analysis demonstrates that to capture repair and replacement costs in an economic analysis, the probabilistic nature of failures need not be explicitly incorporated for all failure distributions. The cost of repairs and replacements from failures that occur in accord with normal, lognormal, or Weibul1 $(B>2)$. distributions can usually be approximated with a deterministic approach (Eq. 2-9). Those that occur in accord with exponential or Rayleigh distributions can be accounted for using Eqs. 2-7 and 2-10, respectively.

\subsubsection{Bathtub-Shaped Failure Distributions}

Frequently a component or subcomponent is vulnerable to multiple failures. For example, a pump may fail shortly after installation because of a manufacturing defect, during its normal service life, or much later because one or more of its moving parts wears out. None of the distributions examined up to this point represent this failure pattern. This pattern requires a combination of failure distributions that yields a decreasing failure rate** initially, followed by a constant failure rate during the service life of the component and an increasing failure rate at the end of the service life. Such a combination is often referred to as a bathtub-shaped curve (see Figure 2-2). In reliability analysis, Weibull distributions can be combined to represent such a failure rate pattern by appropriately selecting the 8 parameters of the distributions (see Appendix A). If adequate empirical data are available to estimate the failure rates and the $\beta s$, this is appropriate. However, as will be seen in Section 3.0, the data available on solar energy system failures do not justify this level of complexity. In place of the

*The total life-cycle cost of a component should also include operation and preventive maintenance costs, the inclusion of which would only strengthen the argument made in this paragraph.

**A failure rate may be loosely defined as the probability of failure in the next instant of time given that the component has not yet failed. See Appendix A for a more precise definition. 


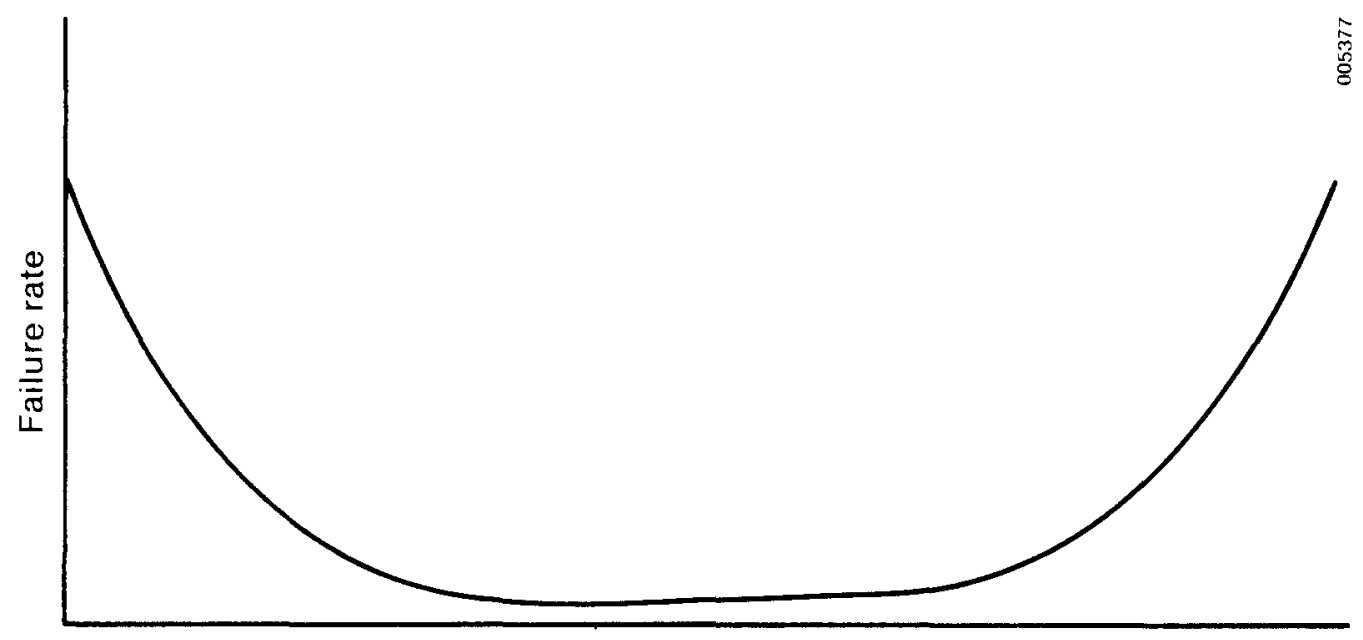

Time

Figure 2-2. Bathtub-Shaped Failure Rates

combination of three Weibulls we examine a simpler form of bathtub-shaped distribution in which a discrete failure probability $P$ is assigned to the first year, and the density function for all subsequent years is the product $(1-P) f(t)$, where $f(t)$ is the density function of a normal distribution. An example of such a distribution is shown in Figure 2-3. Using the same numerical integration techniques as applied to the normal, lognormal, and Weibull distributions in Table 2-2, we have determined LCCM values for this bathtub-shaped distribution. The multipliers are presented in Table 2-4 for the same cases as shown in Table 2-2.

Because of the nonsymmetrical nature of our bathtub-shaped distribution, the deterministic approximation presented earlier for the normal, lognormal, and Weibull distributions is not representative of the cost multipliers found for the bathtub-shaped distribution. However, we found that the same deterministic approach can be applied if we adjust the mean lifetime before applying Eq. 2-9 as follows:

$$
\lambda^{\prime}=P+\frac{(1-P) \lambda}{(1+d) \lambda P(1-P)},
$$

where $\lambda$ is the lifetime for the normal distribution portion of the bathtubshaped distribution. Using this modified $\lambda^{\prime}$ we apply Eq. 2-9 as before to yield an approximation to the repair and replacement LCCM for the bathtubshaped distribution:

$$
\operatorname{LCCM}=\frac{1-\left[\frac{1}{(1+d)^{\lambda^{\top}}}\right]^{\left[N / \lambda^{\prime}\right\rfloor}}{(1+d)^{\lambda^{\prime}}-1} .
$$


Table 2-4. Sample Expected Replacement Cost Multipliers for the Sample Bathtub-Shaped Distribution

\begin{tabular}{|c|c|c|c|c|c|c|c|c|c|c|c|c|}
\hline \multirow{3}{*}{ Case } & \multirow{3}{*}{$\begin{array}{c}\text { Analysis } \\
\text { Period } \\
\text { (yr) }\end{array}$} & \multirow{3}{*}{$\begin{array}{l}\text { Mean } \\
\text { Lifet ime } \\
\quad(y r)\end{array}$} & \multirow{3}{*}{$\begin{array}{c}\text { Nominal } \\
\text { Discount } \\
\text { Rate } \\
(\%)\end{array}$} & \multicolumn{9}{|c|}{ LCCM } \\
\hline & & & & \multicolumn{3}{|c|}{$\mathrm{P}^{\mathrm{b}}=0.1$} & \multicolumn{3}{|c|}{$P=0.2$} & \multicolumn{3}{|c|}{$P=0.5$} \\
\hline & & & & $s=1$ & $s=4$ & Approx. & $s=1$ & $s=4$ & Approx. & $s=1$ & $s=4$ & Approx. \\
\hline 1 & 20 & 4 & 0 & 4.97 & $--c$ & & 5.58 & -- & & 8.52 & -- & \\
\hline 2 & 20 & 4 & 10 & 2.01 & -- & 2.01 & 2.32 & -- & 2.35 & 3.75 & -- & 3.35 \\
\hline 3 & 20 & 8 & 10 & 0.855 & 0.849 & 0.794 & 1.06 & 1.05 & 1.09 & 2.09 & 2.06 & 1.91 \\
\hline 4 & 20 & 16 & 10 & 0.344 & 0.341 & 0.300 & 0.499 & 0.494 & 0.377 & 1.29 & 1.27 & 1.07 \\
\hline 5 & 20 & 4 & 25 & 0.843 & -- & 0.85 & 1.02 & -- & 1.04 & 1.83 & -- & 1.65 \\
\hline 6 & 20 & 8 & 25 & 0.312 & 0.359 & 0.326 & 0.450 & 0.500 & 0.469 & 1.11 & 1.18 & 1.00 \\
\hline 7 & 20 & 8 & 50 & 0.133 & 0.178 & 0.122 & 0.241 & 0.288 & 0.247 & 0.735 & 0.792 & 0.658 \\
\hline 8 & 30 & 4 & 10 & 2.27 & -- & 2.30 & 2.60 & - & 2.62 & 4.16 & -- & 3.76 \\
\hline 9 & 20 & 11 & 10 & 0.501 & 0.593 & 0.600 & 0.672 & 0.772 & 0.716 & 1.54 & 1.67 & 1.47 \\
\hline 10 & 20 & 7 & 10 & 0.997 & - & 1.06 & 1.21 & -- & 1.20 & 2.30 & -- & 2.07 \\
\hline 11 & 20 & 7 & 5 & 1.55 & - & 1.69 & 1.83 & -- & 1.80 & 3.27 & -- & 3.00 \\
\hline 12 & 10 & 4 & 10 & 1.36 & - & 1.22 & 1.59 & -- & 1.68 & 2.68 & -- & 2.37 \\
\hline 13 & 10 & 4 & 25 & 0.731 & -- & 0.683 & 0.896 & -- & 0.917 & 1.65 & -- & 1.42 \\
\hline 14 & 10 & 6 & 10 & 0.753 & -- & 0.608 & 0.948 & -- & 1.06 & 1.91 & -- & 1.71 \\
\hline 15 & 10 & 10 & 10 & 0.315 & 0.392 & 0.451 & 0.446 & 0.545 & 0.510 & 1.10 & 1.31 & 1.08 \\
\hline
\end{tabular}

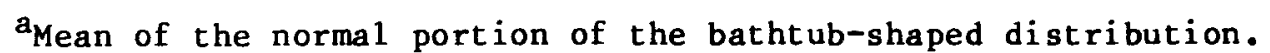

${ }^{b}$ Probability of failure in first year.

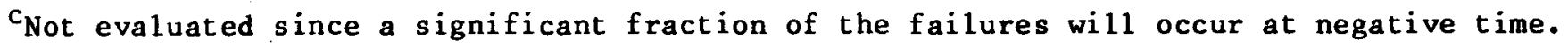




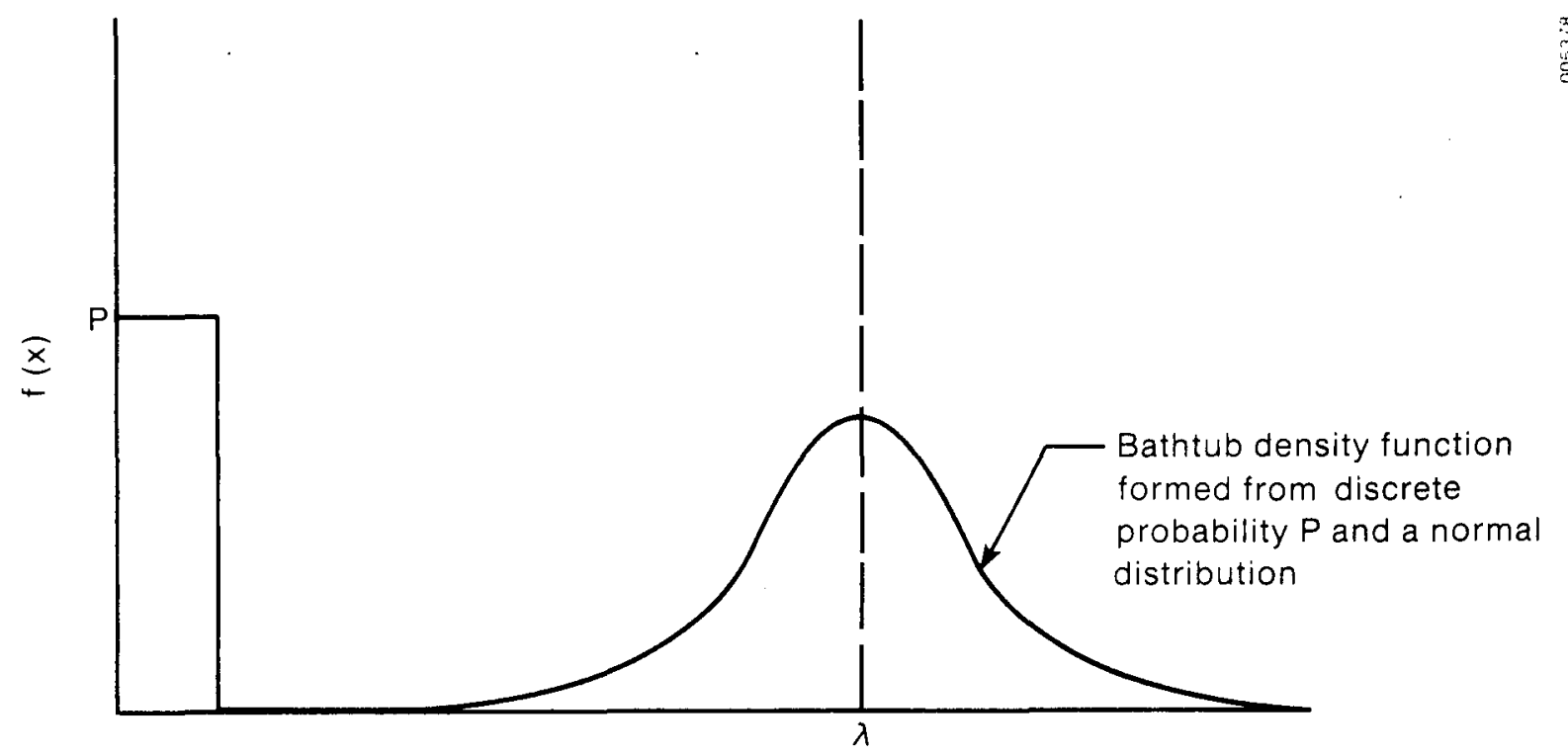

Figure 2-3. Bathtub-Shaped Distribution

This approximation was derived by beginning with the mean lifetime for the bathtub-shaped distribution [i.e., $P+(1-P) \lambda]$ and modifying it to more closely represent the cost multipliers of Table 2-3. The validity of the approximation is substantiated to the extent that the cases in Table 2-4 represent a wide range of the parameters that might be encountered in the economic analysis of solar energy systems.*

A bathtub-shaped distribution such as the one described here may not be appropriate if the probability of component or subcomponent failure in the first year $P$ represents only failures caused by initial installation problems. Our LCCM calculation implicitly assumes that there is a probability $P$ of component or subcomponent failure not only in the first year of system operation but also in each first year after the component or subcomponent is repaired or replaced.

Repair and replacement costs incurred immediately after system installation should be included in any economic analysis that is conducted from a research priority perspective. However, if the method of this report is adopted to analyze consumer costs, care should be taken to include only those repair and replacement costs not covered under the manufacturer's or distributor's warranty.

*The approximation quickly becomes unacceptable as the probability of failure in the first year increases above 0.5. This is not a severe limitation, however, since for most components the probability of an installation or manufacturing defect is considerably less than 0.5 . 


\subsubsection{Integral Subcomponent Failure}

If an entire component must be replaced upon the failure of any one of several integral subcomponents, then the component can again be considered to have multiple possible causes of failure. However, unlike the bathtub-shaped failure distributions previously examined, the failure distribution for such a component must be constructed from the failure distribution of its subcomponents. For example, an absorber plate may fail because of tube leaks or degradation of the absorber coating. Since the absorber fails if either of the two subcomponents fails, the time to failure of, the absorber $Z$ can be considered to be the minimum of the time to failure of the tubes $X$ or the time to failure of the coating $Y$. Mathematically, we have

$$
\mathrm{Z}=\min (\mathrm{X}, \mathrm{Y}) \text {, }
$$

where $X, Y$, and $Z$ are random variables.

If the failure distribution of each of the subcomponents is a Weibull distribution with parameters $\alpha_{i}$ and $\beta$, then the failure distribution of the component is also Weibull with parameters

$$
\alpha=\left(\frac{1}{\sum_{i}\left(1 / \alpha_{i}\right)^{\beta}}\right)^{1 / \beta},
$$

and $B$. Thus, the minimum of two or more exponentials is also exponential, and the minimum of two or more Rayleighs is also a Rayleigh. However, if the $B$ parameters of the Weibull failure distributions of the subcomponents are different or if the subcomponents have normal or lognormal failure distributions, then in many instances it is not possible to derive an analytical expression for the distribution for the minimum. As a first order approximation, it is recommended that Weibull distributions (with the same B parameter for all subcomponents) always be assumed for integral subcomponent failures. Table 2-5 shows the appropriate $B$ parameters to be used as a function of the mean and standard deviation of the subcomponent lifetime. The corresponding parameter $\alpha_{i}$ is found as*
Table 2-5. Selection of the $B$ Parameter for the Weibul1 Distribution

\begin{tabular}{ll}
\hline$\frac{\sigma^{*}}{\lambda}$ & $\beta$ \\
\hline 1.00 & 1 \\
0.52 & 2 \\
0.36 & 3 \\
0.28 & 4 \\
0.23 & 5 \\
0.20 & 6 \\
0.16 & 7 \\
0.15 & 8 \\
\hline
\end{tabular}

$* \sigma$ is the standard deviation for the component lifetime; $\lambda$ is the mean component lifetime.

$* \Gamma(x)=\rho^{\infty} e^{-s} s^{x-1} d s$. Values for the gamma function are tabulated (Hillier and Lieberman 1967). 


$$
\alpha_{i}=\lambda_{i} / \Gamma\left(\frac{\beta+1}{\beta}\right) .
$$

More precise estimates of the Weibull distribution parameters can be easily developed through graphical methods (Locks 1973).

\subsection{DOWNTIME COSTS}

The cost of failure includes not only the cost to repair or replace the failed component but also the cost of additional conventional fuel used by the backup system while the solar system is not operational. If the average annual solar contribution of a system is estimated from field-monitoring installed systems, then the downtime cost of using additional conventional fuel is implicitly included in any economic analysis of the system (i.e., the annual average solar contribution will be less than the contribution that would have been supplied by a perfectly reliable system). However, if simulation models are used to estimate the annual performance, or if downtimes have been excluded from the monitoring data, then the cost of downtime can be included explicitly by this method. The downtime cost $C_{d}$ is directly proportional to the length of the downtime $\left(T_{d}\right)$ according to the formula

$$
C_{d}=T_{d}\left(P_{c} Q_{L} / \eta_{c}\right) F_{s},
$$

where

$$
\begin{aligned}
& \mathrm{P}_{\mathrm{C}}=\text { conventional fuel price } \\
& \mathrm{Q}_{\mathrm{L}}=\text { average load per unit time } \\
& { }_{\mathrm{C}}=\text { conventional system efficiency } \\
& \mathrm{F}_{\mathrm{S}}=\text { solar fraction. }
\end{aligned}
$$

For small solar energy systems, downtime costs can be included by simply adding them to the cost of repair and replacement associated with each failure. This is not an entirely accurate representation and should be avoided if the cost is significant; i.e., when the solar system provides significant energy savings per unit time. For example, there are instances when the failure of one component results in the failure of another. If each is charged the cost of downtime, then this cost has been included twice. For a large solar energy system with significant downtime costs, it may be possible to avoid this double counting error by omitting this cost from the failure cost for each individual component and including it separately, using a system reliability and system LCCM for downtime costs only. Unfortunately, the system reliability calculation can become extremely complex if we assume that some of the components have failure probability distributions other than the exponential (see Argonne 1981). 


\subsection{SYSTEM PERFORMANCE DEGRADATION}

In many cases there is no precise time at which a solar system component can be said to have failed. Rather, the component slowly deteriorates, degrading the system's performance over a period of time. This performance degradation will be implicitly reflected in an economic analysis through the estimated solar contribution only if the estimate is derived from extensive fieldmonitoring data. If the annual solar contribution is estimated from computer simulation models of perfectly reliable systems, then the cost of the additional conventional fuel used during a period of degradation must be explicitly included by the method presented in this report. The burden is on the analyst to determine the point of degradation at which a component can be said to have failed and to include in the cost of failure a degradation cost to account for the additional backup fuel used by the system while the degradation progresses. One viable definition of the time of failure is the point in time at which the repair or replacement is made. The cost of additional backup fuel during the degradation process will vary with both the period of time over which degradation takes place and the severity of the degradation. 
SECTION 3.0

\section{APPLYING THE METHOD}

The method presented in Section 2.0 for calculating reliability costs requires three basic types of data inputs: the mean lifetime, the failure probability distribution, and the cost of failure for each component. In this section we describe the uncertainties inherent in such data for active solar systems, the possible sources for such data, and the use of the method and data for a typical domestic hot water (DHW) system.

\subsection{VARIATIONS AND DATA UNCERTAINTIES}

Like all developing technologies, solar energy suffers from a basic paradox with respect to reliability data. Statistically valid reliability data can be obtained only from representative systems that have been in the field for many years, yet for developing technologies such systems are not representative of current technology. Although many of the components found in solar energy systems have been used for years in other applications (e.g., pumps, fans, heat exchangers, sensors), the conditions under which they are used in solar energy systems can be substantially different. For example, in many solar energy systems, pumps may cycle off and on repeatedly, thermistor sensors may experience extreme temperatures under stagnation conditions, and valves may remain in one position over prolonged off-season periods. Thus, care must be taken in applying long-term field data to new solar energy systems.

Many reliability data collection efforts have attempted to circumvent this paradox by using data from more recently installed systems in the field. There are two problems with these efforts. First, faulty installation dominates system failures and problems in the first year or two. Although these failures are certainly important in any analysis of reliability costs, they vary tremendously and are generally specific to the installer and not to the system itself. Second, to estimate the mean time to failure based on only the total number of failures in the first few years of system operation implicitly presumes an exponential failure distribution (a constant failure rate over time). If, in fact, the failure rate is increasing over time, this approach could result in a significant overestimation of the mean time to failure. For example if, in a sample of 500 systems, 20 failures occur during the first 3 years after installation, the maximum likelihood estimated mean time to failure is 75 years assuming an exponential failure distribution but only approximately 6 years if the failure distribution is Weibull with $B=4$ (see Appendix E).

Another trait of developing industries like solar energy is that they are frequently fragmented with a plethora of products and brands varying widely in maintenance requirements and reliability. To state that the mean time to failure of a collector absorber plate is 15 years because half the brands have experienced 10 year lives while the other half continue to operate 20 years after installation is misleading. The problem is perhaps compounded with respect to solar energy systems because of the diversity of systems (e.g., closed-10op glycol DHW systems and air collector/rockbed space heating systems) and climates experienced. 
The diversity of systems and components also leads to difficulties in defining a failure. Some failures, such as bursting pipes in a water-based DHW system, are discrete, easily identifiable events. Others, such as the slow degradation of system performance caused by discoloration of a plastic glazing, are not as easily defined. Failures such as the latter, in which no single point in time can be identified as the instant at which the failure occurred, make it even more difficult to collect data on mean lifetime and failure probability distributions.

Because of these problems, there is a wide variation in the type and form of O\&M data presented in the 1 iterature. For example, the data from many literature sources are limited to the number of system failures; some sources itemize failures by component; a few present estimates of the mean time to failure; fewer still also show the failures over time (necessary for selection of the failure probability distribution); and almost none present details on the implications (cost to repair or replace) of the failure. One of the best data sources, the National Solar Heating and Cooling Demonstration Program (Greenberg et al. 1981), presents all of these data. However, rather than presenting costs, it categorizes failures as either shutting down the system, partially shutting it down, or not affecting system operations. It is not clear how these categories can be translated into costs for use in an economic analysis.

\subsection{DATA SOURCES}

In spite of the data variations, uncertainties, and problems noted in Section 3.1, reliability costs must be estimated accurately for existing and proposed solar energy systems. To this end, we present a summary of some of the reliability and maintainability data available for active solar energy systems. The principal sources of such data include field performance monitoring studies, government and utility solar demonstration program results, solar manufacturers and installers, professional associations such as ASHRAE, and the experiences of other more established industries using similar components. Several studies have constructed estimates of the mean lifetimes of solar components. However, the lifetime estimates frequently vary by factors of two or more. Although some data exist on the component failures over time, their usefulness in establishing component failure probability distributions is limited because of the relatively short period over which the systems were monitored. Costs for replacement parts are readily available from distributors. Labor costs are available through manufacturers' warranty labor schedules for their installers. System downtime costs can be roughly estimated from the repair and replacement times found in the manufacturers' warranty labor schedules.

To allow easy access and reference, we present a short summary and description of the type of data available and some numerical values for each of the principal sources of useful reliability cost data. 
- A Summary and Assessment of Historical Reliability and Maintainability Data for Solar Hot Water and Space Conditioning Systems (Jorgensen 1984)

This is an excellent literature review of solar reliability data. Many of the other literature sources 1 isted here are included in this report. However, because it is a summary report, in some cases additional data can be collected from the original source reports. Inasmuch as it reflects the data available in the literature, most of the results are presented as the average number of problems encountered by component. Few data are given on mean time to failure, no data are included on the type of failure probability distributions, and no data are given on the cost of failures.

- Final Reliability and Materials Design Guidelines for Solar Domestic HotWater Systems (Argonne 1981)

This is the most comprehensive source found for the failure rates of solar components and subcomponents (see Tables 3-1 through 3-3). Since the authors assume that all failure probability distributions are exponential, mean lifetime estimates are derived from the failure rate estimates by taking their inverse. However, there are some caveats. First, for nonexponential failure distributions, the mean lifetime may be overestimated by taking the inverse of the failure rate. Second, many of the failure rate data have been derived from nonsolar-energy sources. Finally, the exponential failure distributions were used extensively to estimate the failure rates of components from the failure rates of subcomponents. For example, using the mean lifetimes of the collector subcomponents shown in Table 3-1, the authors estimated the mean lifetime of a single collector panel to be 6 months to 5 years. Since this range is obviously low, the authors increased the range to 1 to 10 years (failure rates of $11.4-114$ million hours; see Table 3-3) so as to be more in accord with manufacturers' warranty periods of 5 to 15 years. Data for adjusting failure rates to accommodate different duty cycles are also provided; no cost data are given.

- Analysis of Reliability and Maintainability of Residential and Commercial Solar systems Included in the National solar Heating and Cooling Demonstration Program (Greenberg et al. 1981)

Although this report does not present mean lifetime data, it does contain data on failures over time by component. Approximately 920 residential and 90 commercial systems were monitored for 2 to 4 years after their installation in the years 1975-78. First-year problems are separated from problems in later years. No explicit cost data are given, but three levels of problem severity are specified--shutdown, partial shutdown, and no effect.

- A Reliability and Maintainability Study of Select Solar Energy System Components in the National Solar Data Network (Kendall et al. 1983)

This study produced the component failure rate data shown in Table 3-4. Unfortunately, the data are based on only 16 residential and commercial systems in the National Solar Data Network that were monitored for only 
Table 3-1. Mean Life of Major Elements in Flat-Plate Collectors

\begin{tabular}{lc}
\hline \multicolumn{1}{c}{ Elements } & $\begin{array}{c}\text { Mean-Life Range } \\
\text { (yrs) }\end{array}$ \\
\hline Glazing & 50 \\
$\quad$ Glass & $5-10$ \\
$\quad$ Polymeric sheets & $2-5$ \\
$\quad$ Polymeric films & $1-10$ \\
Seals & $10-30$ \\
Insulation & $20-25$ \\
Absorber plate & $1-5$ \\
Absorber coatings & $5-10$ \\
Paints & $15-30$ \\
Black chrome & \\
Black chrome over dull nickel & \\
\hline
\end{tabular}

Source: Argonne 1981.

Table 3-2. Failure Rates for Control System Electrical and Electronic Components

\begin{tabular}{ll}
\hline \multicolumn{1}{c}{ Components } & $\begin{array}{c}\text { Failure Raţe } \\
\left.\text { (failures } / 10^{6} \mathrm{~h}\right)\end{array}$ \\
\hline Integrated-circuit chip & 0.0028 \\
Carbon resistor & 0.003 \\
Diode & 0.008 \\
Potentiometer & 0.06 \\
12-V relay & 0.10 \\
Capacitor & 0.11 \\
Transformer & 0.5 \\
Rotary switch & 0.5 \\
\hline
\end{tabular}

Source: Argonne 1981. 
Table 3-3. Failure-Rate Ranges for Solar DHW Components

\begin{tabular}{|c|c|c|c|}
\hline Component & $\begin{array}{c}\text { Basic Failure Rate } \\
\text { (failures } / 10^{6} \mathrm{~h} \text { ) }\end{array}$ & $\begin{array}{c}\text { Duty-cycle } \\
\text { Parameter, } \\
d\end{array}$ & $\begin{array}{c}\text { Assumed } \\
\text { Degradation } \\
\text { Parameter, } \\
\text { a }\end{array}$ \\
\hline $\begin{array}{l}\text { Single collector panel } \\
\text { Control system } \\
\text { Storage tank or expansion tank } \\
\text { Polymeric hose } \\
\text { Copper piping system } \\
\text { Pump } \\
\text { Powered valves } \\
\text { Check valves } \\
\text { Pressure relief valves } \\
\text { Air vent or air separator } \\
\text { Heat exchanger } \\
\text { Heat exchanger in storage tank } \\
\text { Motorized damper } \\
\text { Back-draft damper } \\
\text { Fan }\end{array}$ & $\begin{array}{l}11.4-114 \\
5.7-28.5 \\
7.6-23 \\
23-38 \\
0.02-5 \\
8-150 \\
5.7-57 \\
5.7-11.4 \\
5.7-11.4 \\
14-200 \\
2.3-14 \\
11.4-23 \\
11-38 \\
4.5-29 \\
22-44\end{array}$ & $\begin{array}{l}0.25 \\
1.0 \\
1.0 \\
1.0 \\
1.0 \\
0.25 \\
0.25 \\
1.0 \\
1.0 \\
1.0 \\
0.25 \\
1.0 \\
0.25 \\
0.25 \\
0.25\end{array}$ & $\begin{array}{l}0.0-0.5 \\
0.0 \\
0.0 \\
0.0 \\
0.0 \\
0.2-0.4 \\
0.0-0.5 \\
0.0 \\
0.0 \\
0.0 \\
0.2-0.4 \\
0.0 \\
0.2 \\
0.2 \\
0.0\end{array}$ \\
\hline
\end{tabular}

a Base failure rates $f_{b}$ should be adjusted to account for the duty cycle of the component $f_{b}=f_{b}[d+(1-d) a]$.

Source: Argonne 1981.

1 year after operating for an average of 2 years. No data on failure probability distributions or repair and replacement costs are presented.

- ASHRAE Handbook--1980 Systems (ASHRAE 1980)

This handbook presents the median* equipment service life for different equipment items in normal (nonsolar) use, as shown in Table 3-5. The values are based on a nationwide survey conducted by ASHRAE in 1977. The median equipment service 1 ife is the same as the mean lifetime if the failure distribution is symmetrical. No data are given on the distributions of failures over time.

- Long Island Lighting Company Solar Domestic Hot Water Demonstration Program (Hooks 1983)

This utility conducted a residential solar demonstration program in which 632 DHW drainback systems designed specifically for the program were installed in New York between 1978 and 1980, and records were kept

$* 50 \%$ of the failures occur before the median and $50 \%$ after the median. 
Table 3-4. Reliability and Failure Classification by Component

\begin{tabular}{|c|c|c|c|c|c|c|}
\hline \multirow{2}{*}{ Subsystem } & \multicolumn{2}{|c|}{ Number of Failures } & \multirow{2}{*}{$\begin{array}{l}\text { Failure Rate } \\
\text { (failures/yr) }\end{array}$} & \multirow{2}{*}{$\begin{array}{l}\text { Base Failure Rate } \\
\text { (failures } / 10^{6} \text { h) }\end{array}$} & \multicolumn{2}{|c|}{$\begin{array}{c}\text { Mean Time between } \\
\text { Failures }\end{array}$} \\
\hline & Catastrophic & Degradation & & & Hours & Years \\
\hline Pumps & 4 & 0 & 0.07 & 8.2 & 343,000 & 39.1 \\
\hline Valves & 3 & 1 & 0.07 & 8.4 & 119,000 & 13.6 \\
\hline Leaks & 2 & 3 & 0.12 & 13.8 & 72,400 & 8.3 \\
\hline
\end{tabular}

${ }^{a}$ This MTBF has been calculated for catastrophic failures only.

Source: Kendall et al. 1983. 
Table 3-5. Equipment Service Life

\begin{tabular}{|c|c|c|c|}
\hline Equipment & $\begin{array}{l}\text { Median } \\
\text { Years }\end{array}$ & Equipment & $\begin{array}{c}\text { Median } \\
\text { Years }\end{array}$ \\
\hline Air conditioners & & Coils & \\
\hline Window unit & 10 & DX, water, or steam & 20 \\
\hline Residential single or split package & 15 & Electric & 15 \\
\hline Commercial through-the-wall & 15 & Heat exchangers & \\
\hline Water-cooled package & 15 & Shell-and-tube & 24 \\
\hline Computer room & 15 & Reciprocating compressors & 20 \\
\hline Heat pumps & & Package chillers & \\
\hline Residential air-to-air & 10 & Reciprocating & 20 \\
\hline Commercial air-to-air & 15 & Centrifugal & 23 \\
\hline Commercial water-to-air & 19 & Absorption & 23 \\
\hline Rooftop air conditioner & & Cooling towers & \\
\hline Single-zone & 15 & Galvanized metal & 20 \\
\hline Multizone & 15 & Wood & 20 \\
\hline Boilers, hot water (steam) & & Ceramic & 34 \\
\hline Steel water-tube & $24(30)$ & Air-cooled condensers & 20 \\
\hline Steel fire-tube & $25(25)$ & Evaporative condensers & 20 \\
\hline Cast iron & $35(30)$ & Insulation & \\
\hline Electric & 15 & Molded & 20 \\
\hline Burners & 21 & Blanket & 24 \\
\hline Furnaces & & Pumps & \\
\hline Gas- or oil-fired & 18 & Base-mounted & 20 \\
\hline Unit heaters & & Pipe-mounted & 10 \\
\hline Gas or electric & 13 & Sump and well & 10 \\
\hline Hot water or steam & 20 & Condensate & 15 \\
\hline Radiant heaters & & Reciprocating engines & 20 \\
\hline Electric & 10 & Steam turbines & 30 \\
\hline Hot water or steam & 25 & Electric motors & 18 \\
\hline Air terminals & & Motor starters & 17 \\
\hline Diffusers, grilles, and registers & 27 & Electric transformers & 30 \\
\hline Induction and fan-coil units & 20 & Controls & \\
\hline VAV and double-duct boxes & 20 & Pneumatic & 20 \\
\hline Air washers & 17 & Electric & 16 \\
\hline Duct work & 30 & Electronic & 15 \\
\hline Dampers & 20 & Valve actuators & \\
\hline Fans & & Hydraulic & 15 \\
\hline Centrifugal & 25 & Pneumatic & 20 \\
\hline Axial & 20 & Self-contained & 10 \\
\hline Propeller & 15 & & \\
\hline Ventilating roof-mounted & 20 & & \\
\hline
\end{tabular}

Source: ASHRAE 1980.

of warranty claims for 4 years. The summary statistics generated by LILCO do not include estimates of the mean lifetime of the components. Although such estimates could be derived from the raw data that LILCO has stored on its computer, this was not done for two reasons. First, the 
mean lifetime would be distorted because most of the systems have been in operation for 5 years or less. Second, many system improvements have been made based on the early system's problems and failures. Thus, the failure data reflect a system in the process of development. Raw data are also available on labor costs for repair or replacement, but they have not been aggregated into a usable form.

- Survey of System Operational Failure Modes from 122 Residential Solar Water Heater Systems over a Period of Approximately Two Years (ESG 1984)

This study surveyed the owners and installers of 122 DHW systems located in the southeastern United States. Component failures over time (up to 3 years after installation) are presented, but no estimates are made of mean 1 ifetimes. Limited cost data are presented based on 12 failures not covered by warranties.

- "Solar System Performance and Component Reliability after 5 Years" (Goldberg 1978)

This paper presents some data on mean lifetimes, as shown in Table 3-6; however, the paper does not state the source of the data. No data are presented on failures over time or costs.

Table 3-6. Mean Service Life

\begin{tabular}{lc}
\hline \multicolumn{1}{c}{ Components } & $\begin{array}{c}\text { Mean } \\
\text { Service Life } \\
\text { (yrs) }\end{array}$ \\
\hline Collectors & $\infty$ \\
Metal and glass & 3 \\
Wood & 30 \\
Elastomer seals & 20 \\
Pumps & 3 \\
Heavy-duty capacitor start & \\
Sealed & $?$ \\
Controls & 30 \\
Solid state triac & \\
Mechanical relay, 50 x 106 & \\
cycles used 50\% full-10ad rating & 30 \\
Connectors & 20 \\
Copper bellows & \\
Premium elastomer & 11 \\
Storage tanks & 9 \\
Glass lined & 30 \\
Stone lined & \\
Galvanized, protected &
\end{tabular}

Source: Goldberg 1978. 
- "Operational Status of 134 Solar Water Heaters in the Southeastern United States" (Jacobs 1982)

This paper documents a survey of 134 DHW system owners in the Southeast concerning the downtime of their units during 1 year. Most of the results are presented as the fraction of time that the system was down. With the exception of the draindown system results shown in Table 3-7, no data are presented on downtime by the type of failure. No data are presented on mean lifetime, failures over time, or repair and replacement costs.

- Manufacturers. Telephone interviews were held with 11 collector and solar energy system manufacturers to obtain data on reliability and maintenance. Of the 11 manufacturers contacted, only one had a formal operational process for keeping track of failures through their warranty program. Two more were in the process of implementing such a data base. None had estimates of mean lifetime based on their data. All had some component and system cost data. Labor costs for repairs under warranty were decided by most on a case-by-case basis. Only two released warranty labor schedules by type of repair or replacement required. These are summarized in Table 3-8 for a DHW system.

Table 3-7. Status Summary of the Draindown System

\begin{tabular}{lc}
\hline \multicolumn{1}{c}{ Problem } & Days Down \\
\hline No problems reported & 0 \\
Controls failed & 1 \\
Controls failed and replaced & 2 \\
Draindown valve malfunctioned causing freeze damage & 2 \\
Draindown valve malfunctioned causing freeze damage & 2 \\
Draindown valve replaced & 1 \\
Air vent installed after air lock reported & 1 \\
Reporting problems w/draindown valve & 0 \\
System down--freeze damage & 4 \\
Air lock--air vent installed & 5 \\
Draindown valve malfunctioned causing freeze damage & 5 \\
Collectors damaged--freezing & 6 \\
System down--controller problem & 8 \\
Collectors froze & 10 \\
Loose sensor wire & 1 \\
Leak in roof around plumbing & 0 \\
Pump running 24 hours & 0 \\
\hline
\end{tabular}

Source: Jacobs 1982. 
Table 3-8. Summary of Manufacturers' Warranty Labor Schedules

\begin{tabular}{lcc}
\hline \multicolumn{1}{c}{ Repair } & Labor Hours & $\begin{array}{c}\text { Cost }^{\mathrm{b}} \\
(\$)\end{array}$ \\
\hline Replace collector panel & 2.5 & 50 \\
Replace collector glazing & 1.0 & 20 \\
Replace single-function controller & 1.0 & 20 \\
Replace dual-load controller & 1.5 & 30 \\
Replace solder joint & 0.5 & 10 \\
Replace solenoid valve, mixing valve, etc. & 0.5 & 10 \\
Replace draindown valve & 1.0 & 20 \\
Replace main storage tank & 4.0 & 80 \\
Drain and refill closed-loop system & 1.0 & 20 \\
\hline
\end{tabular}

${ }^{a}$ Excludes travel.

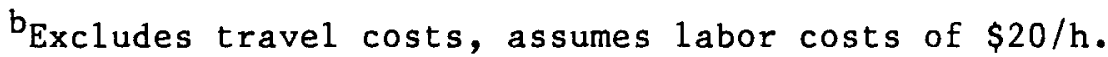

Source: Personal communications with solar system manufacturers.

Although most of the manufacturers did not possess formal data to substantiate their statements, they did provide a consensus on several issues:

- System suppliers do not consider reliability to be a significant problem because they believe they have either obtained reliable components from other manufacturers, improved their own designs, or stopped manufacturing the system (several of the manufacturers contacted no longer sell draindown systems because of their reliability problems).

- Most of the collector problems of 5 years ago have been eliminated. Collector failure rates now appear to be less than $1 \%$ a year. Manufacturers also feel that pump and controller problems have been largely eliminated.

- A large fraction (as high as $90 \%$ ) of the problems today are related to installation.

- The new systems have not been installed long enough for an estimate to be made of their lifetime. The low rate of early failures in new systems suggests a failure distribution closer to normal than exponential.

- Distributors. Local distributors were contacted for component price information. Only those prices necessary for the sample life-cycle cost calculations shown in Section 3.4 were collected. 


\subsection{MISSING DATA ELEMENTS}

Since there are few or no empirical data for selecting failure probability distributions, we established some common-sense guidelines based on the characteristics of the available distributions. For each distribution we present the failure pattern best represented by the distribution, some constraints on the use of the distribution, and several examples for each:

- Exponential. Failure is just as likely to occur at one time as any other. Some examples are broken glazing, electronic failure, and freezing failure.

- Normal. Failure occurs primarily because components wear out. The standard deviation of the 1 ifetime must be less than half the mean lifetime. An approximate formula is available for LCCM for the case in which the mean lifetime approaches or exceeds the analysis period. Some examples are ultraviolet degradation of collector seals and corrosion of valves and tanks.

- Weibull $(\beta \geq 2)$. Failure occurs primarily because one of two or more subcomponents wears out. Or failure is caused primarily by wearout, but the standard deviation of the lifetime is so large as to preclude the use of the normal distribution. Some examples are

- The storage tank with the internal heat exchanger may fail because of corrosive wearout of either the heat exchanger or tank.

- The collector insulation may fail because of outgassing or moisture that accumulates as a result of failed seals.

- The absorber plate may fail because of degradation of the absorber plate coating or because of freezing caused by controller failure.

- Bathtub-Shaped Distribution. Different types of failure can occur as the component ages. Unless empirical data suggest otherwise, we recommend a simple formulation that represents manufacturing-related failures in the first year with a single probability and wearout failure in subsequent years with a normal distribution. For example, pumps not manufactured to specifications may fail in the first year, although later failures may occur because of wearout.

Should more comprehensive failure data become available in the future, it may be possible to replace the common-sense guidelines presented here with statistically validated failure probability distributions. With valid time series data on component failures, it should be possible to employ goodness-of-fit tests, such as the chi-square test or Kalmogorov-Smirnov test, to check the validity of the assumed underlying failure distribution (Mood et al. 1974) and to calculate confidence intervals on variables, such as the mean lifetime of a component (see Appendix E).

The labor costs for repair and replacement can be calculated from manufacturers' warranty labor schedule data. However, the time for a repairman to diagnose, repair, and check out a failure is only part of the downtime, as shown by Figure 3-1. No empirical data were located on the other components 
of the downtime (time-to-failure detection, repairman response time, and parts-on-order time). To obtain a rough estimate of the repairman response time, a simple queuing model of this response time was constructed that showed that the average waiting time will be less than three times the diagnosis and repair time (see Appendix D). Since, as shown in Table 3-8, most repair times are less than a half day, the repairman response time will, on the average, be less than two days. We were not able to devise any estimates for the time-tofailure detection or parts-on-order time (site visits suggest that the former can be very long, since owners are often unaware that a problem exists) (Yarosh et al. 1982). However, assuming that these times are of the same order of magnitude as the response and repair times, it can be concluded that the total average downtime is less than a week for each failure. The cost of this downtime to the system owner is only the cost of the additional backup fuel used while the solar system is down. For a residential-size solar energy system, this cost is typically very small ( $\$ 1-\$ 2 /$ day); for a larger, commercial-size system, the cost can be substantial.

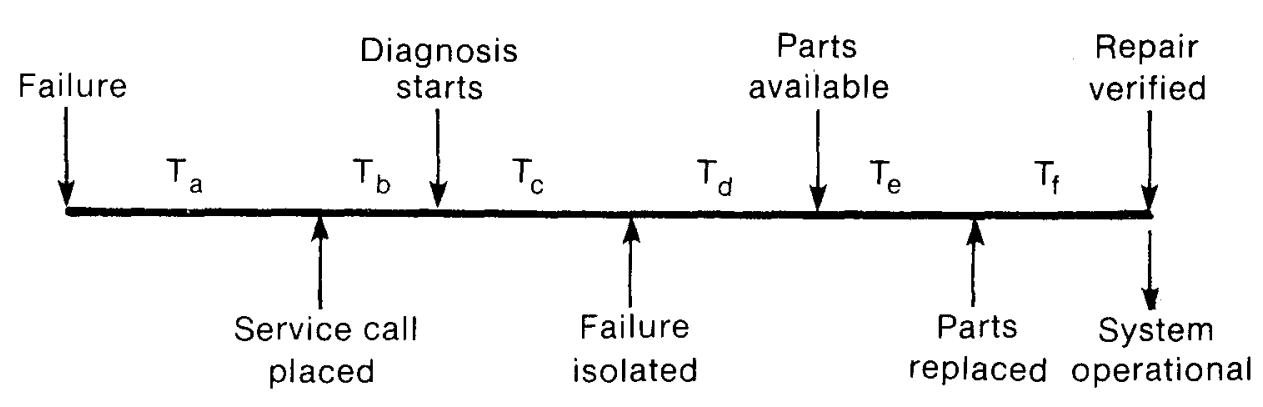

\section{Downtime component}

$T_{a}=$ time to detection

$T_{b}=$ repairman response

$T_{c}+T_{e}+T_{f}=$ diagnosis, repair, checkout

$T_{d}=$ parts on order

\section{Data availability}

No data. Can be reduced with fault detection system

No data. Queuing theory used to find that $T_{b}<3\left(T_{c}+T_{e}+T_{f}\right)$

Warranty labor schedules

No data

Figure 3-1. System Downtime 


\subsection{LIFE-CYCLE O\&M COSTS FOR A CLOSED-LOOP GLYCOL DHW SYSTEM}

To use the preceding methods and data as an example, we determined the 1 ifecycle O\&M costs for a closed-loop glycol DHW system. We first addressed the life-cycle operating and preventive maintenance costs and then followed that with the five steps presented in Section 2.0 for calculating 1 ife-cycle repair and replacement costs.

As our representative system, we chose the two-tank, two-panel configuration shown in Figure 3-2. Recommended annual operating and preventive maintenance procedures for such a system are shown in Table 3-9. With the possible exception of a few items, such as checking sensor calibration, the owner can complete these maintenance procedures at essentially no cost.* Thus, for this system the only 1 ife-cycle O\&M costs investigated will be repair and replacement costs.

Table 3-10 summarizes the findings of the first two steps presented in Section 2.0 for establishing 1 ife-cycle reliability costs:

- Identify all significant failures and the components/ subcomponents that may require repair or replacement as a result of these failures

- Divide the system into components and subcomponents at the lowest possible level with respect to repair and replacement.

The collector panels are broken down into four principal subcomponents that may fail. The underlying assumption is that it is not necessary to discard the entire collector if any one of these subcomponents fails but rather to repair or replace only the subcomponent that fails. Although some manufacturers will automatically replace the entire collector and repair the failed unit back at the factory for later resale, the net cost is approximately the same as when only the subcomponent is repaired or replaced.

Since the single glazing is assumed to be a glass cover, we assume there is no degradation over time. However, the possibility always exists of breakage caused by hail, snow, wind, or vandalism. Since such problems are as likely to arise in the first year after installation as they are after 10 years, we assumed an exponential failure distribution, as shown in Table 3-11 (Table 3-11 presents the results for all components and subcomponents for the five steps of our procedure for determining life-cycle repair and replacement costs). Although we did not find any data in the literature for the rate at which such failures can be expected to occur, we assumed a mean 1 ifetime of 50 years, or equivalently, a failure rate of $2 \% / y r$. Based on Eq. 2-7 and a real discount rate of $7 \%$, this failure distribution yields an LCCM of 0.22 . We apply this to a glazing replacement cost of $\$ 65$ to find that for a single panel the present-value life-cycle repair and replacement cost for glazing alone is $\$ 14$. For our two-panel system the cost is $\$ 28$.

*An owner may elect to have a local HVAC contractor perform these tasks for an annual fee. If so, the costs can be included in the economic analysis by using Eq. 1-1. 


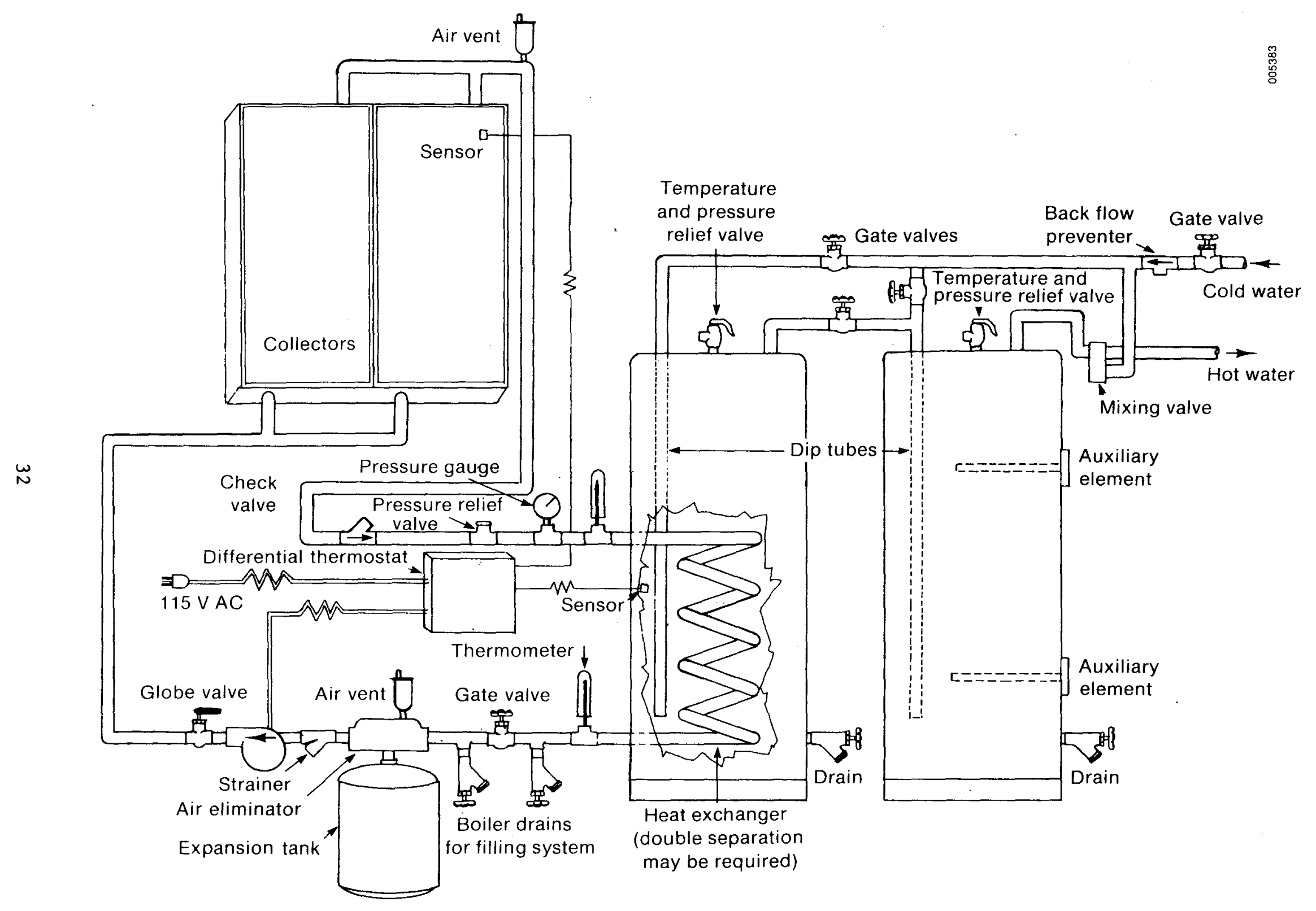

Figure 3-2. Closed-Loop System--Two Tanks 
Table 3-9. Annual Operating and Preventive Maintenance Procedures for a Closed-Loop, Glycol DHW System

Wash collector outer glazing with compounds approved by the manufacturer. (Do not remove dust from polymeric glazings with a dry cloth because it will scratch the glazings.) Inspect absorber plates for degradation during washing.

Inspect flashing and collector-mounting hardware. Tighten, replace, and recaulk as required.

Inspect and tighten hose connections around collector array. Replace any degraded hoses.

Verify that sensors are still in correct locations. Check sensor calibration.

Inspect hand-operated valves for leaks. Adjust packing. Open and close valves to verify proper operation.

Drain and flush all tanks. Clean strainers and valve filters.

Inspect pressure-relief value on tank(s) and collector loop, verifying that valve(s) operates and that exit port is not plugged.

Check level of heat-transfer fluid in expansion tank. Add fluid if needed.

Check the glycol concentration.

Verify $\mathrm{pH}$ of glycol/water solution. Replace or buffer according to manufacturer's specifications.

System should be checked periodically for:

Insulation deterioriation

Leaks

Correct thermostat setting to ensure that setting has not drifted since start-up and testing.

Correct operation:

Verify that pump does not operate at night; use a flowmeter, sight glass, or pressure gauges (if installed).

On a sunny day, verify pump operation by noting if flowmeter or sight glass indicates fluid motion. In addition, check temperature difference between collectors and storage using thermometers and thermowells, as in Figure 3-8. If temperature difference is above high diffential set point of T2-1 and system has not started, call a service person. Also, if temperature difference across heat exchanger is below the low differential set point of $\mathrm{T} 2-2$, and system is running, call a service person.

Check pump lubrication to manufacturer's specifications.

Source: Argonne 1981. 
Table 3-10. Principal Components and Faflure Causes for Closed-Loop, Glycol DHW System

\begin{tabular}{|c|c|c|c|}
\hline Component & Subcomponents & Faflure & Fallure Causes \\
\hline Collector & $\begin{array}{l}\text { Glazing (glass) } \\
\text { Absorber }\end{array}$ & $\begin{array}{l}\text { Breakage } \\
\text { Coating degradation } \\
\text { Tube ruptures } \\
\text { Tube clogging } \\
\text { Degradation of } \\
\text { R-value }\end{array}$ & $\begin{array}{l}\text { Mechanical stress, vandalism } \\
\text { Exposure to thermal cycling, ultraviolet radiation, humidity, } \\
\text { stagnation temperatures, etc. } \\
\text { Freezing as a result of propylene glycol decomposition } \\
\text { Corrosion, scallng } \\
\text { Outgassing, exposure to molsture and stagnation temperatures }\end{array}$ \\
\hline $\begin{array}{l}\text { Control } \\
\text { system }\end{array}$ & $\begin{array}{l}\text { Differential controller } \\
\text { Sensors } \\
\text { Mixing valves } \\
\text { Pressure/temperature } \\
\text { rellef valves } \\
\text { Check valves }\end{array}$ & $\begin{array}{l}\text { Electronic failure } \\
\text { Electronic fallure } \\
\text { Leak1ng } \\
\text { Coil burnout } \\
\text { Leaking } \\
\text { Leaking }\end{array}$ & $\begin{array}{l}\text { Short circults } \\
\text { Stagnation temperatures, thermal cycling } \\
\text { Seats or packing degrade } \\
\text { Cycling } \\
\text { Polymeric seal material takes a permanent set }\end{array}$ \\
\hline $\begin{array}{l}\text { Transport } \\
\text { system }\end{array}$ & $\begin{array}{l}\text { Plping } \\
\text { Expansion tank } \\
\text { Pump } \\
\text { Propylene glycol }\end{array}$ & $\begin{array}{l}\text { Corrosion } \\
\text { Leaking } \\
\text { Bearings selze } \\
\text { Motor falls } \\
\text { Breakdown into acids } \\
\text { Corrosion of transport } \\
\text { system }\end{array}$ & $\begin{array}{l}\text { Use of dissimilar metals, stagnation temperatures } \\
\text { Corrosion } \\
\text { Misalignment caused by air in system or improper motor } \\
\text { Mount, excessive loads, cycling } \\
\text { Improper pH levels } \\
\text { Improper Inhibitor levels }\end{array}$ \\
\hline Storage & $\begin{array}{l}\text { Main tank with integral } \\
\text { heat exchanger } \\
\text { Auxilfary tank with } \\
\quad \text { electric heating element }\end{array}$ & $\begin{array}{l}\text { Leaking } \\
\text { Freezing } \\
\text { Leaking, scaling } \\
\text { Heater element fallure }\end{array}$ & $\begin{array}{l}\text { Corrosion } \\
\text { Check valve fallure causes thermosiphoning to cold } \\
\text { collectors, scallng } \\
\text { Corrosion }\end{array}$ \\
\hline
\end{tabular}


Before proceeding to the life-cycle repair and replacement costs for other components, we will investigate the glazing costs in more detail. The replacement cost of $\$ 65$ is composed of $\$ 25$ in parts cost and $\$ 40$ in labor and other costs. The $\$ 25$ in parts includes the cost of the glass and surrounding seals as estimated by Chamberlain Manufacturing Company (Sims 1976) and updated to 1984 dollars in proportion to the retail cost of a $4 \mathrm{ft} \times 8 \mathrm{ft}$ panel. The labor cost of $\$ 40$ includes $0.9 \mathrm{~h}$ of labor to replace the glass and seals (Sims 1976) at $\$ 20 / \mathrm{h}$ plus $\$ 20$ for travel expenses to and from the installation site, and $\$ 2$ for additional backup fuel consumed by the owner while waiting for the solar energy system to resume. operation. All these costs may be expected to escalate over time. By using the real discount rate of $7 \%$ in calculating the LCCM of 0.22 , we are implicitly assuming that all the costs escalate at the same rate as inflation.

We assume that the absorber will require replacement if either the coating degrades because of corrosion or scaling or the tubes burst from freezing because of weakening of the propylene glycol over time. Since the rate at which each of these failures occurs increases with time, we discard the standard assumption of an exponential failure distribution. Ideally, we would replace the exponential distribution with a distribution that represents the minimum time to failure of three possible failure types. However, we were not able to find failure rate data on the individual failure causes for an absorber. Argonne National Laboratory (ANL 1981) estimated that the mean lifetime for the absorber plate is 20 to 25 years and that of a black chrome over dull nickel coating is 15 to 30 years. Another ANL study (Wolosewicz and Chopra 1979) indicates that freezing can be a significant problem in glycol DHW systems but yields no information on the mean time to failure. Therefore, to incorporate the possibility of all three failure types, we set the mean lifetime of the absorber at 15 years, the low end of the ANL estimates, and assumed a Rayleigh (Weibull with $\beta=2$ ) failure distribution. This distribution allows a larger standard deviation than the normal* and therefore better represents the three different failure possibilities. Equation 2-10 yields an LCCM of 0.47 . The total 1 ife-cycle repair and replacement cost for each absorber plate is $\$ 118$, as shown in Table 3-11.

Collector insulation can also fail for more than one reason. As shown in Table 3-10, degradation can occur over time because of outgassing and moisture that has penetrated through leaking seals. Estimates of mean lifetime for insulation vary from 10 to 30 years. For this analysis we selected a 20 -year lifetime and assumed a Rayleigh failure distribution to represent the larger standard deviation in the time to failure that results from two possible causes.

Collector seals fail from exposure to ultraviolet radiation, humidity, and stagnation temperatures resulting in outgassing or a permanent compression set. Argonne National Laboratory (1981) estimates a seal's mean lifetime at 1 to 10 years. For this example we selected 8 years as a mean lifetime together with a normal failure distribution. The deterministic approximation for this normal distribution (Eq. 2-9) yields an LCCM of 0.92 . Thus, the

*The standard deviation of the normal distribution must be restricted to prevent a significant probability of negative time to failure. 
Table 3-11. Repair and Replacement LCC for a Closed-Loop Glycol DHW System

\begin{tabular}{|c|c|c|c|c|c|c|c|c|c|}
\hline \multirow{2}{*}{$\begin{array}{l}\text { Component/ } \\
\text { Subcomponent }\end{array}$} & \multirow{2}{*}{$\begin{array}{l}\text { Repair and } \\
\text { Parts }^{b}\end{array}$} & \multicolumn{2}{|c|}{ Replacement $\operatorname{Cos} t^{a}$} & \multirow{2}{*}{$\begin{array}{c}\text { Mean } \\
\text { Lifetime } \\
\text { (years) }\end{array}$} & \multirow{2}{*}{$\begin{array}{c}\text { Assumed } \\
\text { Failure } \\
\text { Probability } \\
\text { Distribution }\end{array}$} & \multirow{2}{*}{$\left(\mathrm{d}=0.07^{\mathrm{d}}, \mathrm{LCCM}\right.$} & \multirow{2}{*}{$\begin{array}{c}\text { Repatr/ } \\
\text { Replacement } \\
\text { LCC }\end{array}$} & \multirow{2}{*}{$\begin{array}{l}\text { Number } \\
\text { Units per } \\
\text { System }\end{array}$} & \multirow{2}{*}{$\begin{array}{c}\text { Total } \\
\text { Repair/ } \\
\text { Replacement } \\
\text { LCc }^{\mathbf{e}}\end{array}$} \\
\hline & & $\begin{array}{c}\text { Labor } \\
\text { and } \\
\text { Other }\end{array}$ & Total & & & & & & \\
\hline Collector ( $4 \mathrm{ft} \times 8 \mathrm{ft}$ pane $\mathrm{I})$ & $500^{f}$ & & & & & & & & \\
\hline Glass glazing & 25 & 40 & 65 & 50 & Exponential & 0.22 & 14 & $2^{\mathrm{g}}$ & 28 \\
\hline Absorber & 175 & 75 & 250 & 15 & Rayleigh & 0.47 & 118 & 2 & 236 \\
\hline Insulation & 36 & 60 & 80 & 20 & Rayleigh & 0.31 & 25 & 2 & 50 \\
\hline Seals & 5 & 40 & 45 & 8 & Normal & 0.92 & 41 & 2 & 82 \\
\hline \multicolumn{10}{|l|}{ Control system } \\
\hline Differential controller & 85 & 40 & 125 & 10 & Exponential & 1.08 & 135 & 1 & 135 \\
\hline Sensor & 10 & 40 & 50 & 15 & Exponeatial & 0.72 & 36 & 2 & 72 \\
\hline Mixing valve & 50 & 35 & 85 & 12 & Normal & 0.44 & 37 & 1 & 37 \\
\hline Pressure/temperature & 10 & 30 & 40 & 15 & Normal & 0.36 & 14 & 2 & 28 \\
\hline Relief valve & & & & & & & & & \\
\hline Check valve & 10 & 35 & 45 & 15 & Norma1 & 0.36 & 16 & 2 & 32 \\
\hline \multicolumn{10}{|l|}{ Transport system } \\
\hline Piping & 5 & 30 & 35 & 10 & Exponential & 1.08 & 38 & $\mathbf{I}$ & 38 \\
\hline Expansion tank & 50 & 50 & 100 & 15 & Normal & 0.36 & 36 & 1 & 36 \\
\hline Pump & 130 & 40 & 170 & 12 & Norma1 & 0.44 & 75 & 1 & 75 \\
\hline Heat transfer fluid & 32 & 40 & 72 & 3 & Normal & 3.13 & 225 & 1 & 225 \\
\hline $\begin{array}{l}\text { Storage tank ( } 120 \text { gal } \\
\text { pressurfzed with HEX) }\end{array}$ & 800 & 100 & 900 & 12 & Weibull $(\beta=4)$ & 0.44 & 396 & 1 & 396 \\
\hline Auxiliary tank & 150 & 50 & 200 & 12 & Weibull $(\beta=4)$ & 0.44 & 88 & 1 & 88 \\
\hline TOTAL & & & & & & & & & $\$ 1558$ \\
\hline
\end{tabular}

${ }^{a}$ Cost per fallure. Assumed to escalate at the rate of inflation.

${ }^{b}$ Includes $6 \%$ sales tax.

${ }^{c}$ Includes repairman travel time and cost as well as customer dowatime costs.

$d_{\text {Real discount rate (excludes inflation). }}$

excludes initial costs at the time of original installation.

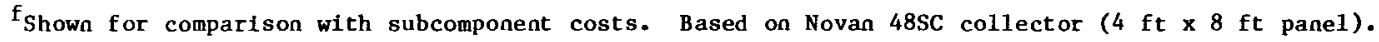

$\mathrm{g}_{\text {Two panels }}$ are assumed. 
life-cycle repair and replacement cost for seals is $\$ 41$; the total cost for both panels of the collector is $\$ 82$.

As shown in. Table 3-10, the control system has been disaggregated into the differential controller, sensors, and valves since each can be replaced individually. The failures of the electronics of the differential controller and sensor are represented by the exponential distribution, which is common for electronic components. Unfortunately, data on the mean lifetime of the electronic subcomponents of the individual controller are not available. Estimates of the mean lifetime of the controller system vary from 4 to 20 years (Argonne 1981; Kendall et al. 1983). Research at SERI indicates that many of the problems may be attributable to the use of thermistor sensors that are incapable of withstanding collector stagnation temperatures (Farrington and Myers 1983). The use of available heat-resistant thermistors may increase the control system lifetime. Thus, we selected a mean lifetime of 15 years for sensors and 10 years for the differential controller. Cost estimates for controller subcomponents were obtained from local distributors in the Denver area. As with the collector labor repair costs, the labor costs for controller repair are based on manufacturers' warranty labor schedules (see Table 3-8) and include travel and downtime costs.

Valve failures are primarily caused by degradation or by the permanent set of the seat material. Estimates of the mean lifetime for pressure/temperature relief valves and check valves range from 10 to 20 years (ANL 1981; Kendall et al. 1983; ASHRAE 1980). In addition to failures caused by the seats, powered valves, such as mixing valves, also fail because of coil burnout. Estimates of the mean lifetime of powered valves range from 2 to 20 years (ANL 1981; Kendall et al. 1983; ASHRAE 1980). We have assumed a normal failure distribution for all three valve types.

Failures in the transport system are usually reported for the transport system as a whole (ANL 1981; Jorgensen 1984), not for the individual subcomponents that make up the transport system. Problems are less prevalent in closed systems than in open systems and are frequently the result of improper maintenance of the heat transfer fluid (Jorgensen 1984). Unlike the other components and subcomponents for which we calculate the life-cycle repair and replacement costs, when a failure occurs in the piping, the entire piping system is not replaced. Thus, the failure rate does not change because a failure occurs. We represent this with an exponential distribution with a mean lifetime of 10 years based on the mean time to failure of 8.3 years determined from the National Solar Data Network Demonstration for a sample of open and closed systems. The cost to repair a plumbing leak ( $\$ 35)$ is assumed to consist principally of 1 abor and travel costs $(\$ 30)$.

The collector-side pump can fail as a result of bearing degradation or seizure from misalignment of the motor mounts or because of air in the system. The pump motor may also fail because of excessive loads or on and off cycling. Estimates of mean pump 1 ifetime vary from 4 to 150 years (ANL 1981; Kendall et al. 1983; ASHRAE 1980). We have assumed a mean lifetime of 12 years and a normal failure distribution.

The last component included in the transport system is the propylene glycol heat transfer fluid. Over time a 50-50 mixture of propylene glycol and water may oxidize into acids and dissolve corrosive heavy metal ions. The mean 
lifetime varies with the attention paid by the owner to the strength, corrosion inhibitor, and $\mathrm{pH}$ buffer levels in the solution. Based on discussions with distributors and installers, we have assumed a 3 -year mean 1 ifetime with a normal distribution. The replacement cost is based on a system fluid capacity of 5 gal (2.5 gal of glycol) and a glycol cost of $\$ 13 / \mathrm{gal}$.

Three tanks are included in the systems. An expansion tank on the collector side is assumed to fail according to a normal failure distribution with a mean lifetime of 15 years because of corrosive effects at the connections [based on mean tank lifetimes of 5 to 15 years (ANL 1981)]. The main storage tank, which includes an internal heat exchanger, can fail because of corrosion or freezing on the load side as the result of a failed check valve and thermosiphoning to cold collectors. If we assume that the mean time to each of these two types of failure is 15 years [heat exchanger mean lifetime estimates range from 5 to 24 years (ANL 1981; Kendall et al. 1983; ASHRAE 1980)] and each has a Weibull distribution with $\beta=4$, then the combined unit also has a Weibull distribution with $\beta=4$ and a mean lifetime of approximately 12 years, as found from Eq. 2-10. The replacement cost for the tank was obtained from a local Denver distributor for a pressurized 120-gal tank with an internal double-walled heat exchanger. The auxiliary tank with backup electric heating element is also assumed to have a 12-year mean lifetime with a Weibull $(B=4)$ failure distribution attributed to the two failure possibilities--leaking tank or failed electric heating element. The LCCM for both storage tanks is calculated using the deterministic approximation (Eq. 2-9).

As shown in Table 3-11, the sum of the 1 ife-cycle repair and replacement costs for all components and subcomponents yields a system life-cycle repair and replacement cost of $\$ 1588$. This is approximately $35 \%$ of the initial system cost of approximately $\$ 4500$. However, do not assume that a consumer will necessarily pay this present-value cost over the life of the system since some of the failures will occur during the warranty period. Thus, the cost of these early failures is presumably already included in the initial system cost. All repair and replacement costs are included here since they are real costs that should be considered in evaluating proposed systems for further research.

The results in Table 3-11 are based on an analysis period of 20 years, which was loosely determined as the time to maximum economic value (see analysis period selection criteria in Appendix F). Figure 3-3 shows the impact of the analysis period on the economic value of the system. For this example an analysis period of 20 years is the point at which the present value of the difference between energy savings and the costs of failures levels off, * as shown by the middle curve in Figure 3-3.

The present value of energy savings as shown in Figure 3-3 increases monotonically with the analysis period since for each year the analysis period is extended, the constant dollar fuel savings is increased by $\$ 320$. This presumes that the price of fuel will escalate at the same rate as inflation. The

*Although the net present value appears in Figure 3-3 to level off at an analysis period of 20 years, in fact, for this example it continues to increase indefinitely at a slow rate. 


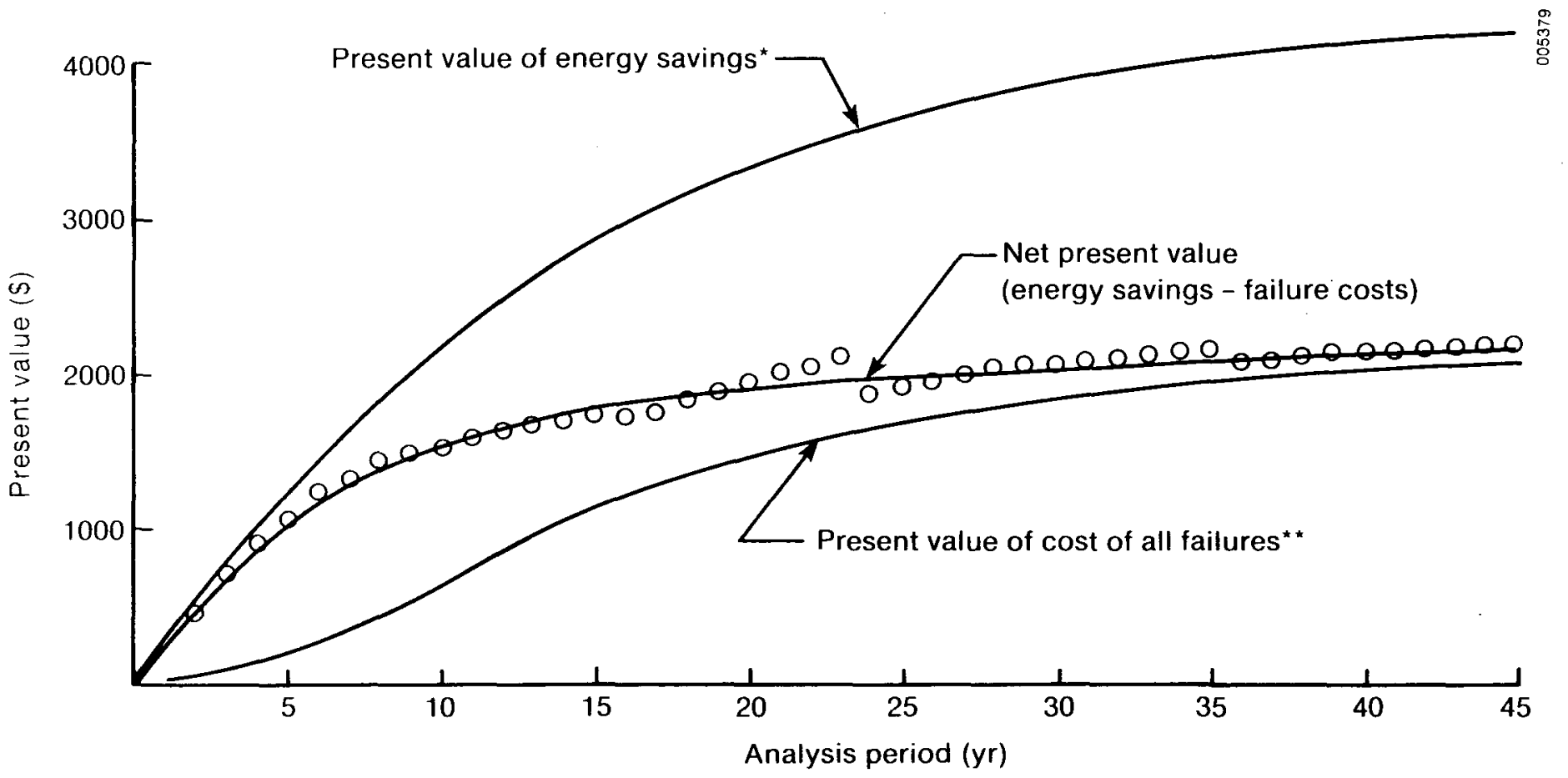

*Annual energy savings $=\$ 320 / \mathrm{yr}$ in constant dollars

**Real annual discount rate $d=0.07$

Figure 3-3. Comparison of Energy Savings and Failure Costs as a Function of Analysis Period 
energy savings curve is concave because of the effect of discounting the constant dollar savings at a real rate of $7 \%$. The present value of failure costs as presented by the bottom curve of Figure 3-3 also increases monotonically with the analysis period; however, it is convex initially because few failures occur in the early years. The curve for the net present value has been visually fitted to the points also shown in Figure 3-3. A curve drawn through the actual points would show obvious discontinuities at 24 and 36 years. These occur because we use the deterministic approximation (Eq. 2-9) for the LCCM of the storage tank, auxiliary tank, pump, and mixing valve, all of which have a mean lifetime of 12 years. The discontinuity is not evident at an analysis period of 12 years since the approximation used when the mean 1 ifetime approaches or exceeds the analysis period (Eq. 2-11) is more accurate. A closer examination would show that smaller discontinuities also exist at multiples of 8 and 15 years, the mean lifetimes of other components for which approximate LCCM calculations have been used.

There is obviously a large degree of uncertainty in the mean lifetime estimates presented in Table 3-11. In Table 3-12 we present some sensitivities to these estimates. It is interesting that even if we use the high end of the ANL mean lifetime ranges (ANL 1981) for each of the components, the system life-cycle repair and replacement cost is still $\$ 1196$ (case 2). The third case in Table 3-12 presents the system 1 ife-cycle repair and replacement cost, assuming, as is the standard practice, that all failure distributions are exponential. This cost is significantly higher than that of the base case as the exponential failure distributions presume a number of failures early in the life of the system when the repair and replacement costs are not discounted very much.

Table 3-12. LCC of Repair and Replacement Costs for a Closed-Loop, Glycol DHW System (Sensitivities)

\begin{tabular}{|c|c|c|c|c|}
\hline Case & $\begin{array}{l}\text { LCC } \\
(\$)\end{array}$ & $\begin{array}{c}\text { Levelized } \\
\text { Cost }\end{array}$ & $\begin{array}{l}\text { Levelized Cost/ } \\
\quad \$ 320 \text { in } \\
\text { Annual Savings }\end{array}$ & $\begin{array}{l}\text { Levelized Cost/ } \\
\$ 4500 \text { Initial } \\
\text { System Cost }\end{array}$ \\
\hline Base case & 1558 & 147 & 0.46 & 0.033 \\
\hline $\begin{array}{l}\text { ANL upper limit on } \\
\text { MTTF, base case } \\
\text { distributions }\end{array}$ & 1196 & 113 & 0.35 & 0.025 \\
\hline $\begin{array}{l}\text { Al1 distributions } \\
\text { assumed exponential, } \\
\text { base case MTTF }\end{array}$ & 2543 & 240 & 0.75 & 0.053 \\
\hline
\end{tabular}

$a_{\text {LCC }}$ was levelized using a $7 \%$ real discount rate. Thus, the levelized cost does not change in constant dollars but increases over time in current dollars. This allows a better comparison with the annual savings, which can also be expected to increase over time with inflation.

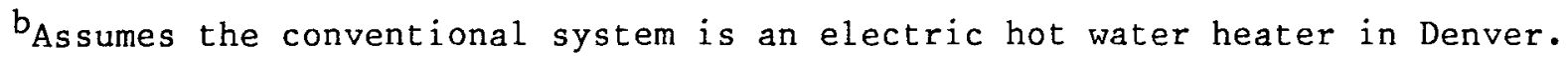


To better appreciate the size of the system's life-cycle repair and replacement cost, Table 3-12 also compares the equivalent levelized cost ( $\$ 147$ for the base case) with the value $(\$ 320 / y r)$ of the annual fuel savings in Denver, assuming that the conventional system is an electric hot-water heater. Since the fuel savings can be expected to increase each year because of inflation and other market factors, we computed the levelized system repair and replacement costs (also shown in Table 3-12) with the real (excludes inflation) discount rate of $7 \%$ used throughout our analysis. Thus, this levelized cost is level in constant dollars, and the actual repair and replacement payout in current dollars can be expected to increase with inflation.

In the introduction to this report, we mentioned that the common method for including $0 \& M$ costs in an economic analysis is to simply assume an annual cost equal to $1 \%$ or $2 \%$ of the initial system cost. For comparison,* Table 3-12 also shows the ratio (f) of the levelized repair and replacement cost to an initial system cost of $\$ 4500$ to be $3.3 \%$. Thus, in the base case the common assumption of $2 \%$ significantly underestimates the repair and replacement costs. This finding should not be taken as a recommendation to substitute $f=3.3 \%$ for the typical value of $f=2 \%$ for all solar energy systems. Each system should be evaluated on its own merits, i.e., its reliability and cost.

*Some studies assume that the O\&M cost remains unchanged throughout the system's lifetime at an annual cost of $2 \%$ of the initial system cost. Others assume it is $2 \%$ in the first year but increases with inflation thereafter. Our comparison is made with the latter. The former underestimates the o\&M costs even further. 
SECTION 4.0

\section{CONCLUSIONS AND RECOMMENDATIONS}

Although the primary intent of the work documented in this report was to develop a method for including O\&M costs in an economic analysis, in the course of designing and testing the method, we reached a number of conclusions:

- The common practice of assuming annual O\&M costs to be a fixed fraction of the initial investment is inaccurate because it does not capture enough system-specific detail.

- Comparisons among technologies based on the assumption that annual O\&M costs are a fixed fraction of the initial investment tend to favor less reliable, less expensive systems.

- The failure data required to estimate repair and replacement costs include not only the expected lifetime of the system components but also the distribution of failures over time.

- The common assumption of a constant failure rate (i.e., exponential failure distribution) will usually result in a significant overestimation. of the mean time to failure from monitored data.

- Data that permit the calculation of the expected lifetime of the components typically found in active solar systems are extremely limited. Data that permit the determination of the failure distributions of the typical components are essentially nonexistent.

- The present-value cost of all repairs and replacements over a 20-year analysis period can be as large as $25 \%-35 \%$ of the initial system cost, even when the expected 1 ifetimes of all components are greater than 10 years.

The principal limitation of the method presented in this report is its requirement for data on the distribution of failures over a period of time and the associated mean time to failure. Data on failure distributions have not been collected in the past primarily because it has been assumed that all failures are exponentially distributed and that failures over a period of time can be determined from only the mean time to failure. Any future system monitoring efforts should not only collect data to determine the mean time to failure on a component or subcomponent level but also emphasize the pattern of failures over a period of time so that the form of the failure distributions can be estimated. In general, this will also require that monitoring periods be extended beyond those used in most past studies. 
SECTION 5.0

REFERENCES

American Society of Heating, Refrigeration, and Air Conditioning Engineers, 1980, ASHRAE Handbook and Product Directory, 1980 Systems, New York, NY.

Argonne National Laboratory, 1981 (Sept.), Final Reliability and Materials Design Guidelines for Solar Domestic Hot Water Systems, ANL/SDP-11, Argonne, IL: ANL.

ESG, Inc., 1984 (Jan.), Survey of System Operational Failure Modes from 122 Residential Solar Water Heater Systems over a Period of Approximately Two Years, ESG-R107-83, Atlanta, GA: ESG, Inc.

Farrington, R. B., and D. Myers, 1983 (Eeb.), Evaluation and Laboratory Testing of Solar Domestic Hot Water Control Systems, SERI/TR-254-1805, Golden, CO: Solar Energy Research Institute.

Goldberg, M. M., 1978, "Solar System Performance and Component Reliability after Five Years," Conference Proceedings: Solar Heating and Cooling Systems Operational Results, SERI/TP-49-063, Golden, CO: Solar Energy Research Institute.

Green, A. E., and A. J. Bourne, 1972, Reliability Technology, New York: John Wiley and Sons.

Greenberg, J., S. Berry, P. Chen, P. Cooke, and C. Yancey, 1981 (Sept.), Analysis of Reliability and Maintainability of Residential and Commercial Solar Systems Included in the National Solar Heating and Cooling Demonstration Program, National Bureau of Standards letter report to Department of Energy. This report also appears as Appendix C, "NBS/HUD Projects Data Analysis" in Cole, M. H., et al., An Assessment of the Field Status of Active Solar Systems, DOE/SF/11485-1.

Hillier, F. S., and G. J. Lieberman, 1967, Introduction to Operations Research, San Francisco: Holden-Day, Inc.

Hooks, S., 1983, Long Island Lighting Company Solar Domestic Hot Water Demonstration Program, October 1978 to December 1982, Draft, Mineola, NY: Long Island Lighting Company.

Jacobs, R. A., 1982 (Sept.), "Operational Status of 134 Solar Water Heaters in the Southeastern United States," Proceedings of the Solar Hot Water Field Test Technical Review Meeting, $14-15$ July 1982, DOE/CH/10122-7, Atlanta, GA: Energy Systems Group.

Jorgensen, G. J., 1984 (May), A Summary and Assessment of Historical Reliability and Maintainability Data for Solar Hot Water and Space Conditioning Systems, SERI/TR-253-2120, Golden, CO: Solar Energy Research Institute. 
Kendal1, P. W., et al., Vitro Laboratories, 1983 (Mar.), A Reliability and Maintainability Study of Select Solar Energy System Components in the National Solar Data Network, SERI/TR-254-1848, Golden, CO: Solar Energy Research Institute.

Locks, M. 0., 1973, Reliability, Maintainability, and Availability Assessment, New Jersey: Hayden Book Company Inc.

Mood, A. M., F. A. Graybi11, and D. C. Boes, 1974, Introduction to the Theory of Statistics, New York: McGraw-Hill, Inc.

Sims, W. H., 1976, "Consideration in the Development of a High Performance Per-Unit-Cost Solar Collector," paper presented at Solar Cooling and Heating: A National Forum held on 12-15 December 1976, Miami Beach, FL.

Wolosewicz, R. M., and P. S. Chopra, 1979 (July), "Freezing Problems and Other Reliability Concerns in Operational Solar Demonstration Sites," The Final Proceedings of the Second Solar Heating and Cooling Commercial Demonstration Program Contractors Review, Vol.2, Huntsville, AL: The Johnson Environmental and Energy Center, DOE/Cs/4131-1.

Yarosh, M. M. et al., 1982 (Jan.), Solar Energy Consumer Protection Report, Cape Canaveral, FL: Florida Solar Energy Center. 


\section{APPENDIX A \\ PROBABILITY DISTRIBUTIONS COMONLY EMPLOYED IN RELIABILITY ANALYSIS}

Probability distributions are frequently used in reliability analysis to represent the probability distribution of the time-to-failure. Such failure probability distributions can be discrete or continuous. Discrete cumulative distribution functions $F(t)$ are easily defined such that a single probability $p_{i}$ is attached to each time step $i$ so the sum over all time steps is equal to one; i.e.,

$$
F(t)=\sum_{i=1}^{t} P_{i},
$$

where

$$
\sum_{i=1}^{\infty} p_{i}=1
$$

The continuous analog of the failure distribution $F(t)$ can be made by making each time step infinitely small so the probability distribution function becomes

$$
F(t)=\int_{0}^{t} f(t) d t
$$

where

$$
\int_{0}^{\infty} f(t) d t=1
$$

and $f(t)$ is the probability density function.

Although every probability distribution function might be used in reliability analysis, experience shows that the pattern of failures in a system over time is more closely represented by certain well-known distributions such as the exponential, Weibul1, normal, and lognormal distributions. In this appendix, we present some of the characteristics of these continuous probability distributions that make them useful in reliability analysis.

\section{A.1 THE EXPONENTIAL DISTRIBUTION}

The principal feature of the exponential distribution is that it is "memoryless." An exponential failure distribution presumes that the probability of failure of a component in the next time increment $\Delta t$ is the same as it was in all the preceding time increments; i.e., there is no memory of how long the component survived. This property is representative of failures such as the destruction of a collector glazing in a hailstorm and of random failures in electrical components. 
Figure A-1 portrays the density function, distribution function, and failure rate function* for the exponential distribution; Table A-1 presents the analytical form of these functions, the mean value of the distribution, and the variance of the distribution. The ease with which the exponential density function can be analytically manipulated and the memoryless property combine to make the exponential the most prevalent distribution in reliability analysis. For our purposes, the constant failure rate of the exponential distribution makes it especially attractive in reliability cost analysis. Another useful property of the exponential distribution in reliability analysis is that the failure distribution of a system with components in series each with an exponential failure distribution is also an exponential distribution. For example, if a component has two subcomponents in series, each with an exponential failure distribution with mean times to failure $\lambda_{1}$ and $\lambda_{2}$, then the failure distribution of the component is also exponential with mean

\section{A.2 THE WEIBULL DISTRIBUTION}

$$
\lambda=\frac{1}{\frac{1}{\lambda_{1}}+\frac{1}{\lambda_{2}}} \text {. }
$$

The exponential distribution is a single case of the more general Weibull distribution (shown in Figure A-1 and Table A-1) obtained by setting the $B$ parameter of the Weibull distribution to 1 and the a parameter to the mean value $\lambda$ of the random variable. The principal attractiveness of the Weibull distribution in reliability analysis is that by changing the $\beta$ parameter one can use different forms of the Weibull to represent failure rates that decrease over time $(\beta<1)$, are constant over time $(\beta=1$, the exponential), or increase over time $(\beta>1)$. These three forms of the Weibull are sometimes combined into a single distribution with a bathtub-shaped failure rate function such as that shown in Figure A-2. This bathtub-shaped distribution permits the representation of early failures caused by installation problems or manufacturing quality control, a low level of failures during the useful life of a system, and a high rate of failure as the component begins to wear out.

Another attraction of the Weibull distribution is that, like the exponential distribution, the failure distribution of a system with components in series each with a Weibull failure distribution with parameters $\beta$ and $\alpha_{i}$ also has a Weibull failure distribution with parameters $\beta$ and

$$
\alpha=\left[\frac{1}{\sum_{i}\left(1 / \alpha_{i}\right)^{\beta}}\right]^{1 / \beta} .
$$

*The failure rate function or hazard function $z(t)$ is defined as

$$
z(t)=\frac{f(t)}{1-F(t)} \text {. }
$$

The product $z(t) \Delta t$ is the probability that a failure will occur between $t$ and $t$ plus $\Delta$, given that it has not occurred by time $t$. 


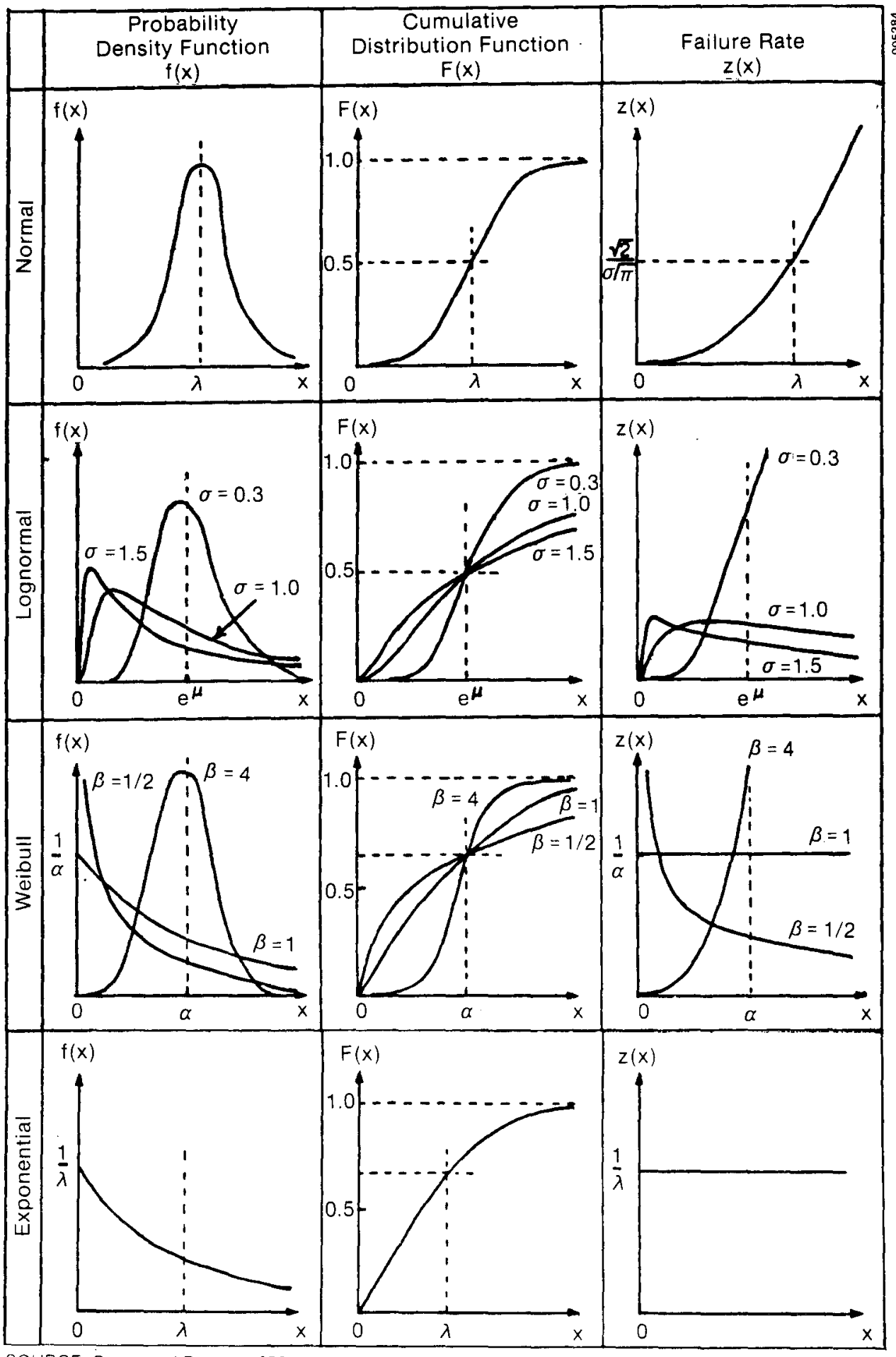

SOURCE: Green and Bourne 1972

Figure A-1. Probability Distributions 
Table A-1. Probability Distribution Punctions

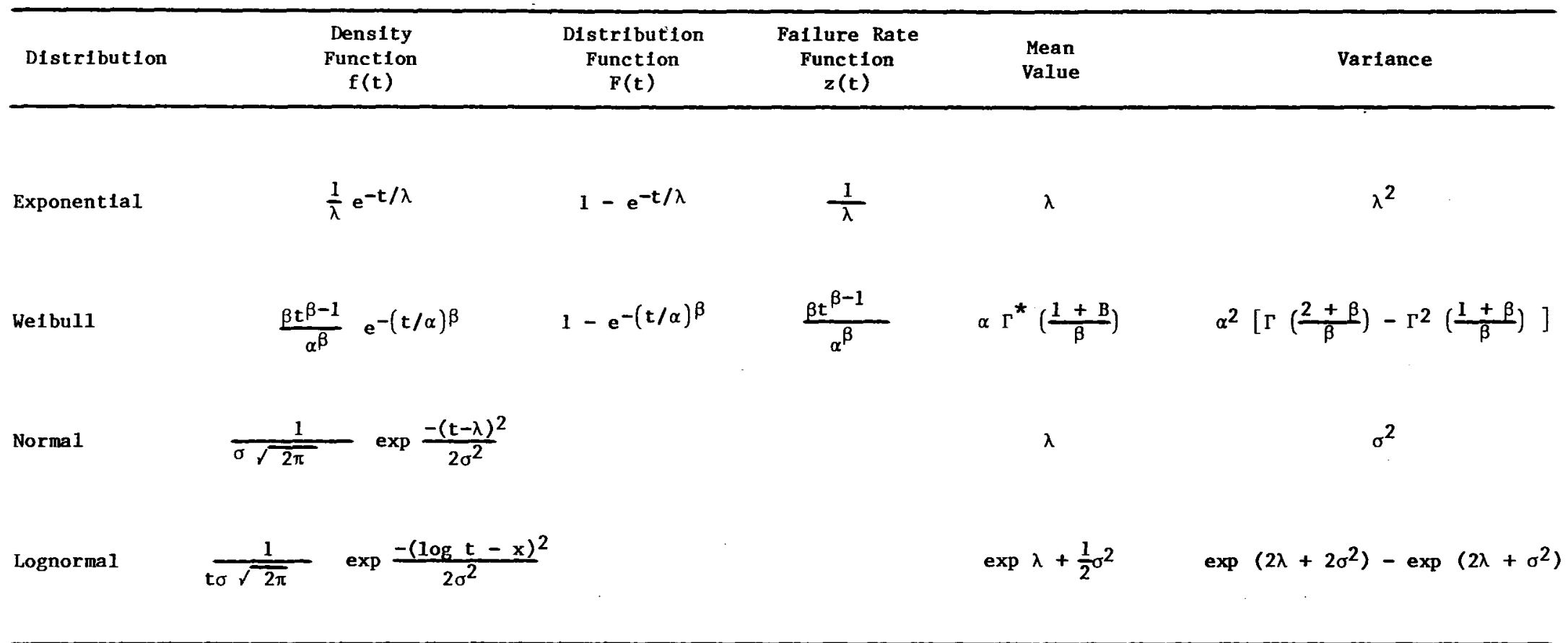

$\star \Gamma(n)=\int_{0}^{\infty} e^{-t} t^{n-1} \partial t$ 


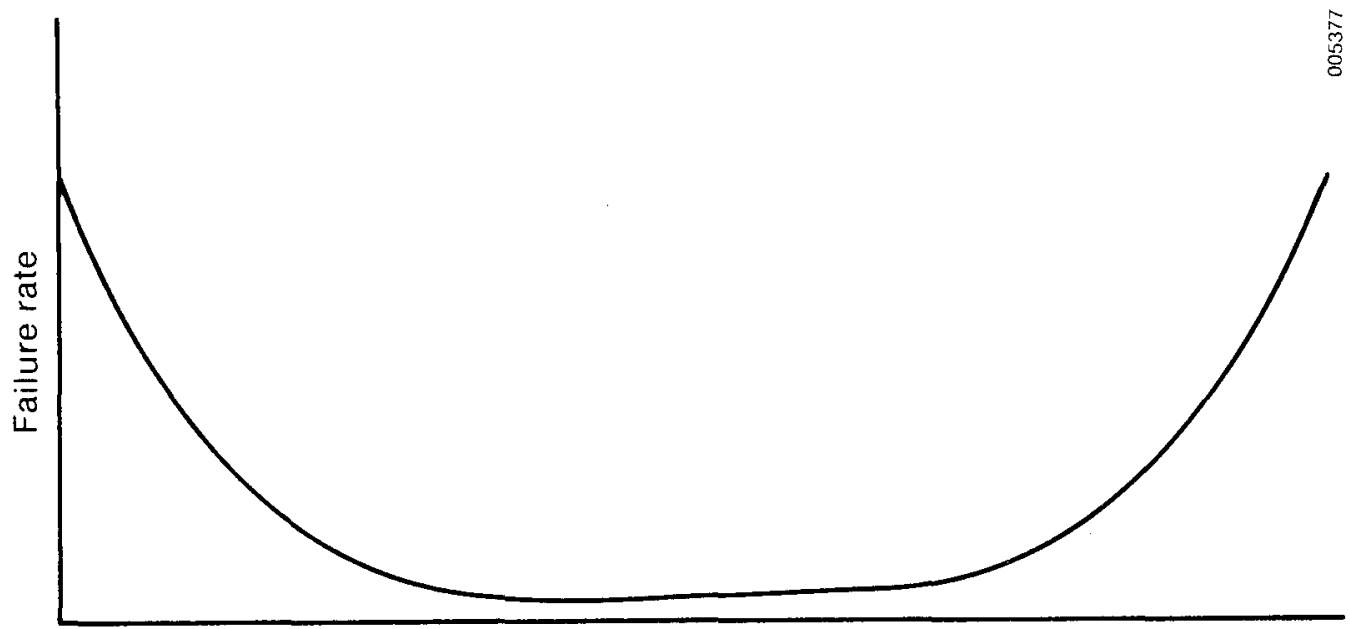

Time

Figure A-2. Bathtub-Shaped Failure Rates

\section{A.3 NORMAL DISTRIBUTION}

Probably the principal attractions of the familiar bell-shaped normal distribution (see Figure A-1 and Table A-1) in reliability analysis are that it is entirely symmetric about the mean and that it has an increasing failure rate with time. As such, the normal distribution is useful in representing failures caused by wearout. In reliability cost analysis another useful characteristic of a normal distribution is that the sum of two normally distributed random variables with mean $\lambda_{1}$ and $\lambda_{2}$ and standard deviations $\sigma_{1}$ and $\sigma_{2}$ is also normally distributed with mean $\lambda=\lambda_{1}+\lambda_{2}$ and standard deviation $\sigma=\left(\sigma_{1}{ }^{2}+\sigma_{2}\right)^{1 / 2}$ (see Appendix $\mathrm{c}$ ). One drawback of the normal distribution is that the time domain extends from negative infinity to positive infinity. Since in reality failures can occur only in positive time, one should be sure that $\sigma<1 / 2 \lambda$. If this is true, the maximum error introduced is less than $2.3 \%(0.023$ is the probability that a failure occurs more than $2 \sigma$ earlier than the mean lifetime).

\section{A.4 LOGNORMAL DISTRIBUTION}

The lognormal distribution eliminates the possibility of a negative time to failure associated with a normal distribution; consequently, it is sometimes used in reliability analysis in place of the normal distribution to represent failures caused by wearout. However, since the Weibull distribution with $\beta>1$ accomplishes essentially the same thing and has other advantages, we did not employ the lognormal in our reliability cost analysis. 


\section{APPENDIX B}

\section{DERIVATION OF AN APPROXIMATE FORMULA FOR THE LIFE-CYCLE COST MULTIPLIER ASSOCIATED WITH A RAYLEIGH FAILURE DISTRIBUTION}

We assume that, at the time of component failure, repair occurs instantaneously and that the system is renewed to its operational state. We define the random variable $V_{j}$ to be the time to failure of the $j$ th component replacement (i.e., $V_{j}$ is the time between repair number $j-1$ and repair number $j$ ). Since the same component is being repaired or replaced each time, each of the $V_{j}$ has the same failure distribution and is independent of the others. If we define the random variable $w_{i}$ to be the time from initial system operation to the ith failure of the component, then we see that

$$
w_{i}=\sum_{j=1}^{i} v_{j}
$$

The expected value of this sum of random variables is the sum of the expected values:

$$
E\left(w_{i}\right)=\sum_{j=1}^{i} E\left(V_{j}\right)=\sum_{j=1}^{i} \lambda=i \lambda .
$$

Since the $\mathrm{V}_{j}$ are independent, the variance Var of this sum of random variables is the sum of the variances

$$
\operatorname{Var}\left(w_{i}\right)=\sum_{j=1}^{i} \operatorname{Var}\left(V_{j}\right)=i \sigma^{2},
$$

where $\lambda$ and $\sigma$ are the mean and standard deviation, respectively, of the component lifetime.

As more and more failures occur, $\operatorname{Var}\left(W_{j}\right)$ grows without bound until after an infinite number of failures we see that $\operatorname{Var}\left(W_{i}\right)=\infty$, and the probability of a failure is the same in all time periods. Thus, after an infinite number of failures the rate of failure has a constant value of $1 / \lambda$. In fact, for a component failure distribution with an increasing failure rate, this renewal rate of failure (RROF) approaches the value $1 / \lambda$ fairly quickly, as shown in Figure B-1 for a Rayleigh distribution. The RROF oscillates about the rate $1 / \lambda$ since the early failures are most frequent at multiples of the mean time to failure $\lambda$. The oscillations are damped with time since Var ( $W_{i}$ ) grows with time. We avoid the computational complexities of the oscillating RROF curve by approximating it with a curve that grows exponentially closer to the value $1 / \lambda$ with time as shown by the dashed 1 ine of Figure $B-1$ and the formula:

$$
\text { RROF }=1 / \lambda\left(1-e^{-A t / \lambda}\right),
$$

where $\mathrm{A}$ is a constant to be determined. 


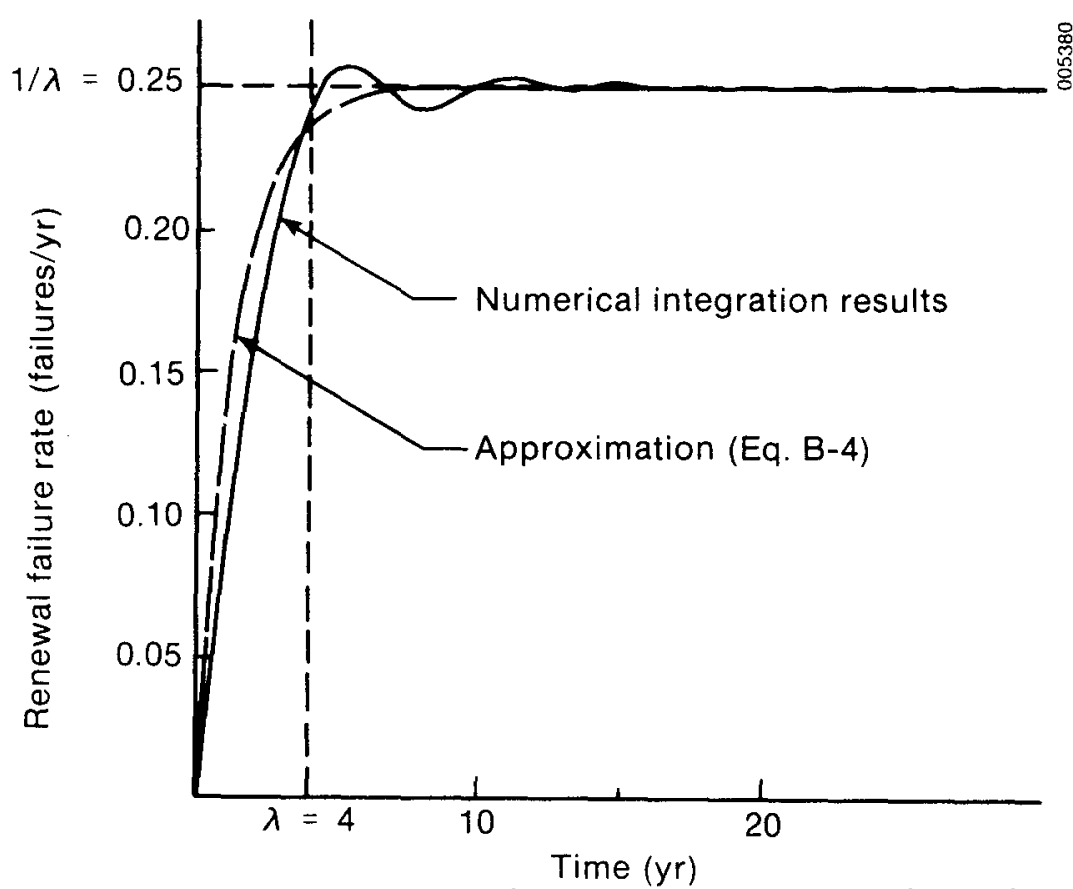

Figure B-1. Renewal Rate of Failure for the Rayleigh Distribution

Applying the discount factor $e^{-d^{\prime} t}$ ( $d^{\prime}$ is the continuous discount rate*) and integrating over the analysis period yields

$\operatorname{LCCM}=\int_{0}^{N} 1 / \lambda\left(1-e^{-A t / \lambda}\right) e^{-d^{\prime} t} \delta t=\frac{1-e^{-d^{\prime} n}}{\lambda d^{\prime}}-\frac{1-e^{-N\left(A / \lambda+d^{\prime}\right)}}{A+\lambda d^{\prime}}$.

Adjusting the value of $A$ to produce a close approximation yields $A=3$ for the Rayleigh distribution. Other values of $A$ could be used to approximate other failure distributions with increasing failure rates such as the normal. We do not investigate this possibility here.

*The continuous discount rate $d$ ' can be found from the annual discount rate by the formula $d^{\prime}=\ln (1+d)$. 


\section{APPENDIX C}

\section{DERIVATION OF AN APPROXIMATE FORMULA FOR LCCM FOR REPAIR AND REPLACEMENT COSTS WHEN THE COMPONENT MEAN LIFETIME APPROACHES OR EXCEEDS THE ANALYSIS PERIOD}

We begin by deriving an exact formula for LCCM for repair and replacement costs. This formula is an infinite series in which each term may be intractable. By assuming a normal failure distribution each of the intractable terms in the infinite series can be evaluated by referencing a normal failure distribution table. For those cases in which the component mean lifetime approaches or exceeds the analysis period, the infinite series is reduced to a single term.

As in Appendix $B$, we define $V_{j}$ to be the time to failure of the $j$ th component replacement (i.e., $V_{j}$ is the time between repair or replacement number $j-1$ and repair or replacement number $j$ ). Since the same component is being repaired or replaced each time, each of the $V_{j}$ has the same failure distribution and is independent of the others. If we define $w_{i}$ to be the time from initial system operation to the ith failure of the component, then we see that

$$
w_{i}=\sum_{j=1}^{i} v_{j}
$$

Furthermore, if we define $f_{i}(t)$ to be the probability density function for each of the random variables $W_{i}$, then we can express the present value cost multiplier $C_{i}$ of the $i$ th failure during the analysis period as

$$
c_{i}=\int_{0}^{N} f_{i}(t) e^{-d^{\prime} t} \partial t
$$

where $d^{\prime}$ is the continuous (i.e., compounding continuously) discount rate.* Finally the LCCM for repair and replacement costs for all failures during the analysis period is

$$
\operatorname{LCCM}=\sum_{i=1}^{\infty} C_{i}=\sum_{i=1}^{\infty} \int^{N} f_{i}(t) e^{-d^{\prime} t \partial t}
$$

By Eq. C-1 each density function $f_{i}$ is the density function for the sum of $i$ random variables $v_{j}, j=1,2, \cdot . \cdot, i$. If we assume that the $v_{j}$ are normally distributed with mean $\lambda$ and standard deviation $\sigma$, then the density function $f_{i}$ of $W_{i}$ is also normally distributed with mean $\lambda_{i}=i \lambda$ and standard deviation $\sigma_{i}=\sigma \sqrt{i}$. In this case Eq. C-3 becomes

$$
\operatorname{LCCM}=\sum_{i=1}^{\infty} \int^{N} \frac{1}{\sigma \sqrt{i} \sqrt{2 \pi}} \exp \left[\frac{-(t-i \lambda)^{2}}{2 i \sigma^{2}}\right] e^{-d^{\prime} t} \partial t .
$$

*The continuous discount rate $d$ ' can be found from the annual discount rate $d$ by the formula $d^{\prime}=\ln (1+d)$. 
By combining the exponential terms and completing the square of the resulting exponent with respect to $t, E q . C-4$ can be reduced to

$\operatorname{LCCM}=\sum_{i=1}^{\infty} \exp \left[i\left(\frac{d^{\prime} 2 \sigma^{2}}{2}-\lambda d^{\prime}\right) \frac{1}{\sigma \sqrt{2 \pi i}} \int^{N} \exp \left\{\frac{-\left[t-\left(i \lambda-d^{\prime} i \sigma^{2}\right)\right]^{2}}{2 i \sigma^{2}}\right\} \partial t,(C-5)\right.$ or

$\operatorname{LCCM}=\sum_{i=1}^{\infty} \exp \left[i\left(\frac{d^{\prime} 2 \sigma^{2}}{2}-\lambda d^{\prime}\right)\right]\left[F\left(\frac{N-i \lambda+d^{\prime} i \sigma^{2}}{\sigma \sqrt{i}}\right)-F\left(\frac{d^{\prime} i \sigma^{2}-i \lambda}{\sigma \sqrt{i}}\right)\right], \quad(C-6)$ where $F(x)$ is the standardized normal cumulative distribution function evaluated at $x$.

When the mean 1 ifetime of the component $\lambda$ approaches or exceeds the analysis period $\mathrm{N}$, the term in brackets in Eq. C-6 goes very quickly to zero. Therefore, the infinite series can be reasonably approximated by only the first term $(i=1)$ :

$$
\operatorname{LCCM} \approx \exp \left(\frac{d^{\prime} 2 \sigma^{2}}{2}-\lambda d^{\prime}\right)\left[F\left(\frac{N-\lambda+d^{\prime} \sigma^{2}}{\sigma}\right)-F\left(\frac{d^{\prime} \sigma^{2}-\lambda}{\sigma}\right)\right] .
$$




\section{APPENDIX D}

\section{RESPONSE TIME OF REPAIRMAN}

To derive a rough estimate of the time required for a repairman to become available, we first establish a limit on the number of repairmen. Suppose that, on the average, $\phi$ service calls are received each day by an installation and repair company and that the mean repair time (in days, including travel) is $1 / \mu$ ( $\mu$ is the number of repairs per repairman per day). Then the minimum number of repairmen at the company is $\phi / \mu$. Any fewer repairmen will result in an ever-increasing waiting 1 ist and intolerably long (even infinite) waiting times. Even if exactly $\phi / \mu$ repairmen are available, the waiting time may be extremely long since the service calls are received at random intervals.

Since additional repairmen will cost the company money in the form of wages, the company should seek to keep the number of repairman ( $r$ ) close to the ratio $\phi / \mu$ as long as the customers' average waiting time does not become excessively long. Figure D-1 presents the average customer waiting time* (normalized by the repair time $1 / \mu$ ) for this minimum number of repairmen; i.e., for those cases in which

$$
\mathbf{r}-1<\phi / \mu<\mathbf{r}
$$

In general, the average waiting time is relatively short, unless $\phi / \mu$ approaches $r$. For example, the average customer waiting time is only 0.7 days for a repairman to set out from a company with 10 repairmen $(r=10)$ that receives an average of nine service calls per day $(\phi=9)$ for repairs that take an average of one day $(1 / \mu=1.0$, includes travel time). However, the waiting time becomes 3.6 days if the number of service calls per day increases to 9.75 , and 19.6 days if there are an average of 9.95 service calls per day. $* *$

*The waiting times were determined based on a steady-state multiple server (i.e., multiple repairmen) queue model in which the time between service calls is assumed to be an exponentially distributed random variable with a mean time between calls of $1 / \phi$ days, and the time to make the service repair is also assumed to be an exponentially distributed random variable with a mean repair time of $1 / \mu$ days. The waiting time $W$ equation is (Hillier and Lieberman 1967) as follows:

$$
W=\frac{(\phi / \mu)^{r+1}}{\phi r ! r(1-\phi / \mu r)^{2}} /\left[\sum_{n=0}^{r-1} \frac{(\phi / \mu)^{n}}{n !}+\frac{(\phi / \mu)^{r}}{r !} \frac{1}{(1-\phi / \mu r)}\right]
$$

*: These waiting times would be only half as large were the service repair time assumed to have a constant value (i.e., if the service repair time were not a random variable) of one day. (See Hillier, F. S., and G. J. Lieberman, 1967, Introduction to Operations Research, San Francisco: Holden-Day, Inc.) 


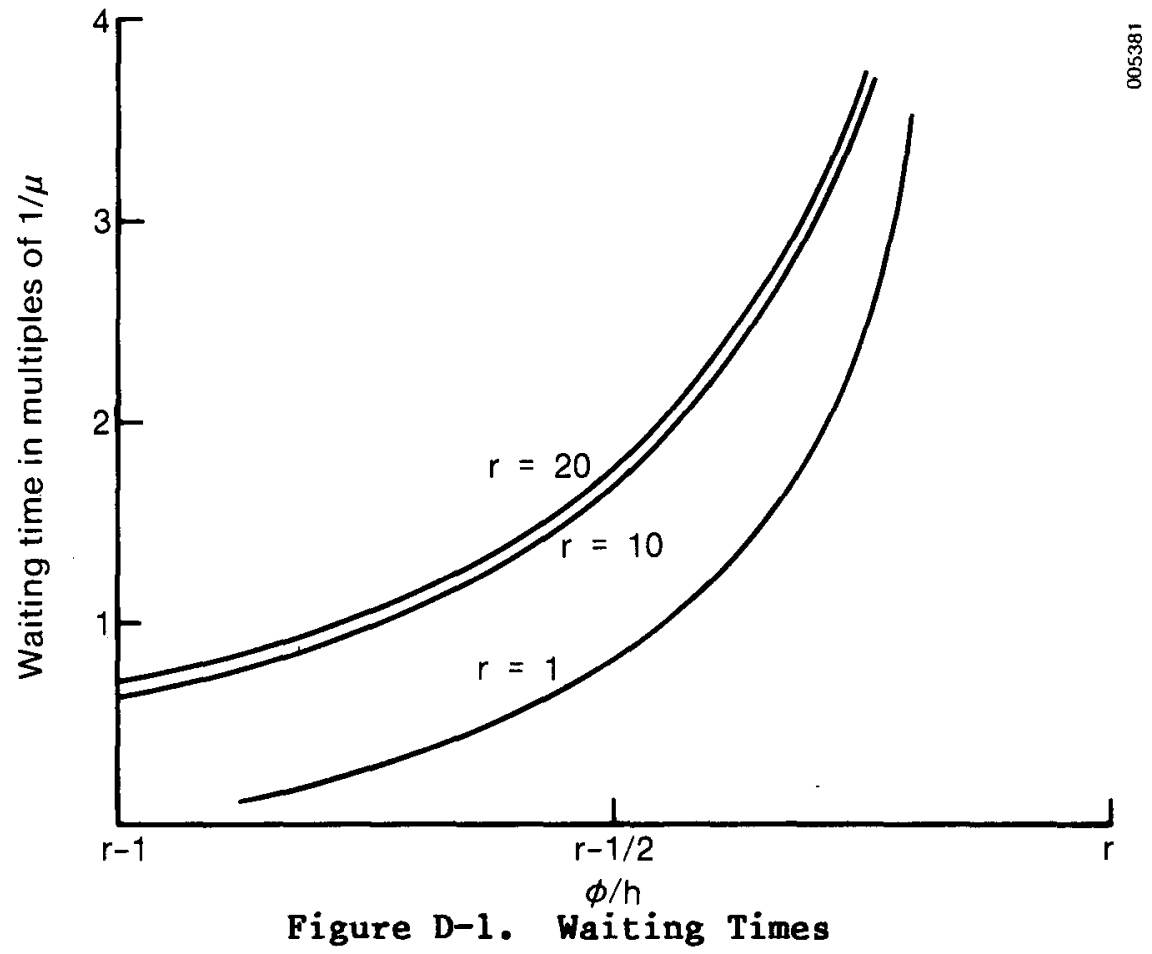

To prevent the waiting times from becoming unreasonably long, we assume that the company will add another repairman to its staff if $\phi / \mu$ is within 0.05 of the current number of repairmen; i.e., we assume that

$$
r-1<\phi / \mu+0.05<r \text {. }
$$

Thus, for a company with $r$ repairmen the ratio $\phi / \mu$ will 1 ie somewhere within the range

$$
r-1.05<\phi / \mu<r-0.05 \text {. }
$$

Assuming a uniform distribution for $\phi / \mu$ within this range, we can find the average waiting time as a function of only the number of repairmen within the company. Table D-1 presents these average waiting times* (normalized by the repair time). For example, if a company has 10 repairmen, then the expected average waiting time is 2.80 times the repair time. Since most repair times are less than a half day, the results in Table D-1 indicate an average wait of less than two days.

These results are based on a static analysis in which the parameters of the service call and repair time distributions are constant over time. In reality, a number of factors might lead to longer or shorter average waiting times, such as seasonal variations in customer service requirements, personnel vacations, business expansion or contraction, and the introduction of new components or technologies.

*These times were determined by numerical integration of the expected-value equation. 
Table D-1. Expected Average Waiting Times for Repairman Response

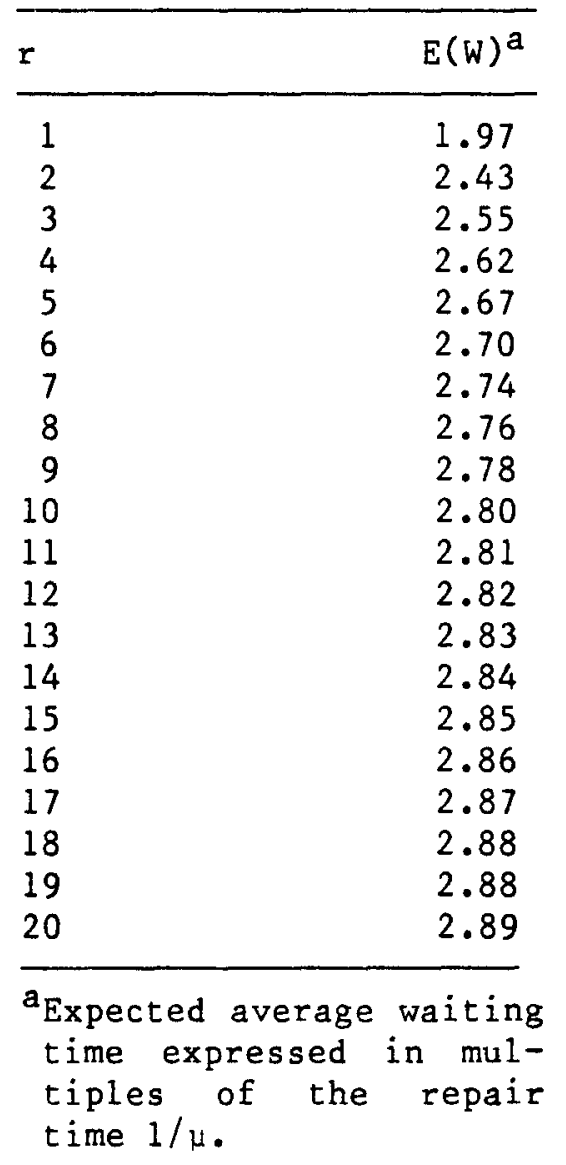




\section{APPENDIX E}

\section{SAMPLING}

Although sufficiently accurate empirical data do not exist to perform valid statistical tests on the failure probability distributions of the components of active solar systems, we present here a brief summary of some of the more useful statistical tests in reliability costs analysis. In addition, we briefly investigate how large a sampling of failures must be to obtain a given level of confidence in the results.

For our reliability costing analyses, we are interested in two principal types of statistical tests. These tests are directly related to the inputs of the life-cycle costing method for repairs and replacements presented in the body of this report. They include

- Tests on the "goodness-of-fit" of the distribution of the sample to the assumed underlying population failure distribution

- Tests on the mean lifetime of a component in which a confidence interval is established around a point estimate of the mean lifetime.

Since goodness-of-fit tests such as the chi-square test and Kolmogorov-Smirnov test can be applied without special considerations for different assumed underlying population failure distributions or the reliability test conditions, we refer the reader to the numerous statistics texts (Green and Bourne 1972; Yarosh et a1. 1982) that describe these tests. Standard statistics texts include ample descriptions of the establishment of confidence intervals on sample means through methods developed around the weak law of large numbers or the central limit theorem. These confidence interval methods are applicable regardless of the underlying population failure distribution when the sample consists of $n$ failure times from a sample of $n$ systems and components. However, empirical field data on active solar system failures are not normally collected in this fashion. Typically, field data on active solar system failures are collected over a period of y years beginning immediately after installation and include the replacement (and possibly additional failures) of any failed components. For example, the reliability data for a component from a field demonstration program might include the times to failure of the 20 failures of the component that occurred from the 500 systems in the program during the 3 years the systems were monitored. The confidence intervals that result from this type of sampling depend on the assumed underlying population failure distribution.

\section{E.1 THE EXPONENTIAL DISTRIBUTION}

Martz and Waller (1982) present confidence intervals for the mean component lifetime $\lambda$ when time-truncated sampling with replacement as described earlier is used and the assumed underlying failure distribution is exponential:

$$
\frac{2 S}{x_{1-\gamma / 2}^{2}(2 r+2)} \leq \lambda \leq \frac{2 S}{x_{\gamma / 2}^{2}(2 r)} \text {, }
$$


where $1-\gamma$ is the probability that the population mean is within the interval,

$$
\begin{aligned}
& S=\text { ny is time on test } \\
& \mathrm{n}=\text { number of systems monitored } \\
& y=\text { period over which the systems are monitored } \\
& r=\text { number of failures that occurred }
\end{aligned}
$$

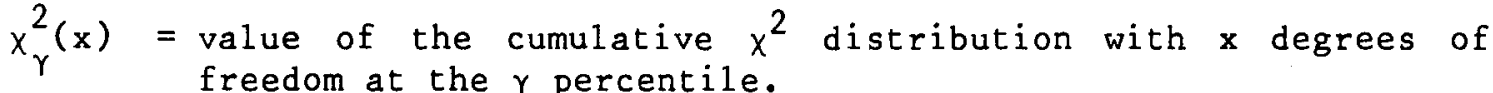

For the example given here in which 20 failures occurred in 500 systems and components over a 3-year period, the $95 \%$ confidence interval for the mean lifetime $\lambda$ (the probability is 0.95 that the population mean lifetime is within the interval) is

or

$$
\frac{2 \times 500 \times 3}{x_{0.975}^{2}(2 \times 20+2)} \leq \lambda \leq \frac{2 \times 500 \times 3}{x_{0.025}^{2}(2 \times 20)},
$$

$$
48.6 \leq \lambda \leq 122.8 \text { years. }
$$

For the same example, the maximum 1 ikelihood point estimate for $\lambda$ is

$$
\lambda=\frac{\mathrm{ny}}{\mathrm{r}}=75 \text { years } .
$$

Note that the confidence interval is not symmetric around the maximum likelihood estimate but is much looser on the upper bound side, reflecting that we know the pattern of failures in the early years but not in the later years. Also note that to construct the mean lifetime point estimate and confidence interval for the exponential distribution, it is not necessary to know the actual time of failure of the individual components but only the number of failures that occurred during the monitoring period.

The confidence interval of Eq. E-1 can also aid in the design of monitoring studies when the failure distribution is expected to be exponential. An a priori estimate of the mean lifetime $\lambda$ together with the desired confidence interval and confidence level $\gamma$ can be used to determine the total time on test statistic ny (the product of the number of systems and components monitored and the length of time for which they are monitored). For example, suppose we wish the lower bound of a $95 \%$ confidence interval to be $\varepsilon_{L}=80 \%$ of the mean; i.e.,

$$
\frac{2 n y}{x_{0.975}^{2}(2 r+2)}=\varepsilon_{L} \lambda=0.8 \lambda \text {. }
$$


We can substitute the expected value for $r$ found by solving Eq. E-2 for $r$ and dividing both sides by the a priori estimate of the mean lifetime $\lambda$ to yield

$$
\frac{2 n y / \lambda}{x_{0.975}^{2}(2 n y / \lambda+2)}=\varepsilon_{L} \text {. }
$$

Because this equation includes the $x^{2}$ term, it cannot be solved explicitly for the total time on test statistic $S=$ ny. However, interpolation in Table E-1 can be used to determine ny if $\lambda$ has been estimated. For our example, if the mean lifetime is expected to be 5 years, then to establish a two-sided $90 \%$

Table E-1. Exponential Distribution Confidence Intervals on Mean Lifetime

\begin{tabular}{|c|c|c|c|}
\hline$\gamma$ & $n y / \lambda$ & (1 ower bound) & (upper bound) \\
\hline 0.05 & $\begin{array}{r}2 \\
5 \\
10 \\
20 \\
30 \\
50 \\
70 \\
100 \\
150 \\
200\end{array}$ & $\begin{array}{l}0.28 \\
0.43 \\
0.54 \\
0.65 \\
0.70 \\
0.76 \\
0.79 \\
0.82 \\
0.85 \\
0.87\end{array}$ & $\begin{array}{l}8.26 \\
3.08 \\
2.09 \\
1.64 \\
1.48 \\
1.35 \\
1.28 \\
1.23 \\
1.18 \\
1.16\end{array}$ \\
\hline 0.10 & $\begin{array}{r}2 \\
5 \\
10 \\
20 \\
30 \\
50 \\
70 \\
100 \\
150 \\
200\end{array}$ & $\begin{array}{l}0.32 \\
0.48 \\
0.59 \\
0.69 \\
0.74 \\
0.79 \\
0.82 \\
0.85 \\
0.87 \\
0.89\end{array}$ & $\begin{array}{l}5.63 \\
2.54 \\
1.84 \\
1.51 \\
1.39 \\
1.28 \\
1.23 \\
1.19 \\
1.15 \\
1.13\end{array}$ \\
\hline 0.20 & $\begin{array}{r}2 \\
5 \\
10 \\
20 \\
30 \\
50 \\
70 \\
100 \\
150 \\
200\end{array}$ & $\begin{array}{l}0.38 \\
0.54 \\
0.65 \\
0.74 \\
0.78 \\
0.83 \\
0.85 \\
0.88 \\
0.90 \\
0.92\end{array}$ & $\begin{array}{l}3.75 \\
2.06 \\
1.61 \\
1.38 \\
1.29 \\
1.21 \\
1.18 \\
1.14 \\
1.11 \\
1.10\end{array}$ \\
\hline
\end{tabular}


confidence interval $(\gamma=0.1)$ on $\lambda$ with lower limit equal to 4 years $\left(\varepsilon_{L}=0.8\right)$, we would have to monitor for approximately 300 system-years $(n y / \lambda=60)$. Thus, we could monitor 100 systems $(n=100)$ for 3 years $(y=3), 150$ systems $(n=150)$ for 2 years $(y=2)$, or any other combination in which ny $=300$.

\section{E.2 THE WEIBULL DISTRIBUTION}

In general, simple, closed-form confidence intervals such as that presented in Eq. E-1 for time truncated samples with replacement are not available for failure distributions other than the exponential. However Martz and Waller (1982) point out that if the time to failure $T$ has a Weibull distribution with parameters $\alpha, \beta$, then the time to failure raised to the $\beta$ power, $\mathrm{T}^{\beta}$, has an exponential distribution with mean $\alpha^{\beta}$ :

$$
\begin{gathered}
P(T<t)=\int_{0}^{t} \frac{\beta x^{\beta-1}}{\alpha^{\beta}} e^{-\left(\frac{x}{\alpha}\right)^{\beta}} d x, \\
P\left(T^{\beta}<t\right)=P\left(T<t^{1 / \beta}\right)=\int_{0}^{t^{1 / \beta}} \frac{\beta x^{\beta-1}}{\alpha^{\beta}} e^{-\left(\frac{x}{\alpha}\right)^{\beta}} d x .
\end{gathered}
$$

Substituting $y=x^{\beta}$,

$$
P\left(T^{\beta}<t\right)=\int_{0}^{t} \frac{1}{\alpha^{\beta}} e^{-\frac{y}{\alpha^{\beta}}} d y .
$$

We can use this fact to establish a simple, closed-form confidence interval on the mean lifetime, assuming a Weibull distribution with $\beta$ known and time truncated sampling with replacement. By Eq. E-1 the confidence interval on $\alpha^{B}$ is

$$
\frac{2 S}{x_{1}^{2}-\gamma / 2(2 r+2)} \leq \alpha^{B} \leq \frac{2 S}{x_{\gamma / 2}^{2}(2 r)} \text {. }
$$

Since the mean 1 ifetime $\lambda$ of a Weibull distribution is

$$
\lambda=\alpha \Gamma\left(\frac{1+\beta}{\beta}\right),
$$

we can convert the confidence interval given by $E q$. E-7 to a confidence interval on $\lambda$

$$
\Gamma\left(\frac{1+\beta}{\beta}\right)\left[\frac{2 S}{x_{1-\gamma / 2}^{2}(2 r+2)}\right]^{1 / \beta} \leq \lambda \leq \Gamma\left(\frac{1+\beta}{\beta}\right)\left[\frac{2 S}{\chi^{2}{ }_{\gamma / 2}(2 r)}\right]^{1 / \beta},
$$

where $r$ is still the number of failures that occurred during the monitoring period, and $S$, the rescaled total time on test statistic, is the sum over all components and systems monitored of the times to failure and the survival times each raised to the $B$ power. Thus, unlike the exponential distribution records must be kept of the individual times to failure of the systems and components. 
The confidence interval of Eq. E-9 can also be used to determine an approximation for the required sample size $n$ and monitoring period $y$ when the failure distribution is known to be Weibull. To do so, however, requires that an estimate be made for both $r$ and $s$. An estimate for $r$, the number of failures during the monitoring period, can be derived by exploiting the relationship between the Poisson and exponential distributions and Eq. E-6. Since the time to failure raised to the $\beta$ power $\mathrm{T}^{\beta}$ is exponentially distributed, the number of times that $\mathrm{T}^{\beta}$ is less than $\mathrm{y}\left[\mathrm{N}\left(\mathrm{T}^{\beta}, \mathrm{y}\right]\right.$ has a Poisson distribution:

$$
P\left[N\left(T^{\beta}, y\right)=k\right]=\frac{e^{-n y / \alpha^{\beta}}\left(n y / \alpha^{\beta}\right) k}{k !},
$$

or

$$
P[N(T, y)=k]=\frac{e^{-n} y^{\beta} / \alpha^{\beta}\left(n y^{\beta} / \alpha^{\beta}\right)^{k}}{k !} .
$$

Thus, the number of times that $T$ is less than $y$ also has a Poisson distribution with expected value $\bar{r}$ (i.e., $\bar{r}$ is the expected number of failures).

$$
\bar{r}=n y^{\beta} / \alpha^{\beta} \text {. }
$$

Since the expected value of the total time on test statistic $S$ appears to be intractable for $B>1$, we have computed the expected value of $\mathrm{S} / \mathrm{ny}^{\beta}$ numerically for several values of $\beta$ and $y / \lambda$, as shown in Table E-2. Because of the many variables involved, we have not constructed a table for the Weibull with $\beta>1$ similar to Table E-1 for the exponential. Instead we leave it to the reader to use Eqs. E-9 and $\mathrm{E}-12$ and Table E-2 to find the appropriate monitoring period and number of systems and components necessary to achieve the desired confidence interval following the example given here.

Example: We will develop a field monitoring study to find the mean time to failure of a component that is suspected of failing because of wearout according to a Weibull

\begin{tabular}{|c|c|c|}
\hline$B$ & $y / \lambda$ & $\mathrm{s} / \mathrm{ny}^{B}$ \\
\hline 2 & $\begin{array}{l}0.2 \\
0.3 \\
0.4 \\
0.5 \\
0.7 \\
1 \\
1.5 \\
2\end{array}$ & $\begin{array}{l}0.990 \\
0.977 \\
0.960 \\
0.939 \\
0.887 \\
0.796 \\
0.642 \\
0.524\end{array}$ \\
\hline 4 & $\begin{array}{l}0.2 \\
0.3 \\
0.4 \\
0.5 \\
0.7 \\
1 \\
1.5 \\
2\end{array}$ & $\begin{array}{l}0.999 \\
0.997 \\
0.992 \\
0.980 \\
0.925 \\
0.741 \\
0.317 \\
0.143\end{array}$ \\
\hline 8 & $\begin{array}{l}0.2 \\
0.3 \\
0.4 \\
0.5 \\
0.7 \\
1 \\
1.5 \\
2\end{array}$ & $\begin{array}{l}1.0 \\
1.0 \\
1.0 \\
0.999 \\
0.984 \\
0.763 \\
0.071 \\
0.010\end{array}$ \\
\hline
\end{tabular}

Table E-2. Time on Test Statistic 
distribution with $B=4$ and an a priori estimate of the mean lifetime of $\lambda=10$ years. Two hundred systems are available. How long should they be monitored to be $95 \%$ confident that the mean lifetime is greater than 7 years?

We begin by simply choosing an arbitrary, but reasonable, trial value for the monitoring period of $y=5$ years. Then, according to Eqs. E-8 and E-12, we see that

$$
\begin{aligned}
& \alpha=(\lambda / \Gamma)\left(\frac{\beta+1}{\beta}\right)=\frac{10}{0.9064}=11.03, \\
& \bar{r}=200 \times\left(\frac{5}{11.03}\right)^{4}=8.4,
\end{aligned}
$$

and from Table E-2,

$$
\mathrm{S} / \mathrm{ny}^{\beta}=0.980
$$

Since $n=200$ and $y^{B}=625$,

$$
S=122,500 \text {. }
$$

Inserting these values into the left side of Eq. E-9, we have*

or

$$
\Gamma\left(\frac{5}{4}\right)\left[\frac{245,000}{x_{0.95}^{2}(18.8)}\right]^{1 / 4} \leq \lambda
$$

$$
8.61 \leq \lambda \text {. }
$$

Since the one-sided $95 \%$ confidence interval is tighter than our original goal, we reduce the trial value for the number of years that the systems are monitored to three and reevaluate our confidence interval.

By equation E-12 we see that

$$
\bar{r}=200\left(\frac{3}{11.03}\right)^{4}=1.1,
$$

and from Table E-2,

$$
\mathrm{S} / \mathrm{ny}^{B}=0.997
$$

Since $n=200$ and $y^{8}=81$, then we see that

$$
S=16,151 \text {, }
$$

* Note that since this is only a one-sided confidence interval, the $\chi^{2}$ statistic is evaluated at the $1-\gamma=0.05$ percentile, not the $1-\gamma / 2$ percentile. 
and our new, one-sided confidence interval is

$$
\Gamma(5 / 4)\left[\frac{32303}{x_{0.95}^{2}(4.2)}\right]^{1 / 4}=6.87 \leq \lambda .
$$

Similarly, if the monitoring period is 4 years, the one-sided $95 \%$ confidence interval is

$$
\Gamma(5 / 4)\left[\frac{101581}{x_{0.95}^{2}(8.9)}\right]^{1 / 4}=7.99 \leq \lambda
$$

Therefore, 4 years is a sufficiently long monitoring period to be at least $95 \%$ confident that the mean 1 ifetime is more than 7 years when 200 systems are monitored. Of course, once the monitoring study is complete, the validity of the assumed Weibull $(\beta=4)$ distribution should be checked through the $\chi^{2}$ test for goodness-of-fit to the sample results.

\section{E.3 REEERENCES}

Green, A. E., and A. J. Bourne, 1972, Reliability Technology, New York: John Wiley and Sons.

Martz, H. F., and R. A. Waller, 1982, Bayesian Reliability Analysis, New York: John Wiley and Sons.

Yarosh, M. M., et a1., 1982 (Jan.), Solar Energy Consumer Protection Report, Cape Canaveral, FL: Florida Solar Energy Center. 


\section{APPENDIX F}

\section{THE ANALYSIS PERIOD}

By explicitly representing reliability costs, many of which occur many years after system installation, the analysis period chosen for an economic evaluation can significantly affect the final results. For many nonsolar evaluations the analysis period is set equal to the expected lifetime of the system being analyzed. However, in the preceding discussion on repair and replacement costs we recognize that for most component-based solar energy systems there is no point in time at which the entire system could be said to have expired. With the exception of a few catastrophic failures such as the freezing or corrosion of an entire system, components will normally be repaired or replaced as they fail. Thus, for solar energy systems the concept of a system lifetime is ill-defined, and we must use some other basis to establish an analysis period.

Solar energy systems, unlike most other consumer products, 1ack a wel1-defined system lifetime. For example, automobiles, which share the property of having many components, have a more well-defined lifetime for several reasons. Automobiles are a high visibility product, and people frequently sell an old one just to get a newer, more fashionable model. The absence of installation and removal costs also encourages the decision to discard the old car in favor of a new one. A very important factor in the decision to retire an automobile is that component failures in an automobile can have substantial costs over and above the actual repair and replacement costs. These can include towing expenses, time lost, and safety hazards. Finally, since automobiles have many more mechanical components that can wear out than most solar energy systems, failures become much more frequent as the automobile ages. When the cost of failures becomes prohibitive, the automobile's useful life is ended.

In the absence of a well-defined system lifetime for solar energy systems, there remains the difficulty of specifying a valid analysis period for the economic analysis of these systems. We could use several alternative periods. These are listed here, those most highly recommended appear first. However, since the choice depends on the specifics of the analysis, the more highly recommended alternatives may not always be feasible. In establishing research priorities, the time to maximum economic value is the preferred time period.

1. Ownership period. This is probably the best period for the individual investor to use in the analysis if he or she can estimate the resale value at the end of the ownership period. However, from a national perspective, such a period is not well-defined.

2. The time to maximum economic value. If a number of expensive components can be expected to fail at about the same time (i.e., their mean lifetimes are the same, and standard deviation of the lifetimes is small), then an analysis period shorter than their mean lifetime will probably produce the maximum economic system value. An analysis period equal to or slightly greater than the mean lifetime of the components produces an economic value reduced by the probable cost of repairing or replacing the components. This is the criterion typically used for residential solar 
systems, and the collector is the single most expensive component. If the cost of a single component or a set of components with similar failure rates does not outweigh the cost of the rest of the system, then this is not a viable means for choosing an analysis period. It is unlikely that an owner will scrap an entire system when only one relatively inexpensive component expires.

3. The expected time to catastrophic total system failure. Catastrophic system failures include freezing of multiple components and extensive corrosion throughout the system. For most well-built systems, this time will be prohibitively long.

4. Discount rate. Set the analysis period to the point at which the present value of future revenues and costs is less than $x \%(e . g ., 5 \%)$ of the face value. Since individual returns and costs beyond this point are insignificant, they are ignored. In the event that the escalation rate for a given revenue or cost (e.g., the fuel price escalation rate) exceeds the discount rate, this definition of the analysis period may yield an infinite value.

5. The time at which the present value of all replacements equals the initial system cost. This is an arbitrary point that is appealing only because it provides a point at which, in a sense, one may have bought an entirely new system. The arbitrariness of this period becomes evident when we compare a cheap, unreliable system with an expensive, reliable system. The two will have vastly different analysis periods, but the comparative evaluation will require us to select one of the two.

6. Loan period. For new residential systems, the 30 -year period common for most home mortgages may be appropriate. However, for the other systems for which only short-term loans are available, substantial costs and/or benefits may be ignored.

7. Infinity. If the components are replaced indefinitely, this is a viable alternative. However, in reality, the system will eventually be scrapped; e.g., when the house on which a residential system is installed is destroyed. Furthermore, infinite series can be hard to work with, can require infinite extrapolations of many input parameters (e.g., fuel costs), and can be difficult to grasp. Finally, they can lead to infinite present-value results.

For the example problem presented in section 3.4, an analysis period of 20 years was chosen based on maximum economic value, since an average ownership period is not well-defined (see Section 3.4). 


\section{DISTRIBUTION LIST}

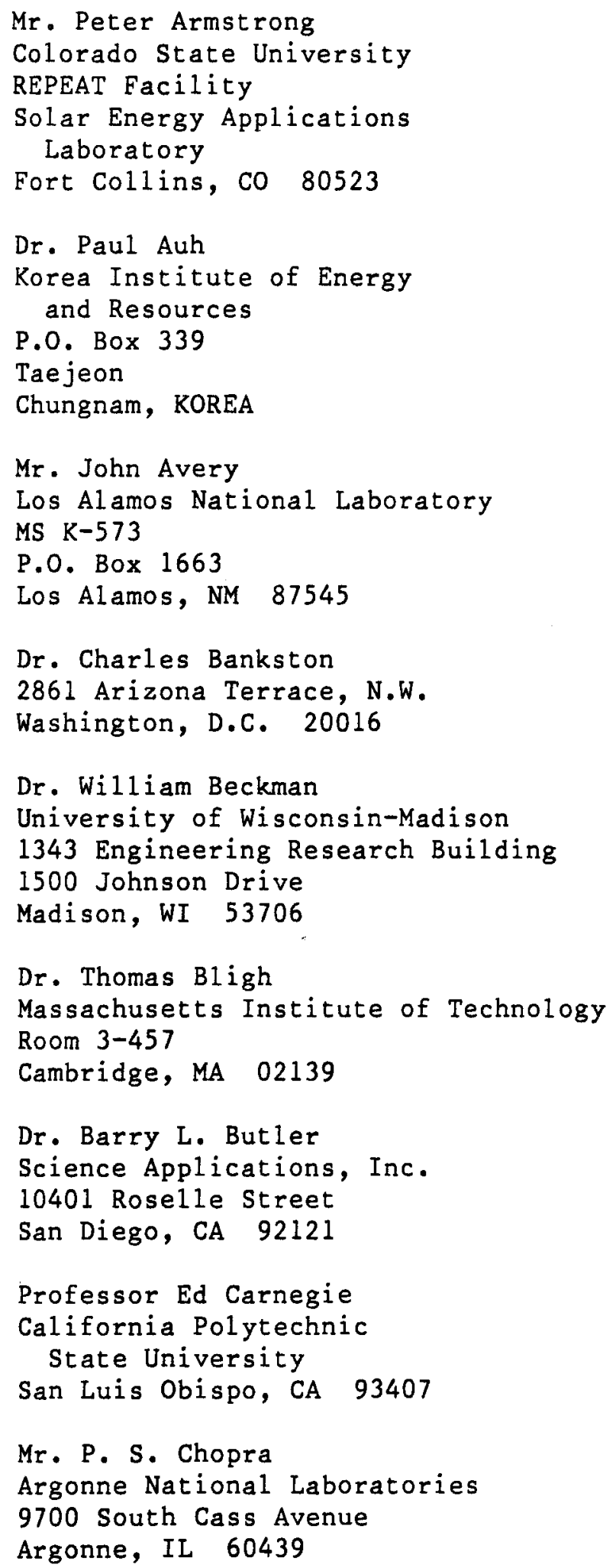

Dr. David Claridge

University of Colorado

Department of Civil Engineering

Boulder, CO 80302

Dr. Kirk Collier

Collier Engineering

Route 2, Box 240

Cave Creek, AZ 85331

Mr. James Collner, Director

Research and Engineering

American Solar King

P.O. Box 7399

Waco, TX 76710

Mr. Thomas A. Coultos

Office of Energy-Related Inventions

National Bureau of Standards

Gaithersburg, MD 20899

Mr. Charles J. Cromer, P.E. Florida Solar Energy Center 300 State Road 401

Cape Canaveral, FL 32920

Mr. Gaspar DeGaetano

Water Heating Systems Section

Residential Branch

310 Credit Union Building

715 Market Street

Chat tanooga, TN 37401

Mr. Francis deWinter

Atlas Corporation

308 Encinal Street

Santa Cruz, CA 95060

Mr. Robert D. Dikkers

National Bureau of Standards Technology B-148

Washington, D.C. 20234

Dr. John Duffie

University of Wisconsin-Madison 1500 Johnson Drive

Madison, WI 53706 
Mr. Ed Durlak (Code L-63)

Naval Civil Engineering Lab.

Port Heuneme, CA 93043

Dr. Hunter Fanney

National Bureau of Standards

Thermal Solar Group

Building 226, Room B-126

Washington, D.C. 20234

Mr. Freeman Ford

Solar Energy Industries Assoc. 1001 Connecticut Avenue, N.W.

Suite 800

Washington, D.C. 20036

Mr. Ed Gray

Science Applications, Inc.

1710 Goodridge Drive

McLean, VA 22102

Mr. Joe Greenberg

National Bureau of Standards

Room B320, B1dg. 226

Gaithersburg, MD 20899

Dr. Gerry Guinn

Alabama Solar Energy Center

University of Alabama

Huntsville, AL 35899

Mr. Robert Hassett

$\mathrm{CE}-311.1$

Forst 1

U.S. Dept. of Energy

Washington, D.C. 20585

Mr. Dick Hayter

Engineering Extension Programs

Bard Hall

Mannhattan, KS 66506

Mr. David Holmes

Civil Engineering Laboratory

Port Hueneme, CA 93043

Honeywel1, Inc.

10400 Yellow Circle Dr.

Minnetonka, MN 55343

Attn: Manager, Solar Group
Mr. Peter Jacobs

Novan Energy, Inc.

1630 North 63rd Street

Boulder, CO 80301

Dr. Robert Jones

Los Alamos National Laboratory

P.0. Box 1663

Los Alamos, NM 87545

Mr. Gary Jorgensen

Boulder Electrooptic

2388 Bluff Street

Suite 498

Boulder, CO 80301

Mr. Paul W. Kendall

Vitro Laboratories

14000 Georgia Avenue

Silver Spring, MD 20910

Mr. William J. Kennish

Vice President

TPI, Inc.

5010 Sunnyside Avenue, Suite 301

Beltsville, MD 20705

Dr. Sandy Klein

University of Wisconsin-Madison

1500 Johnson Drive

Madison, WI 53706

Mr. Jon Klima

Community College of Denver

Red Rocks Campus

Solar Division

Golden, CO 80401

Mr. Carlo La Porta

SEIA

115615 th Street, N.W.

Suite 520

Washington, D.C. 20005

Mr. Robert Le Chevalier

DOE San Francisco Operations office

333 Broadway

Oakland, CA 94612

Dr. George Lof

Solaron Corporation

1885 W. Dartmouth Avenue

Englewood, CO 80110 
Mr. Bob Lorand

Science Applications, Inc.

1710 Goodridge Drive

McLean, VA 22102

Dr. Peter Lunde

Solar Engineering Consultant

Hartford Graduate Center

275 Windsor Street

Hartford, CT 06120

Mr. Bill Marlatt

Rockwel1 ETEC

P.O. Box 1449

Canoga Park, CA 91304

Mr. Harry Martz

Los Alamos National Laboratory

P.O. Box 1663

Los Alamos, NM 87545

Dr. John Mitchell

University of Wisconsin-Madison

1500 Johnson Drive

Madison, WI 53706

Mr. Stan Moore

Los Alamos National Laboratory

MS $\mathrm{K}-571$

P.0. Box 1663

Los. Alamos, NM 87545

Dr. Jeff Morehouse

T-6-1

Science Applications, Inc.

1710 Goodridge Drive

McLean, VA 22102

Dr. Fred Morse

CE-31

Forst 1

U.S. Dept. of Energy

Washington, D.C. 20585

Dr. Don Neeper

Los Alamos National Laboratory

P.0. Box 1663

Los Alamos, NM 87545
Mr. Andrew J. Parker

Executive Vice President Mueller Associates, Inc. 1900 Sulphur Spring Road

Baltimore, MD 21227

Mr. Ed Pollock

Vitro Laboratories

14000 Georgia Avenue

Silver Spring, MD 20910

Mr. Richard Rittlemann

Burt, Hill, Kosar,

Rittleman Associates

400 Morgan Center

Butler, PA 16001

Mr. David Robison

Oregon Department of Energy

Renewable Resources

102 Labor and Industries Building

Salem, OR 97310

Ms. Sherry Rossi

Vitro Laboratories

14000 Georgia Avenue

Silver Spring, MD 20910

Mr. William W. Schertz

Argonne National Laboratory

9700 South Cass Avenue

Argonne, IL 60439

Mr. William Scholten

Science Applications, Inc.

1710 Goodridge Drive

McLean, VA 22102

Dr. Donald Schultz

Systems \& Industrial Engineering Dept. University of Arizona

Tucson, AZ 85721

Dr. William Shurcliff

19 Appleton Street

Cambridge, MA 02138

Mr. Graham Siegel

TVA

240 Chestnut Street Towers 11

Chat tanooga, TN 37401 
Mr. Morris Ska1ka

CE-311

Forst 1

U.S. Dept. of Energy

Washington, D.C. 20585

Mr. Jay Stein

American Mechanical Supply

3080 South Zuni Street

Englewood, CO 80110

Mr. Burt Swerdling

Project Engineer

Grumman Energy Systems, Inc. 445 Broadhollow Road

Melville, NY 17747

Dr. Mike Wahlig

Lawrence Berkeley Laboratory

University of California

1 Cyclotron Road

Berkeley, CA 94720

Dr. Mashuri Warren

Lawrence Berkeley Laboratory

University of California

1 Cyclotron Road

Berkeley, CA 94720

Dr. William S. Wilhelm

Brookhaven National Laboratory

Department of Applied Science

Upton, New York 11973

\section{Solar Energy Research Institute}

D. Benson

R. Farrington

L. Flowers

B. Gupta

D. Johnson

F. Kreith

A. Lewandowski

L. M. Murphy

T. Penney

J. Thornton
Mr. Tom Williams

Battelle Pacific Northwest Laboratories P.O. Box 999

Richland, WA 99352

Dr. Byron Winn, Ph.D.

Mechanical Engineering Department

Colorado State University

Et. Collins, CO 80523

Mr. R. M. Wolosewicz

Argonne National Laboratories

9700 South Cass Avenue

Argonne, IL 60439

Wyle Labs

Solar Testing Group

7800 Govenors Drive West

Huntsville, AL 35807

Dr. Marvin Yarosh

Florida Solar Energy Center

300 State Road 401

Cape Canaveral, FL 32920

Professor John Yellot

901 West El Caminito

Phoenix, AZ 85021 


\begin{tabular}{|c|c|}
\hline \begin{tabular}{c|l|l}
$\begin{array}{c}\text { Document Control } \\
\text { Page }\end{array}$ & $\begin{array}{l}\text { 1. SERI Report No. } \\
\text { SERI/TR-253-2616 }\end{array}$ & 2. NTIS Accession No. \\
\end{tabular} & 3. Recipient's Accession No. \\
\hline \multirow{3}{*}{$\begin{array}{l}\text { 4. Title and Subtitle } \\
\text { A Method for Including Operation and Maintenance Costs } \\
\text { in the Economic Analys is of Active Solar Energy } \\
\text { Systems }\end{array}$} & \multirow{2}{*}{$\begin{array}{l}\text { 5. Publication Date } \\
\text { August } 1986\end{array}$} \\
\hline & \\
\hline & 6. \\
\hline $\begin{array}{l}\text { 7. Author(s) } \\
\text { Wal ter D. Short }\end{array}$ & 8. Performing Organization Rept. No. \\
\hline \multirow{2}{*}{$\begin{array}{l}\text { 9. Performing Organization Name and Address } \\
\text { Solar Energy Research Institute } \\
1617 \text { Cole Blvd. } \\
\text { Golden, Colorado } 80401\end{array}$} & $\begin{array}{l}\text { 10. Project/Task/Work Unit No. } \\
3002.10\end{array}$ \\
\hline & $\begin{array}{l}\text { 11. Contract (C) or Grant (G) No. } \\
\text { (C) } \\
\text { (G) }\end{array}$ \\
\hline \multirow[t]{2}{*}{ 12. Sponsoring Organization Name and Address } & $\begin{array}{l}\text { 13. Type of Report \& Period Covered } \\
\text { Technical Report }\end{array}$ \\
\hline & 14. \\
\hline \multicolumn{2}{|l|}{ 15. Supplementary Notes } \\
\hline \multicolumn{2}{|c|}{$\begin{array}{l}\text { 16. Abstract (Limit: } 200 \text { words) } \\
\text { For a developing technology such as solar energy, the costs for operation and } \\
\text { maintenance (O\&M) can be substantial. In the past, most economic analyses in- } \\
\text { cluded these costs by simply assuming that an annual cost will be incurred that is } \\
\text { proportional to the initial cost of the system. However, in assessing the eco- } \\
\text { nomics of new systems proposed for further research and development, such a simpli- } \\
\text { fication can obscure the issues. For example, when the typical method for in- } \\
\text { cluding o\&M costs in an economic analysis is used, the o\&M costs associated with a } \\
\text { newly developed, more reliable, and slightly more expensive controller will be } \\
\text { assumed to increase--an obvious inconsistency. The method presented in this report } \\
\text { replaces this simplistic approach with a representation of the o\&M costs that } \\
\text { explicitly accounts for the uncertainties and risks inherent in the operation of } \\
\text { any equipment. A detailed description of the data inputs required by the method } \\
\text { is included as well as a summary of data sources and an example of the method as } \\
\text { applied to an active solar heating system. }\end{array}$} \\
\hline \multirow{3}{*}{\multicolumn{2}{|c|}{$\begin{array}{l}\text { 17. Document Analysis } \\
\text { a. Descriptors Cost; Economic Analysis; Failures; Life-Cycle Cost; Maintenance; } \\
\text { Operation; Reliability; Repair; Solar Equipment } \\
\text { b. Identifiers/Open-Ended Terms }\end{array}$}} \\
\hline & \\
\hline & \\
\hline \multirow{3}{*}{$\begin{array}{l}\text { 18. Availability Statement } \\
\text { Nationa } 1 \text { Technical Information Service } \\
\text { U.S. Department of Commerce } \\
5285 \text { Port Royal Road } \\
\text { Springfield, Virginia } 22161\end{array}$} & 19. No. of Pages \\
\hline & 83 \\
\hline & $\begin{array}{r}\text { 20. Price } \\
\text { A05 }\end{array}$ \\
\hline
\end{tabular}

